\title{
Alterações eletrocardiográficas preditoras de fibrilação atrial (FA) em pacientes com doença renal crônica no primeiro ano de hemodiálise
}

Dissertação apresentada à Faculdade de Medicina da Universidade de São Paulo para obtenção do título de Mestre em Ciências

Programa de Ciências Médicas

Área de concentração: Processos Inflamatórios e Alérgicos

Orientadora: Profa. Dra. Maria Lucia Bueno Garcia

(Versão corrigida Resolução CoPGr 6018/11, de 13 de outubro de 2011. A versão original está disponível na Biblioteca da FMUSP)

São Paulo 2020 
Dados Internacionais de Catalogação na Publicação (CIP)

Preparada pela Biblioteca da

Faculdade de Medicina da Universidade de São Paulo

Creprodução autorizada pelo autor

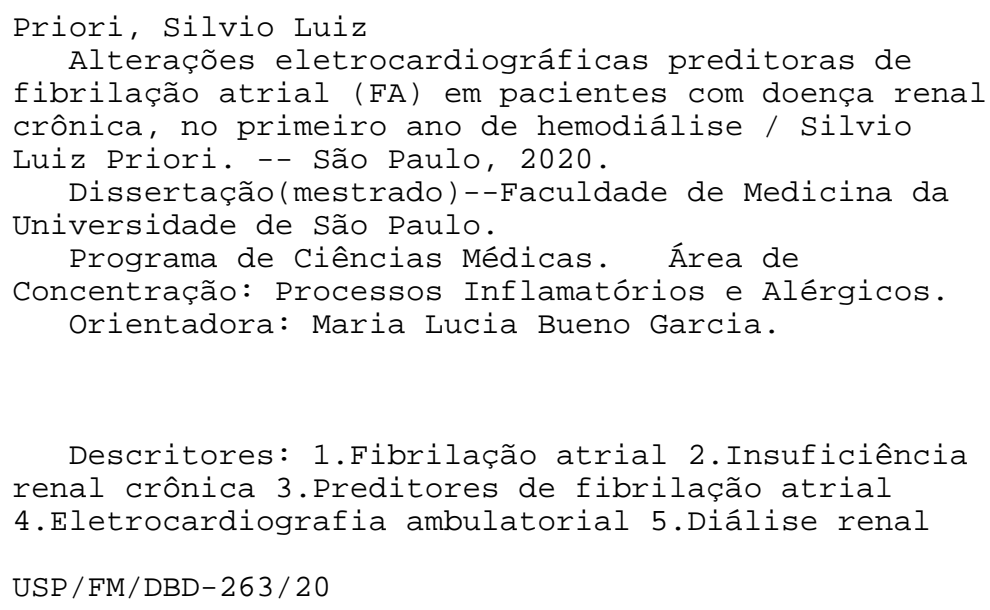

Responsável: Erinalva da Conceição Batista, CRB-8 6755 


\section{DEDICATÓRIA}

Aos meus pais, Angelina Gonçalves Priori e Sérgio Luiz Priori (In memoriam), por terem me ensinado os valores fundamentais da vida. Em especial à minha mãe pelo exemplo de força, de vontade de viver e por não ter medido esforços para que eu pudesse abraçar a carreira da Medicina.

À minha esposa, Denise Reis Priori, por incentivar e apoiar meu crescimento profissional e por sempre acolher minhas dificuldades. Às minhas filhas, Ariane Cardoso Priori e Sophia Reis Priori, pela compreensão nos momentos mais difíceis e, muitas vezes, de ausência necessária.

Às minhas irmãs, Neusa e Carmem Lúcia (In memoriam), Cida, Eugênia Márcia e Tereza, por todo apoio, cumplicidade e incentivo nesses anos todos de vida acadêmica. 


\section{AGRADECIMENTOS ESPECIAIS}

À minha orientadora, Dra. Maria Lúcia Bueno Garcia, pelos ensinamentos, pelo exemplo de ética e cidadania, pela oportunidade, carinho, respeito, influência, críticas e sugestões em todas as etapas desta dissertação. Sua valiosa e competente presença foi responsável por me fazer acreditar neste projeto e tornar possível sua realização. Minha especial admiração e gratidão.

Ao Departamento de ECG do HCFMUSP, em especial, ao Dr. José Grindler, amigo e profissional competente, por todo apoio, confiança, incentivo, oportunidades concedidas e parceria. Meu muito obrigado.

À Enfermeira Marlene Alves Pereira Silveira por todo suporte e disponibilidade na realização das análises eletrocardiográficas (Holter) desta pesquisa. Meus sinceros agradecimentos. 


\section{AGRADECIMENTOS}

À direção do Hospital Municipal Antônio Giglio de Osasco pelo apoio à pesquisa, dando liberdade e disponibilidade de tempo para conduzir este estudo. Obrigado pela confiança.

Ao Dr. Washington Luiz da Silva Correia, responsável pela Unidade Nefrológica de Osasco (UNASCO) que abriu as portas para a realização da pesquisa e por todo suporte operacional. Grato pelas oportunidades que me foram concedidas.

Aos residentes de Clínica Médica do Hospital Municipal Antônio Giglio de Osasco pela cooperação e disponibilidade na fase de coleta de dados.

À minha secretária, Rosana Claudia Ramos de Carvalho, pela eficiência, dedicação e paciência.

Aos médicos assistentes e colaboradores do Departamento de ECG do HCFMUSP, em especial, Dr. Acácio Fernandes Cardoso e Dr. Alfredo José da Fonseca pelas contribuições que muito enriqueceram este trabalho.

À equipe técnica e administrativa do Departamento de ECG do HCFMUSP, Catia, Josefina, Lizandra, Maria Ester, Maria Inez, Renato, Simone e Ana Paula, pela boa vontade, especialmente, como facilitadores de suporte à pesquisa.

Aos pacientes que participaram deste estudo por terem contribuído com a dimensão e a forma do objeto deste estudo. Meus sinceros agradecimentos e gratidão. 


\section{NORMALIZAÇÃO ADOTADA}

Esta dissertação está de acordo com as seguintes normas, em vigor no momento desta publicação:

Referências: adaptado de International Committee of Medical Journals Editors (Vancouver).

Universidade de São Paulo. Faculdade de Medicina. Divisão de Biblioteca e Documentação. Guia de apresentação de dissertações, teses e monografias. Elaborado por Anneliese Carneiro da Cunha, Maria Julia de A. L. Freddi, Maria F. Crestana, Marinalva de Souza Aragão, Suely Campos Cardoso, Valéria Vilhena. 3a ed. São Paulo: Divisão de Biblioteca e Documentação; 2011.

Abreviaturas dos títulos dos periódicos de acordo com List of Journals Indexed in Index Medicus. 


\section{SUMÁRIO}

Lista de abreviaturas

Lista de figuras

Lista de tabelas

Resumo

Abstract

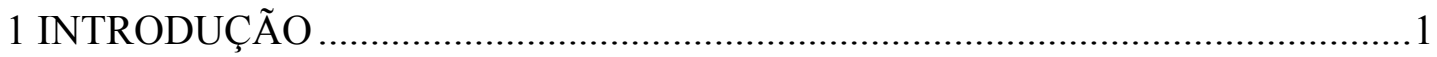

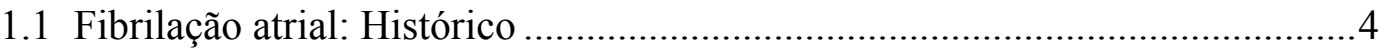

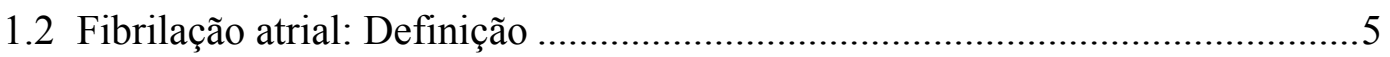

1.3 Eletrofisiologia da fibrilação atrial ........................................................6

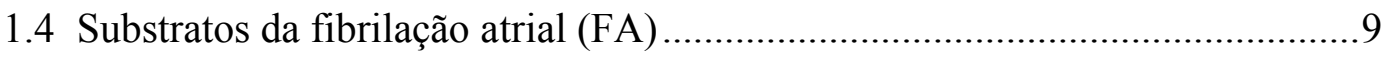

1.4.1 A remodelação atrial .......................................................................10

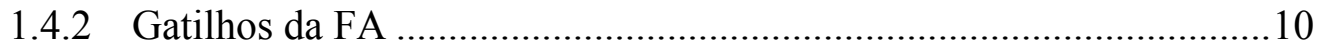

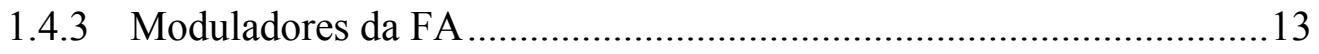

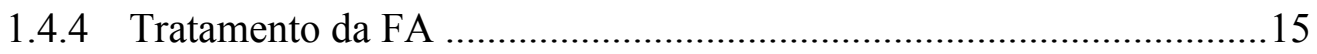

1.5 Doença Renal Crônica (DRC) ................................................................... 17

1.5.1 Cálculo da Função Renal ..............................................................19

1.5.2 Estadiamento da Doença Renal Crônica ............................................20

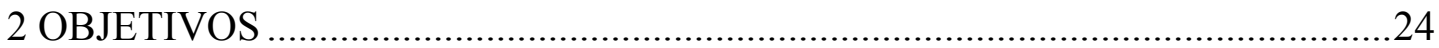

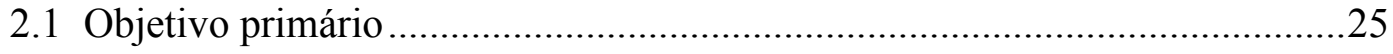

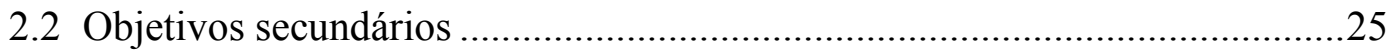

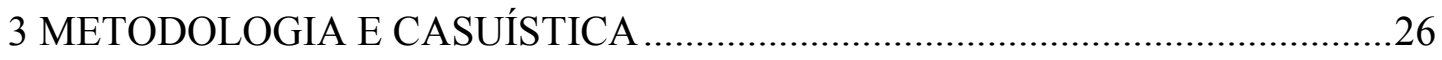

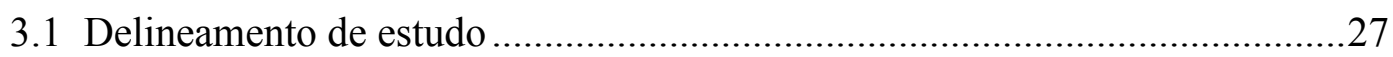

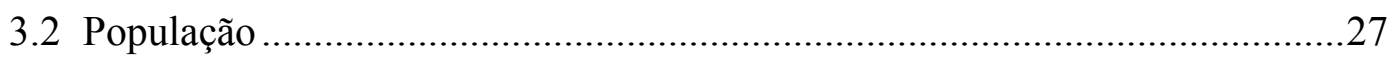

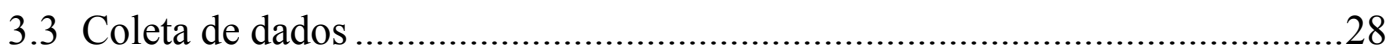

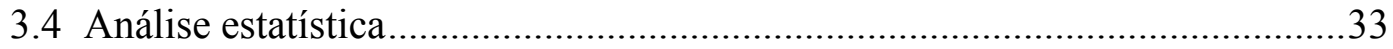

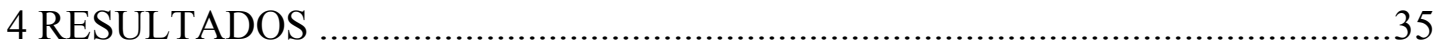

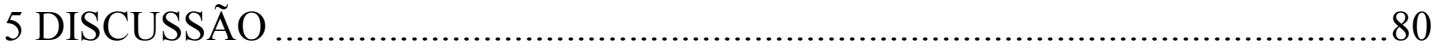

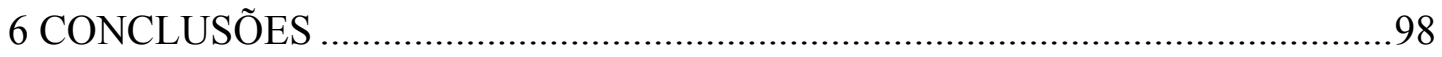

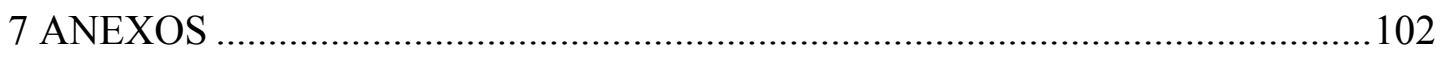

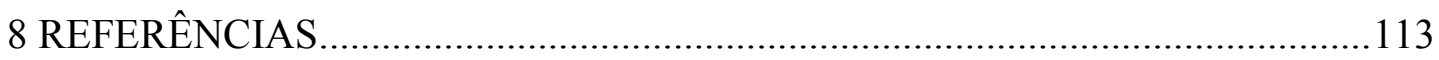

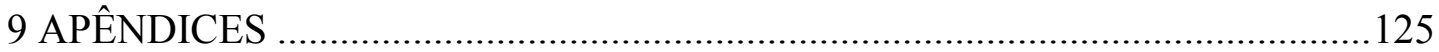




\section{LISTAS}

\section{ABREVIATURAS}

\begin{tabular}{ll} 
AD & Átrio Direito \\
AE & Átrio Esquerdo \\
AOS & Apneia Obstrutiva do sono \\
AVC & Acidente Vascular Cerebral \\
AVE & Acidente Vascular Encefálico \\
C.G & Cockroft Gault \\
CKD-EPI & Cronic Kidney Disease Epidemiology \\
CV & Calcificação Vascular \\
CVE & Cardioversão Elétrica \\
CVQ & Cardioversão Química \\
DAC & Doença Arterial Coronariana \\
DCV & Doença Cardiovasculares \\
DIAM DIAS & Diâmetro Diastólico \\
DIAM SIST & Diâmetro Sistólico \\
DLP & Dislipidemia \\
DM & Diabetes Mellitus \\
DPOC & Doença Pulmonar Obstrutiva Crônica \\
DRC & Doença Renal Crônica \\
ECG & Eletrocardiograma \\
EDTA & Ethylenediamine Disease Epidemiology \\
ESSV & Extrassístole Supra Ventricular \\
ESV & Extrassístole Ventricular \\
FA & Fibrilação Atrial \\
FANV & Fibrilação Atrial Não Valvar \\
FC & Frequência Cardíaca \\
FE & Freção \\
\hline
\end{tabular}




\begin{tabular}{|c|c|}
\hline HAS & Hipertensão Arterial Sistêmica \\
\hline IAM & Infarto Agudo do Miocárdio \\
\hline $\mathrm{IC}$ & Insuficiência Cardíaca \\
\hline $\mathrm{ICC}$ & Insuficiência Cardíaca Congestiva \\
\hline IMC & Índice de massa corpórea \\
\hline $\mathrm{K}$ & Potássio \\
\hline MIA & Nutrição, Inflamação, Aterosclerose (Síndrome MIA) \\
\hline MORD & Modification Of Diet In Renal Disease \\
\hline NA & Sódio \\
\hline NFK & National Kidney Fundation \\
\hline PCR & Proteína C Reativa \\
\hline PTH & Paratormônio \\
\hline S IA & Septo Inter Atrial \\
\hline SBC & Sociedade Brasileira Cardiologia \\
\hline SIV & Septo Inter Ventricular \\
\hline TEP & Trombo Embolismo Pulmonar \\
\hline TFG & Taxa Filtração glomerular \\
\hline TRS & Terapia Renal Substitutiva \\
\hline TSVNS & Taquicardia Supraventricular Não Sustentada \\
\hline TSVS & Taquicardia Supraventricular Sustentada \\
\hline TVNS & Taquicardia Ventricular Não Sustentada \\
\hline TVP & Trombose Venosa Profunda \\
\hline TVS & Taquicardia Ventricular Sustentada \\
\hline VAV & Válvula Átrio Ventricular \\
\hline VOL.DIAST & Volume Diastólico \\
\hline VOL.SIST & Volume Sistólico \\
\hline
\end{tabular}




\section{FIGURAS}

Figura 1 - Desenho esquemático dos átrios ilustrando os mecanismos da fibrilação atrial baseado em múltiplas reentradas intra-atriais............. 7

Figura 2 - Desenho esquemático ilustrando o conceito do comprimento de ondas

Figura 3 - Desenho esquemático ilustrando o conceito de massa crítica para a manutenção da FA. Estrutura semelhante à figura 2

Figura 4- Desenho esquemático ilustrando o conceito de FA focal

Figura 5 - Desenho esquemático com estruturas e abreviaturas iguais às da figura1, ilustrando os sítios de origem da FA focal

Figura 6 - Fluxograma de Recrutamento de Pacientes 
TABELAS

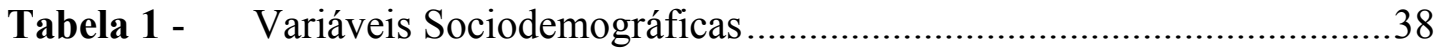

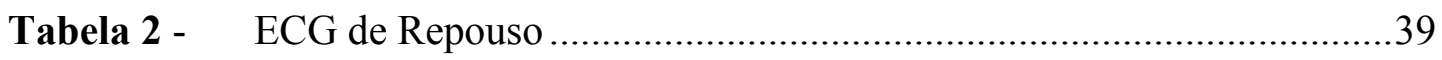

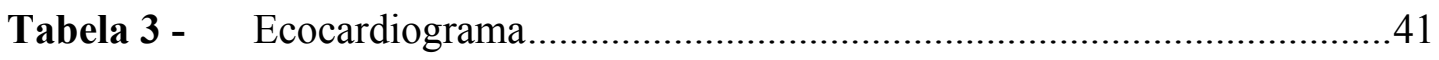

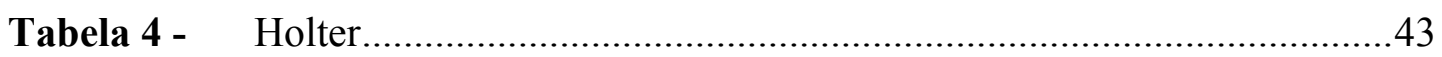

Tabela 5 - Holter Gatilhos-Eletrofisiológicos .................................................4

Tabela 6 - Exames Laboratoriais Plasmáticos......................................................45

Tabela 7 - Exames Laboratoriais Plasmáticos Categorizados

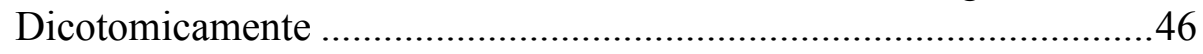

Tabela 8 - Relação Covariáveis e o Desfecho Gatilhos Eletrofisiológicos ...........48

Tabela 9 - Regressão Logística Binária Univariada. Variável Dependente Gatilhos Fisiológicos.......................................................................49

Tabela 10 - Regressão Logística Binária Múltipla. Variável Dependente Gatilhos Fisiológicos ...................................................................50

Tabela 11 - Associação Variável Dependente ESV e Covariáveis ........................51

Tabela 12 - Regressão Logística Binária Univariada. Variável Dependente

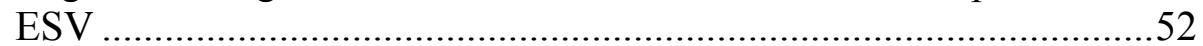

Tabela 13 - Regressão Logística Binária Múltipla. Variável Dependente ESV ....53

Tabela 14 - Associação de Intervalo QT Obtido pelo Holter e Covariáveis ..........54

Tabela 15 - Regressão Logística Binária Univariada. Variável Dependente

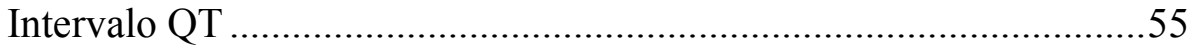

Tabela 16 - Regressão Logística Binária Multivariada. Dependente: Diminuição do Intervalo QT ............................................................56

Tabela 17 - Associação de Covariáveis e Átrio Esquerdo ......................................57

Tabela 18 - Regressão Logística Binária Univariada. Dependente: Átrio

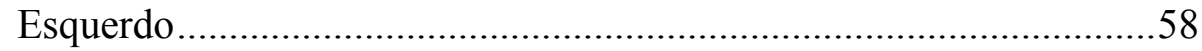

Tabela 19 - Regressão Multivariada Logística Binária. Dependente Alteração de Átrio Esquerdo 
Tabela 20 - Associação Volume Diastólico e Covariáveis

Tabela 21 - Regressão Univariada Multivariada Binária Logística. Dependente Volume Diastólico

Tabela 22 - Regressão Multivariada Logística Binária. Dependente Volume Diastólico

Tabela 23 - Associação Covariáveis e Dependentes Volume Sistólico

Tabela 24 - Regressão Logística Binária Univariada. Dependente Volume Sistólico

Tabela 25 - Regressão Binária Logística Multivariada Dependente Alteração de Volume

Tabela 26 - Associação entre Alteração do Diâmetro Sistólico e as Covariáveis pelo Teste Qui-quadrado

Tabela 27 - Regressão Univariada Logística Binária Dependente Alteração Diâmetro Sistólico.

Tabela 28 - Regressão Múltipla Binária Logística com Dependente Alteração do Diâmetro Sistólico.

Tabela 29 - Associação entre Covariáveis Significativas e a Dependente Alteração do Diâmetro Diastólico.

Tabela 30 - Regressão Univariada Dependente Alteração do Diâmetro

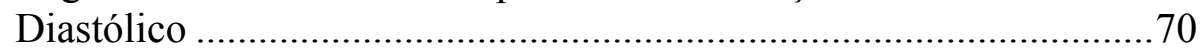

Tabela 31 - Regressão Múltipla Logística Binária. Dependente Alteração do Diâmetro Diastólico

Tabela 32 - Associação Covariáveis com Dependente Alteração do Septo Interatrial

Tabela 33 - Regressão Univariada entre Covariáveis e Dependente Alterações do Septo Interatrial

Tabela 34 - Regressão Múltipla Binária Logística. Variável Dependente Septo Interatrial

Tabela 35 - Associação Covariáveis e a Dependente Alterações de Átrio Direito

Tabela 36 - Regressão Univariada. Dependente Átrio Direito................................76

Tabela 37 - Associação Covariáveis e Dependente VAV .......................................77 
Tabela 38 - Regressão Univariada Logística Binária das Covariáveis Significativas nos Testes Qui-quadrado em Relação a Dependente

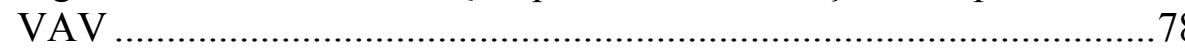

Tabela 39 - Variáveis Dependentes e Fatores de Risco ........................................79 


\section{RESUMO}

Priori SL. Alterações eletrocardiográficas preditoras de fibrilação atrial (FA) em pacientes com doença renal crônica no primeiro ano de hemodiálise [dissertação]. São Paulo: Faculdade de Medicina, Universidade de São Paulo; 2020.

Introdução: Fibrilação atrial (FA) é arritmia supraventricular de alta prevalência, relacionada à mortalidade e morbidade da população. Em pacientes renais crônicos dialíticos, a FA atinge 36\% deles comprometendo o prognóstico da doença renal. Objetivo: Prevalência de preditores de FA em pacientes no primeiro ano de hemodiálise. Método: Estudo, prospectivo observacional, transversal, em pacientes dialíticos de 20 e 80 anos sem fibrilação atrial, pertencentes ao serviço de Hemodiálise UNASCO e HMAG em Osasco-SP, divididos em 2 grupos - I: até 06 meses, grupo II: de 7 a 12 meses. Foram coletados dados sociodemográficos, eletrocardiograma de repouso, Holter 24-48 horas, ecocardiograma transtorácico e exames de laboratório (função renal, eletrólitos e inflamatórios). Dados submetidos a análises teste $\mathrm{T}$ student, Qui-quadrado e regressão logística binaria. Resultados: Todos os pacientes eram hipertensos e com lesão de órgãos alvo com alto risco cardiovascular. Ambos os grupos são predominantemente masculinos, quinquagenários, escolaridade fundamental, raça branca, não solteiros, naturais da região sudeste e metropolitana, com mais de duas medicações gerais e mais de duas morbidades, sendo o grupo 2 com pacientes mais idade, peso, medicações, morbidades e preditores cardiovasculares. ECG de repouso tem ritmo sinusal na totalidade, discretas alterações da ativação atrial em pacientes do grupo 2 e presença de arritmias (ESV) no grupo 2. Holter: presença de gatilhos eletrofisiológicos e alteração do intervalo QT, (QTi: grupo1: 26\%, grupo2: $40 \%, \mathrm{p}=0,21$; gatilhos eletrofisiológicos grupo1: $34 \%$, grupo 2: $60 \%, p=0,027$; Ecocardiograma: grupo 1 com discreta alteração de volume e diâmetro diastólico; grupo 2: alterações estruturais referentes a câmaras esquerdas e funcionais (FE: 8,57\% p=0,06; AE: 37,14\% p $<0,001$ AD: 17,14\%p=0,08 SIA: 28,57\% p<0,001; Vol.Sist.: 45,72\%\% $\mathrm{p}<0,001$; Diam.Sist.: 25,72\%p=0,001; Vol.Diast.: 46,72\%,p<0,001; Diam.Diast: $31,43 \% \quad p=0,001 ; \quad$ VAV:20\% $\quad p=0,04 ; \quad$ Val.Sem.: $\quad 5,72 \% \quad p=0,13$; contratilidade: $11,43 \%$ ) $p=0,03$; Massa Ventricular 45,7\% p $<0,001$. Laboratório: nos exames pré-diálise, a baixa função renal foi semelhante nos 2 grupos $p=0,45$. Bic de $\mathrm{Na}$, Cálcio, Magnésio apresentaram-se alterados em ambos os grupos com maior intensidade no grupo $1 \mathrm{p} \leq 0,01$. Fatores de risco para preditores de FA (gatilhos eletrofisiológicos e ESV) foram idade (6x), volumes ventriculares (diastólico 9x e sistólico 6x), intervalo QT $(>8 \mathrm{x})$ e medicações cardiovasculares $(5 \mathrm{x})$. Fatores de risco para alterações estruturais mais relevantes $\mathrm{AE}$ e volume diastólico foram idade (8x), tipo de arritmia (ESV 5x) e tempo de hemodiálise (20x). Conclusão: fatores preditores de Fibrilação atrial ocorreram após 6 meses do início da hemodiálise em pacientes renais crônicos sendo os eventos elétricos mais precoces a alteração do intervalo QT e ESV. Esses dados devem ser investigados regularmente após 6 meses de instalação da hemodiálise crônica a fim de programar medidas preventivas farmacológicas e não farmacológicas de FA nessa população, principalmente em 
pacientes mais velhos e com maior tempo de hemodiálise crônica que apresentam maior risco para essa arritmia e alterações estruturais cardíacas. É provável que os fatores de risco reflitam também a influência da doença hipertensiva crônica de base que era comum em todos os pacientes analisados.

Descritores: Fibrilação atrial; Insuficiência renal crônica; Preditores de fibrilação atrial; Eletrocardiografia ambulatorial; Diálise renal. 


\section{ABSTRACT}

Priori SL. Electrocardiographic predictor changes of the atrial fibrillation $(A F)$ in patients with chronical kidney disease in his/her first year of hemodialysis [dissertation]. São Paulo: "Faculdade de Medicina, Universidade de São Paulo"; 2020 .

Introduction: Atrial fibrillation (AF) is a supraventricular arrhythmia of high prevalence, related to the population's mortality and morbidity. In chronic kidney dialysis patients, AF reaches $36 \%$ of them, compromising the kidney disease prognosis. Objective: The prevalence of AF predictors in patients in their first year of hemodialysis. Method: Prospective, Observational study, transversal, in dialytic patients within 20 to 80 years old without atrial fibrillation, belonging to the UNASCO and HMAG Hemodialysis service in Osasco-SP, divided into 2 groups - I: up to 6 months, group II: 7 to 12 months. Sociodemographic data, electrocardiogram at rest, Holter monitor 24-48 hours, transthoracic echocardiogram, and laboratory tests (kidney function, electrolytes and inflammatory) were collected. The data were submitted to analysis t-test, chi-square, and logistic regression analysis. Results: All patients were hypertensive and had a target organ damage with high cardiovascular risk. Both groups are predominantly males, quinquagenarian, elementary schooling, white, not single, from the southeast and metropolitan region, taking more than two general medicine and more than two morbidities, and group 2 with more ancient patients, weigher, more medicine, morbidities, and cardiovascular predictors. ECG at rest has sinus rhythm in its totality, discreet changes of the atrial activation in patients of group 2 and the presence of arrhythmias (PVC) in group $2 p=0,23$. Holter monitor: presence of electrophysiologic triggers and changes in the interval QT, (QT interval: group 1: $26 \%$, group $240 \%, \mathrm{p}=0,21$; electrophysiologic triggers (group 1: 34\%, group 2: 60\%p=0,027; Echocardiogram: group 1 with discreet change of the volume and diastolic diameter; group 2: structural changes referred to left chambers and functionals (EF: 8,57\%,p=0,06 LA: 37,14\%,p $<0,001$ RA: 17,14\%,p-0,08 IAS: $28,57 \%$ p $<0,001$ Syst.Vol: $45,72 \% \quad \mathrm{p}<0,001$ Syst.Diam: 25,72\% $\mathrm{p}=0,001 \quad$ Dyst.Vol: $45,72 \% \mathrm{p}<0,001 \quad$ Dyst.Diam: $31,43 \% \quad \mathrm{p}=0,001$; AV: $20 \% p=0,04$; Sem.Val: $5,72 \% p=0,13$ contractility: $11,43 \% p=0,03$; ventricular mass $45,7 \%, p<0,001$. Laboratory: in pre-dialysis tests, the low kidney function was similar in the 2 groups $p=0,45$. Sodium Bicarbonate, Calcium, Magnesium, which were altered in both groups with greater intensity in group $1 \mathrm{p} \leq 0,01$. Risk factors to AF predictors (electrophysiological triggers and PVC) were age (6x), ventricular volumes (diastolic 9x and systolic 6x), QT interval $(>8 x)$ and cardiovascular medicine $(5 \mathrm{x})$. Risk factors to more relevant structural changes LA and diastolic volume were age (8x), a kind of arrhythmia (PVC 5x) and hemodialysis duration (20x). Conclusion: predictor factors of the Atrial Fibrillation occur after 6 months of the hemodialysis beginning in chronic kidney patients and the most precocious electric events were the change of the QT interval and PVC. These data must be investigated regularly after 6 months of the chronic hemodialysis installation to 
program AF preventable pharmacological and non-pharmacological measures to this population, mainly in more ancient patients and with a greater chronic hemodialysis exposure that present greater risk to this arrhythmia and cardiac structural changes. It is possible that the risk factors also reflect the influence of the basic chronic hypertensive disease which was common in all patients analyzed.

Descriptors: Atrial fibrillation; Renal insufficiency, chronic; Atrial fibrillation predictors; Electrocardiography, ambulatory; Renal dialysis. 
1 INTRODUÇÃO 


\section{INTRODUÇÃO}

Fibrilação Atrial (FA) é a arritmia cardíaca sustentada mais frequente na prática clínica. Nos Estados Unidos, estima-se que essa arritmia acometa dois milhões de habitantes ${ }^{1,2}$. Na população geral, a prevalência de FA aumenta progressivamente com a idade, evoluindo de $0,5 \%$ na sexta década até aproximadamente $10 \%$ em octogenários. A possibilidade de se desenvolver FA é cerca de 50\% maior em homens do que em mulheres. A FA está associada a um aumento significativo da morbidade e mortalidade, resultando em custos médicohospitalares expressivos. Essa observação tem sido atribuída às consequências hemodinâmicas adversas geradas pela perda da contração atrial e por frequências cardíacas não controladas e, sobremaneira, aos eventos tromboembólicos, principalmente, cerebrais $1,2,3$.

A Fibrilação Atrial (FA) ocorre quando anormalidades eletrofisiológicas alteram o tecido atrial e promovem formação/propagação anormal do impulso elétrico ${ }^{2,3}$. Muitos fatores de risco clínicos estão associados ao aumento no risco de FA e, possivelmente, participam da elevação na prevalência observada nas últimas décadas. Além dos fatores de risco clássicos (hipertensão, diabetes, doença valvar, infarto do miocárdio e insuficiência cardíaca) ${ }^{2,3,4}$, observam-se novos fatores de risco potenciais, que podem ocasionar grandes implicações no manejo clínico da FA. Dentre eles, destaca-se a presença de apneia obstrutiva do sono (AOS), a obesidade, o uso de bebidas alcoólicas, o exercício físico, a história familiar e os fatores genéticos ${ }^{2}$, mas na prática clínica, a influência da obesidade e da AOS parece impactar significativamente na abordagem terapêutica dos pacientes portadores de FA $^{2}$. A doença renal crônica (DRC) e fibrilação atrial (FA) configuram doenças correlacionadas ${ }^{5}$, relevantes na qualidade de vida e na morbimortalidade. Existem poucos estudos sobre as características epidemiológicas, clínicas e eletrocardiográficas e as consequências da prática clínica da FA na DRC em pacientes no primeiro ano de terapia dialítica. 
Pacientes com doença renal crônica (DRC) são considerados de alto risco para doenças cardiovasculares (DCV), responsáveis por $40-50 \%$ dos óbitos nessa população ${ }^{6}$.

O elevado risco cardiovascular na DRC poderia, em parte, ser explicado por um sinergismo entre os fatores de risco tradicionais e os denominados emergentes, derivados do estado urêmico, o qual predispõe aterosclerose acelerada e mortalidade precoce ${ }^{6}$. Além disso, há o fato de os pacientes progredirem para a DRC já com DCV avançada, em razão da concomitância dos fatores de risco como diabetes e hipertensão arterial (causalidade epidemiológica) e a presença da síndrome da mánutrição, inflamação e aterosclerose (MIA) que, conjuntamente, levariam à aterosclerose acelerada. Os fatores emergentes, em sua maioria, causa ou consequência da disfunção endotelial, tornam-se mais importantes à medida que a disfunção renal progride. Entre esses fatores, destacam-se: distúrbios do metabolismo mineral e ósseo, hiper-homocisteinemia, estresse oxidativo e inflamação. Todos os fatores de risco interagem, aumentando a mortalidade cardiovascular na DRC ${ }^{6}$.

Os distúrbios do metabolismo mineral e ósseo, caracterizados por alterações nas concentrações séricas de cálcio, fósforo e paratormônio (PTH), associam-se com a calcificação extra óssea, seja arterial, valvular e miocárdica, além de desempenharem importante papel na patogênese da hipertrofia e fibrose miocárdica. A calcificação vascular $(\mathrm{CV})$ é fortemente associada a eventos cardiovasculares e à morte ${ }^{6}$. Na DRC, existe uma associação paradoxal entre alguns fatores de risco tradicionais e a mortalidade. Assim, hipercolesterolemia, hipertensão arterial sistêmica (HAS) e sobrepeso conferem aparente "proteção" a esses pacientes, determinando uma epidemiologia reversa. Níveis séricos de colesterol se correlacionam positivamente com a albuminemia e, negativamente, com os níveis de proteína C-reativa (PCR) e interleucina 6, refletindo a síndrome MIA ${ }^{1,2}$.

Sabe-se ainda que a Fibrilação Atrial e a Doença Renal Crônica frequentemente coexistem determinando impacto ominoso no desfecho cardiovascular com implicações terapêuticas relevantes para os pacientes e incidência epidêmica de eventos cerebrovasculares isquêmicos ${ }^{5}$. 


\subsection{FIBRILAÇÃO ATRIAL: HISTÓRICO}

A primeira referência à Fibrilação Atrial (FA) vem de citações na obra "The Yellow Emperor's classic of Internal Medicine" de um médico imperador chinês, chamado Huang Ti Nei ChingSu Wen que viveu no período de 1696 a 1558 a.C. Entretanto, cientificamente, a FA começou a ser conhecida no século XV, período em que recebeu várias denominações, todas se referindo ao ritmo irregular e acelerado observado na arritmia (delirium cordis, pulsus irregulares perpetuus, “palpitações revoltosas", etc.) ${ }^{7,8}$. Os conhecimentos sobre a FA se iniciaram com o estudo dos pulsos periféricos e, posteriormente, pelo auxílio e correlação com a ausculta

cardíaca ${ }^{9}, 10$. Por muito tempo, a denominação pulsus irregulares perpetuus foi utilizada por se considerarem patológicas apenas as situações sustentadas, desconhecendo-se o paroxismo das crises de FA.

Com o advento do registro do pulso venoso, Vulpian, em 1847, foi o primeiro a dar o nome de mouvementfibrillaire ao visualizar o átrio de um cão em FA. ${ }^{10}$ Entretanto, foi James Mackenzie, em 1894, que mostrou, por meio de registro do pulso venoso, em paciente com estenose mitral, não existir nenhum sinal de atividade atrial quando havia irregularidades do pulso. Tal observação permitiu concluir que os átrios não apresentam contração durante a FA, criando, então, uma nova terminologia: auricular paralysis ${ }^{12}$.

No início do século XX, Eithoven, após toda evolução no conhecimento da FA, com a utilização do registro de pulso venoso, começou a tirar suas primeiras conclusões utilizando o registro da atividade elétrica cardíaca: o eletrocardiograma. No ano de 1903, ele publicou o primeiro traçado eletrocardiográfico de FA. Descreveu-se um caso de "pulsusinaequalis et irregularis" em que os complexos QRS estavam normais, porém ocorrendo irregularmente e com uma "interferência elétrica" que não permitia a identificação da atividade elétrica atrial ${ }^{13}$. Nessa data, o traçado eletrocardiográfico registrava fielmente a FA, porém não se entendia ainda o que ocorria com a atividade elétrica nos átrios durante o episódio arrítmico ${ }^{13}$. 
Foi Hering, em 1906, que interpretou a "interferência elétrica" descrita por Eithoven, como atividade elétrica atrial, nomeando-a de ondas "f" ${ }^{14}$. Um ano mais tarde, Lewis correlacionou todos os achados eletrocardiográficos do ritmo regular e irregular com as alterações hemodinâmicas e contráteis atriais presentes no ritmo sinusal e na FA, respectivamente ${ }^{15,16}$.

\subsection{FIBRILAÇÃO ATRIAL: DEFINIÇÃO}

A Fibrilação Atrial é uma arritmia supraventricular em que ocorre uma completa desorganização na atividade elétrica atrial, fazendo com que os átrios percam a capacidade de contração, não gerando uma sístole atrial. Ao eletrocardiograma, a ausência de despolarização atrial reflete-se com ausência das ondas P e uma irregularidade entre os espaços R-R ${ }^{1}$.

A Fibrilação Atrial é uma arritmia complexa, com diversas apresentações clínicas. Ela afeta pacientes com ou sem cardiopatia estrutural clinicamente detectável ${ }^{4}$. No último caso, a FA é dita solitária ou idiopática. Quanto à duração, tradicionalmente a FA é classificada em: a) Paroxística, quando os episódios são revertidos espontaneamente ou com intervenção médica em até sete dias; b) persistente, com episódios superiores a sete dias ou persistente de longa duração para casos com duração superior a 1 ano; c) permanente é utilizada nos casos em que as tentativas de reversão ao ritmo sinusal não serão mais instituídas. Fibrilação Atrial não valvar é definida por FA na ausência de estenose mitral reumática, válvula mecânica ou biológica ou plastia mitral. Apesar de vários métodos farmacológicos e não farmacológicos, muitas vezes curativos, hoje disponíveis para o manuseio das arritmias cardíacas, o impacto do tratamento antiarrítmico na história natural da FA permanece modesto. Na ausência de fatores precipitantes identificáveis e corrigíveis, a recorrência da FA é comumente observada. Dessa forma, a redução da frequência cardíaca e/ou duração das recorrências têm sido consideradas um resultado terapêutico satisfatório. Os resultados desapontadores refletem a complexidade do(s) substrato(s) responsáveis pelo desenvolvimento da $\mathrm{FA}^{1,2,4}$. 
Os pesados custos sociais e econômicos associados à FA, aliados à ausência de tratamentos comprovadamente eficazes para essa condição, desencadearam intensas investigações clínicas e experimentais visando elucidar os mecanismos envolvidos na gênese e perpetuação da FA. O entendimento desses processos tem proporcionado o desenvolvimento de estratégias preventivas e terapêuticas bastante promissoras, que detêm o potencial de revolucionar o tratamento da FA e analisar o impacto desses avanços na abordagem terapêutica de pacientes com essa arritmia ${ }^{4}$.

\subsection{ELETROFISIOLOGIA DA FIBRILAÇÃO ATRIAL}

Formação de circuitos reentrantes: existem evidências sólidas de que a FA se baseia em reentradas intra-atriais múltiplas e contínuas (Figura 1). Diversas ondas de ativação independentes trafegam contínua e aleatoriamente através do miocárdio disponível (despolarizável) circundando regiões onde há bloqueio funcional da condução as quais, por sua vez, também se deslocam randomicamente. Dependendo das propriedades eletrofisiológicas do tecido atrial, essas ondas de ativação poderão manter-se indefinidamente, ou, por outro lado, extinguir-se, interrompendo o processo fibrilatório. No primeiro caso, as ondas de ativação sempre encontram tecido em condições de ser despolarizado, ao passo que, no último, há poucas regiões despolarizáveis disponíveis, levando à colisão entre as ondas e sua consequente extinção ${ }^{4}$. 


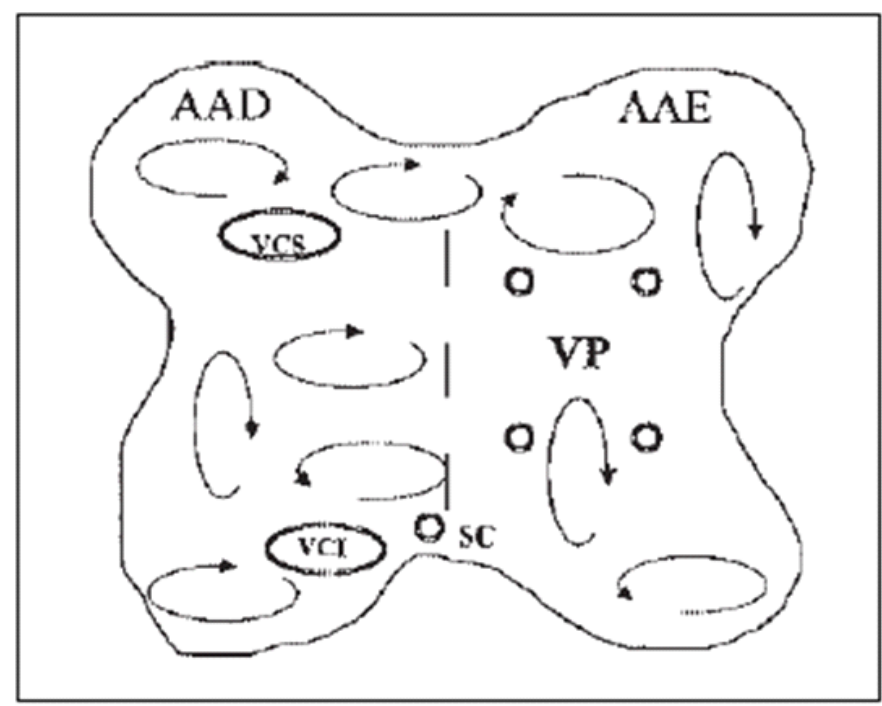

FONTE: Fenelon G, De Paola AAV. Novas ideias sobre os mecanismos eletrofisiológicos da fibrilação atrial e suas implicações terapêuticas. Reblampa 2000;13(1):5-12 ${ }^{4}$.

AAD: apêndice atrial direito; AAE: apêndice atrial esquerdo; SC: seio coronariano; VCI: veia cava inferior; VP: veias pulmonares.

Figura 1 - Desenho esquemático dos átrios ilustrando os mecanismos da fibrilação atrial baseado em múltiplas reentradas intra-atriais. As setas representam ondas de ativação. $O$ pontilhado representa o septo interatrial

Para que um circuito reentrante se forme, é necessário ocorrer bloqueio unidirecional da condução e o tempo de recirculação do impulso até o local de origem precisa ser mais longo que o período refratário do segmento proximal do circuito. Caso esse tempo seja mais curto, o impulso chegará ao local de origem durante a refratariedade do segmento proximal do circuito e a reentrada não se completará. Em outras palavras, o comprimento anatômico do circuito precisa ser igual ou mais longo do que a distância percorrida pela onda de ativação durante o período refratário. Esse conceito define o chamado comprimento de onda, que equivale ao produto do período refratário e da velocidade de condução ${ }^{7}$. Para uma mesma massa de tecido, comprimentos curtos de ondas, resultantes de períodos refratários curtos, velocidades de condução lentas, ou ambos, são mais propícios a desenvolverem circuitos reentrantes do que comprimentos longos de onda (Figura 2) 4 . 


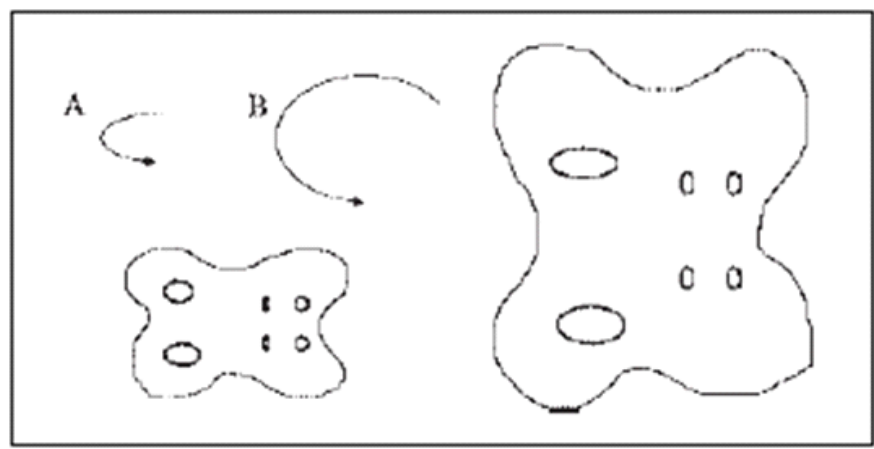

FONTE: Fenelon G, De Paola AAV. Novas ideias sobre os mecanismos eletrofisiológicos da fibrilação atrial e suas implicações terapêuticas. Reblampa 2000;13(1):5-12 ${ }^{4}$.

Figura 2 - Desenho esquemático ilustrando o conceito do comprimento de ondas. As setas representam ondas de ativação. O tamanho das setas equivale ao comprimento de onda. A onda menor (A), por ter comprimento de onda curto, poderia provocar reentrada nos 2 átrios representados. Contudo a onda maior (B) só poderia desencadear reentrada no areio grande. $\mathrm{O}$ átrio menor não possui massa suficiente para acomodar a onda B

Em cães, a indutibilidade de FA se correlaciona mal com o período refratário e com a velocidade de condução isoladamente. Entretanto, o comprimento de onda apresenta forte correlação com a indutibilidade de FA ${ }^{1,}{ }^{15}$. O conceito do comprimento de onda parece se aplicar também a humanos, como sugerem dados sobre a indutibilidade de FA durante o mapeamento intra-operatório de pacientes submetidos a tratamento cirúrgico de vias acessórias atrioventriculares ${ }^{4}$.

A gênese das arritmias cardíacas depende das interações complexas entre os componentes do triângulo de Coumel, a saber: substratos, gatilhos (extrassístoles, mais frequentemente) e os fatores moduladores (Sistema Nervoso Autônomo, eletrólitos, isquemia, etc.). Sob condições propícias, sejam elas espontâneas ou artificiais (Estudos Eletrofisiológicos) pode haver o desenvolvimento de FA. Basta que o comprimento de onda alcance valores críticos. Por isso, frequentemente, há indução de episódios de FA durante estudos eletrofisiológicos, que, na sua maioria, terminam espontaneamente em segundos ou poucos minutos e, geralmente, são considerados não específicos ${ }^{16}$. Todavia, os pacientes com FA espontânea apresentam peculiaridades nos componentes do triângulo de Coumel as quais determinarão o início e a eventual perpetuação da arritmia ${ }^{4}$. 


\subsection{SUBSTRATOS DA FIBRILAÇÃO ATRIAL (FA)}

O conceito de massa crítica: é intuitivo que, quanto maior o tamanho dos átrios, maiores as chances de haver desenvolvimento e perpetuação de FA. De fato, um dos melhores preditores para o desenvolvimento da FA é o tamanho dos átrios ${ }^{17}$. Como o comprimento de onda é o maior determinante da indutibilidade de FA, para um mesmo comprimento de onda, quanto maior for a quantidade de tecido disponível, mais provável será a formação e a perpetuação de um circuito reentrante 15, 18 . Portanto, quanto maiores forem os átrios, maiores serão as chances de as ondas de ativação que constituem a FA encontrarem tecido em condições de ser despolarizado, perpetuando, assim, a arritmia (Figura 3) ${ }^{4}$.

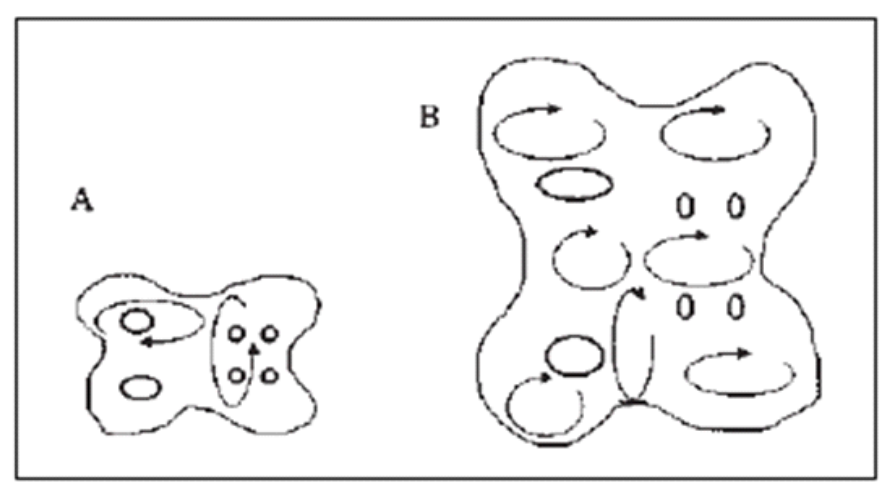

FONTE: Fenelon G, De Paola AAV. Novas ideias sobre os mecanismos eletrofisiológicos da fibrilação atrial e suas implicações terapêuticas. Reblampa 2000;13(1):5-12 ${ }^{4}$.

Figura 3 - Desenho esquemático ilustrando o conceito de massa crítica para a manutenção da FA. Estrutura semelhante à Figura 2. O átrio pequeno (A) só pode acomodar 2 frentes de ativação, aumentando a possibilidade de elas colidirem e se extinguirem. Essa possibilidade é mais remota no átrio grande $(\mathbf{B})$, pois a quantidade de ondas é maior

Além disso, o aumento das dimensões atriais que acompanha diversas cardiopatias resulta frequentemente no desenvolvimento de fibrose intersticial e desconexão elétrica entre os miócitos atriais ${ }^{19,20}$. Essas alterações provocam retardo da condução em vários segmentos de tecido, favorecendo o encurtamento do comprimento de onda e a indução e perpetuação da FA ${ }^{4}$. 


\subsubsection{A remodelação atrial}

A FA parece ter tendência a se auto perpetuar. Vários estudos demonstram que quanto maior for a duração da FA, menor é a chance de sucesso na reversão química da arritmia ${ }^{21,22}$. Da mesma forma, há uma tendência de os episódios de FA paroxística evoluírem em frequência e duração até se tornarem permanentes ${ }^{23}$. Portanto, suspeitava-se que a FA, provavelmente, desencadeava alterações atriais que facilitavam a sua perpetuação.

Estudos experimentais recentes ${ }^{24,25}$ mostraram que a indução repetida de FA por meio de estimulação elétrica atrial de alta frequência (400 bpm) fazia com que os episódios induzidos de FA paroxística se tornassem progressivamente mais duradouros até que ficassem persistentes. Esse processo foi chamado de remodelação elétrica atrial ${ }^{26} \mathrm{e}$, fundamentalmente, caracteriza-se pela redução dos períodos refratários atriais promovida pelas frequências atriais rápidas observadas durante os episódios de FA. Acredita-se que a remodelação elétrica seja mediada pelo acúmulo intracelular de cálcio. Corroborando essa hipótese, o pré-tratamento com verapamil parece atenuar a remodelação elétrica ${ }^{25}$. Trabalhos recentes sugeriram que pacientes com FA também apresentam remodelação elétrica atrial ${ }^{27,28}$. Esses resultados sugerem que, pela redução da refratariedade atrial, a FA promove o encurtamento do comprimento de onda favorecendo a sua própria manutenção ${ }^{4}$.

Um outro mecanismo pode ser operativo na autoperpetuação da FA. Um estudo ecocardiográfico prospectivo ${ }^{29}$ sugere que a FA, por si só, pode resultar em crescimento dos átrios, consequentemente, aumentado a massa de tecido disponível para a perpetuação de arritmia. Ademais, evidências experimentais ${ }^{30}$ revelaram que a FA causa alterações ultra estruturais, principalmente em mitocôndrias, muito similares às observadas no miocárdio hibernante, que podem resultar em morte celular. Dessa forma, além da remodelação elétrica, a FA pode promover remodelação anatômica ${ }^{4}$.

\subsubsection{Gatilhos da FA}

Uma vez iniciado o episódio de FA, sua perpetuação dependerá das características do substrato. Em átrios aumentados e fibrosados, a chance de a FA 
persistir é grande. Já nos átrios sem anormalidades detectáveis - FA solitária - os episódios tendem a ser paroxísticos ${ }^{30,31}$. No primeiro caso, o início da FA não chega a ser surpreendente, já que uma única extrassístole atrial pode induzir bloqueio unidirecional numa região em que haja retardo da condução e desencadear uma reentrada.

Contudo, nos átrios "normais", a probabilidade de uma extrassístole atrial isolada iniciar um episódio de FA é bem menor, ainda mais considerando o caráter recorrente da FA solitária. Essas peculiaridades foram parcialmente esclarecidas com a investigação dos gatilhos que iniciam os episódios de FA.

FA focal. O primeiro modelo experimental de FA foi desenvolvido em $1947^{32}$. A colocação de aconitina em um sítio atrial criava um foco automático que disparava a uma frequência tão rápida que o restante dos átrios não conseguia manter uma ativação sincrônica, ou seja, criavam-se áreas com condução lenta e áreas com bloqueio da condução. Como resultado, havia o desenvolvimento da chamada condução fibrilatória que gerava padrão eletrocardiográfico de FA. O isolamento do foco de aconitina interrompia a FA, restaurando-se o ritmo sinusal.

Em 1959, o advento da hipótese da FA baseada em múltiplas reentradas intraatriais ${ }^{25}$ fez com que o conceito de FA focal fosse pouco explorado.

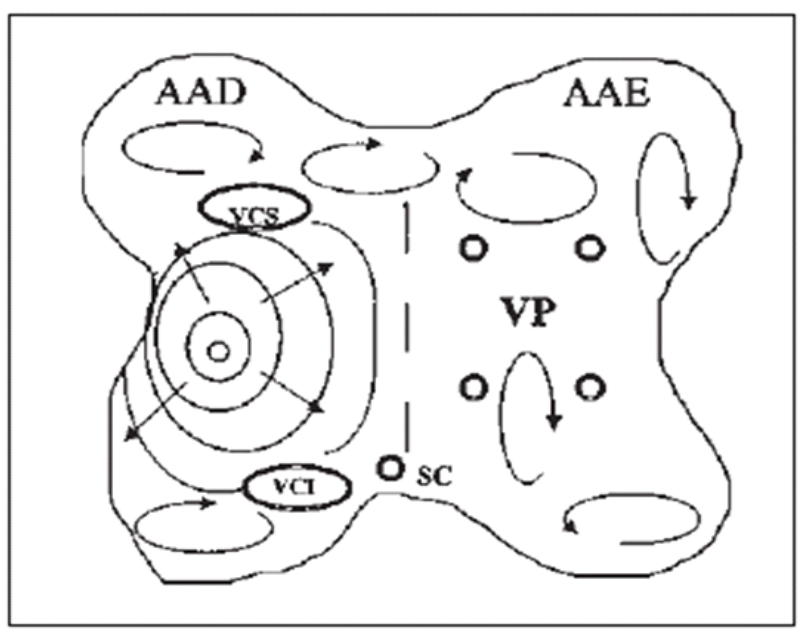

FONTE: Fenelon G, De Paola AAV. Novas ideias sobre os mecanismos eletrofisiológicos da fibrilação atrial e suas implicações terapêuticas. Reblampa 2000;13(1):5-12 ${ }^{4}$.

Figura 4- Desenho esquemático ilustrando o conceito de FA focal. Estrutura e abreviaturas iguais à da figura 1. Ondas de ativação radiais (setas retas) se propagam a partir de foco automático no átrio direito (ponto cheio) 
Estudos recentes envolvendo pacientes com FA paroxística levaram à redescoberta do conceito de FA focal ${ }^{33,34}$. Pôde ser demonstrado que, em casos selecionados, a FA era iniciada por focos automáticos que geravam condução fibrilatória e padrão eletrocardiográficos de FA. Mapeamento endocavitário detalhado revelou que esses focos se localizam predominantemente nas veias pulmonares, principalmente nas superiores. Menos frequentemente, esses focos podem ser encontrados no átrio direito, ao longo da crista terminalis. A criação de lesões puntiformes com energia de radiofrequência no sítio de origem desses focos foi capaz de interromper a FA, confirmando o caráter focal de arritmia. É importante salientar que esses estudos envolveram pacientes com coração estruturalmente normal. Portanto, não se sabe se os mecanismos focais descritos se aplicam a pacientes com cardiopatia estrutural.

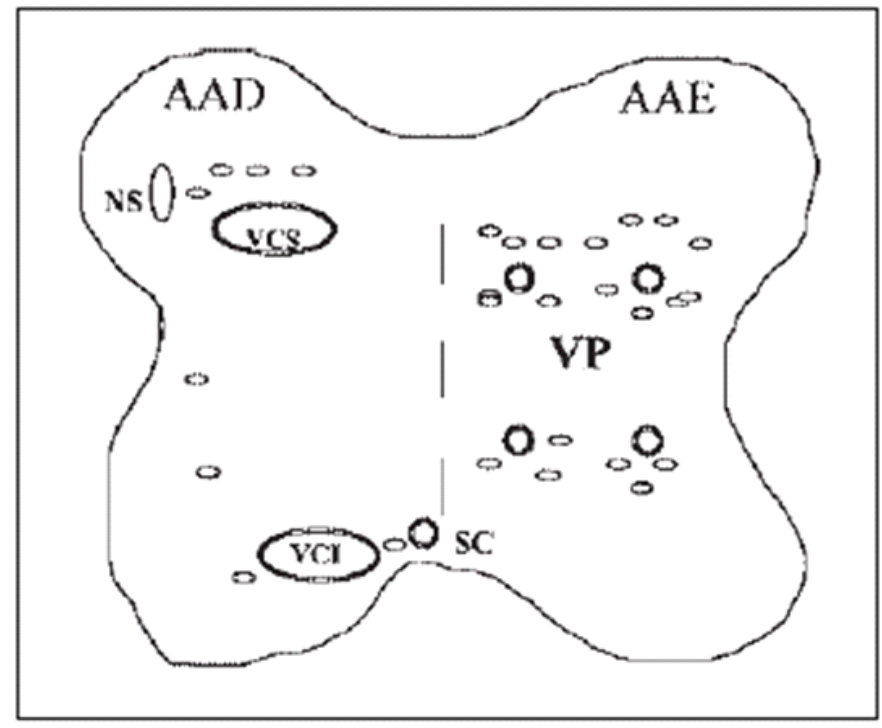

FONTE: Fenelon G, De Paola AAV. Novas ideias sobre os mecanismos eletrofisiológicos da fibrilação atrial e suas implicações terapêuticas. Reblampa 2000;13(1):5-12 ${ }^{4}$.

Figura 5 - Desenho esquemático com estruturas e abreviaturas iguais às da figura1, ilustrando os sítios de origem da FA focal. A quantidade de pontos cheios representa aproximadamente a incidência desses focos em cada local. Nota-se que os focos se concentram principalmente nas veias pulmonares e no átrio esquerdo ao longo da crista terminalis, NS: nó sinusal 
No estudo de Stambler BS, Shepard RK, Turner DA, Fenelon G. Chronic atrial dilatation induces prolongation of atrial refractoriness and atrial tachyarrhythmias. J Am Coll Cardiol.1997;29:63A (Abstract), explorou-se a eletrofisiologia atrial de cães com insuficiência cardíaca congestiva induzida pela estimulação ventricular rápida $(240 \mathrm{bpm})$ durante 3 semanas e se desenvolveu um modelo experimental de arritmias atriais ${ }^{35}$. Os resultados preliminares apontaram que o desenvolvimento da insuficiência cardíaca promovia a indutibilidade de taquicardia atrial focal ${ }^{35}$. Tipicamente, essas arritmias se originam nos átrios direito em toda a extensão da crista terminalis e, menos frequentemente, nas veias pulmonares ${ }^{36}$. Esses focos automáticos se mostram passíveis de ablação por radiofrequência utilizando técnicas convencionais. Digno de nota é o fato de que se pôde demonstrar que, dependendo da frequência de disparo do foco, há o desenvolvimento de condução fibrilatória, resultando em padrão intracavitário e eletrocardiográfico de FA. A exemplo da FA focal observada clinicamente, um episódio de FA persistente pôde ser interrompido com a ablação de um foco ectópico na veia pulmonar inferior. Esses resultados sugerem que a insuficiência cardíaca promove alterações eletrofisiológicas atriais que favorecem o surgimento de focos ectópicos que, eventualmente, podem desencadear episódios de FA. Essa hipótese necessita de confirmação clínica ${ }^{4}$.

\subsubsection{Moduladores da FA}

Sistema nervoso autônomo: há muito se reconhece, experimentalmente, que a estimulação vagal facilita o desencadeamento e a manutenção da FA ${ }^{4}$. A estimulação colinérgica, obtida pela estimulação elétrica do nervo vago, ou com a administração de drogas como a acetilcolina e adenosina, consistentemente reduz os períodos refratários atriais ${ }^{4}$, dessa forma encurtando significativamente $\mathrm{o}$ comprimento de onda. Posteriormente, investigações em pacientes com FA paroxística solitária identificaram um subgrupo cujas características sugerem a participação do vago na gênese da arritmia ${ }^{4,37}$. Nesses pacientes, os episódios de FA são geralmente precedidos por bradicardia sinusal e, frequentemente, ocorrem 
durante períodos em que se observa tônus vagal acentuado, como durante o sono, estado pós-prandial e na fase de relaxamento após esforços físicos intensos 4 .

A atuação do sistema nervoso simpático na gênese da FA não é bem conhecida podendo ocorrer por sua ação no substrato e pela estimulação de gatilhos (focos ectópicos). Em alguns pacientes com FA paroxística 4, 37, os episódios arrítmicos ocorrem na vigência de tônus adrenérgico acentuado, como no período matutino, durante exercício ou estresse psicológico. De forma semelhante, a ativação do sistema nervoso simpático parece contribuir para o desenvolvimento de FA no hipertireoidismo e no pós-operatório de cirurgia cardíaca ${ }^{4}$.

Processos inflamatórios: processos inflamatórios cardíacos, tais como pericardite, miocardite e pós-operatório de cirurgia cardíaca, podem cursar com episódios de FA. Achados de biópsia e marcadores inflamatórios (proteína C reativa) em pacientes com FA paroxística solitária sugerem que a inflamação pode contribuir para o início ou manutenção da fibrilação atrial ${ }^{38}$.

Fatores genéticos. Uma pesquisa recente avaliando três famílias do norte da Espanha com FA familiar (21 de 49 membros tinham FA), identificou uma mutação no cromossoma dos indivíduos afetados. A localização dessa mutação é a mesma dos genes que codificam os receptores alfa e beta-adrenérgicos, sugerindo que a FA familiar pode ser causada por alterações do automatismo cardíaco. Deve-se ressaltar, contudo, que a ocorrência de FA familiar é muito rara. Portanto, são necessários estudos adicionais para que se determine até que ponto defeitos genéticos podem constituir fatores de risco para $\mathrm{FA}^{1,2}$.

Fatores Cardiovasculares: são condições reconhecidas como relacionadas à Fibrilação Atrial - hipertensão arterial sistêmica, cardiomiopatias, valvopatias, defeitos cardíacos congênitos, doença arterial coronariana, arritmias cardíacas (extrassístoles ventriculares e supraventriculares, taquicardias ventriculares e supraventriculares sustentadas e não sustentadas ${ }^{1,2}$, disfunção da tireoide, diabetes melito, doença pulmonar obstrutiva crônica (DPOC), doença renal crônica 39, 40, 41 , consumo excessivo de álcool, tabagismo, estresse hemodinâmico.

Mais recentemente, reconheceu-se a síndrome metabólica também como condição de risco para FA, apesar de o termo ser referente a um conjunto de várias 
condições, incluindo fatores de risco para FA já reconhecidos. Além dos citados, estão ainda relacionados à FA a obesidade ${ }^{39,42,43}$ e a síndrome da apneia do sono ${ }^{40,}$ 43,44 .

Existem diversos estudos associando FA e o risco de acidentes vasculares encefálicos (AVE), tanto de origem isquêmica como de hemorrágica e mortalidade. FA e IC são entidades concomitantes em um número elevado de pacientes e o aparecimento de FA em pacientes portadores de IC eleva o risco de morte em até 2 vezes. Por fim, as mulheres possuem maior susceptibilidade ao desenvolvimento de fenômenos tromboembólicos e mortalidade do que os homens ${ }^{6}$.

\subsubsection{Tratamento da FA}

O tratamento da FA é sobremaneira individualizado e as opções devem ser sempre discutidas com o paciente. É importante ter em mente as recomendações das diretrizes nacionais e internacionais sobre cada caso. Existem duas abordagens possíveis que serão realizadas de acordo com o paciente ${ }^{2,3}$.

Nos casos de pacientes sintomáticos, jovens, FA isolada, FA secundária tratada ou ainda portador de IC, deve-se reverter a FA com cardioversão química (CVQ) ou cardioversão elétrica (CVE) e controlar o ritmo com antiarrítmico. A anticoagulação deve ser realizada de acordo com o risco a ser discutido posteriormente. Os pacientes que não se enquadrem em nenhuma das situações descritas devem ter apenas controlada a FC e receber anticoagulação de acordo com o risco $2,3,4$.

No controle da FC, podem ser utilizados betabloqueadores (esmolol, propranolol e metoprolol foram altamente efetivos para controle da FC nos estudos), bloqueadores de canal de cálcio não diidropiridínicos e os também usados como antiarrítmicos, amiodarona e sotalol ${ }^{2,3}$.

Os antiarrítmicos têm sido amplamente estudados por formarem um dos pilares do tratamento da FA persistente naquele paciente previamente discutido com indicação de cardioversão. Deve-se considerar, para a escolha do antiarrítmico a ser indicado, a classe do medicamento (farmacocinética), as comorbidades do paciente, 
os efeitos colaterais do fármaco e, na nossa realidade, a respectiva disponibilidade no mercado. Os antiarrítmicos recomendados para pacientes sem doença estrutural é a Propafenona. Enquanto nos pacientes com doença estrutural, é preferível utilizar Amiodarona para pacientes com IC ou Sotalol para aqueles com insuficiência coronariana. Esses fármacos foram estudados e possuem evidência científica de $\mathrm{OR}<1$ para desfechos desfavoráveis. É contraindicado utilizar Propafenona em pacientes com cardiopatia ${ }^{2,3}$.

Existe também a ablação do nó atrioventricular recentemente sistematizada como terapia para FA. As indicações para essa intervenção são: FA refratária gerando terapia inapropriada do cardioversordesfibrilador implantável (CDI); FA em pacientes ressincronizados; FA refratária em pacientes jovens sintomáticos $2,3,4$.

Finalmente, outro importante aspecto da terapêutica dos pacientes com FA é a anticoagulação. $\mathrm{O}$ grande risco relacionado à FA é a possibilidade de formação de trombo e o episódio de um acidente vascular encefálico (AVC) cardioembólico. Nesse sentido foram desenvolvidos algoritmos de avaliação do risco para AVC, assim os pacientes com alto risco são identificados e o uso de anticoagulantes orais (ACO) se impõe. Estudiosos desenvolveram dois escores importantes para uma melhor abordagem do paciente. O CHA2DS2VASc e o HASBLED ${ }^{1,2,3}$.

Nos estudos realizados, viu-se que paciente com IC, HAS, mais de 65 anos, sobretudo mais de 75 anos 2,3, diabetes melito, AVC prévio, doença vascular e, ainda, do sexo feminino, são pacientes com maior risco de desenvolver um AVC. Pacientes com escore CHA2DS2VASc de 0 são de muito baixo risco e, por isso, não requerem ACO. Pacientes com escore CHA2DS2VASc de 1 não têm indicação formal de ACO, mas podem receber de acordo com o médico e com o paciente. Já para os pacientes CHA2DS2VASc maior ou igual a 2, a ACO é mandatória ${ }^{3}$.

Por outro lado, alguns pacientes apresentam alto risco de sangramento e, portanto, a indicação de ACO deve ser meticulosa. No escore HASBLED, são avaliados pacientes hipertensos, com anormalidade de função renal ou hepática, AVC prévio, predisposição a sangramento, labilidade de INR, idade $>65$ anos e uso de drogas e/ou álcool. HASBLED $>3$ indica risco de hemorragia. A indicação de 
ACO se sobrepõe em muitas situações e a decisão será feita pela equipe assistente após ponderação do caso ${ }^{2,3}$.

A anticoagulação pode ser realizada com diferentes fármacos. Além dos antagonistas de vitamina $\mathrm{K}$, já amplamente utilizados, surgiram recentemente os $\mathrm{NACO}$, que são inibidores do fator IIa/trombina (Dabigatran) e os inibidores diretos do fator Xa (Rivaroxaban, Apixaban, Edoxabana). Em relação à varfarina, os NACO apresentam a vantagem de não exigirem um controle constante do INR com a mesma ação anticoagulante e fator de segurança. No entanto, os NACO são contraindicados em pacientes com insuficiência renal e não são seguros em pacientes portadores de valvulopatias. Portanto, nesse caso é utilizada a varfarina como $\mathrm{ACO}^{2,3,4}$.

Existem ainda terapias especiais para casos difíceis como paciente de alto risco tromboembólico e contraindicação importante ao uso de ACO. Para esses casos, deve-se considerar a oclusão percutânea do apêndice atrial esquerdo indicada e orientada por um especialista ${ }^{2,3}$.

Esses aspectos discutidos são os principais passos da terapia de um paciente com FA e são de fundamental importância para o médico generalista, portanto objetivou-se trazer o manejo da FA atualizado pelos últimos estudos publicados e, recentemente, assimilado pela SBC nas II Diretrizes Brasileiras de Fibrilação Atrial publicadas em abril de $2016^{1,2,3,4}$.

\subsection{DOENÇA RENAL CRÔNICA (DRC)}

A Doença Renal Crônica (DRC) vem se tornando preponderante na população mundial e intrinsecamente relacionada ao envelhecimento ${ }^{45}$. A doença renal crônica constitui hoje um importante problema médico e de saúde pública. No Brasil, a prevalência de pacientes mantidos em programa crônico de diálise mais que dobrou nos últimos oito anos. De 24.000 pacientes mantidos em programa dialítico em 1994, alcançamos 59.153 pacientes em 2004. A incidência de novos pacientes cresce cerca de 8\% ao ano, tendo sido 18.000 pacientes em 2001. Neste cenário, em que mais de 100 mil pacientes se encontram em Terapia Renal Substitutiva (TRS), o 
gasto com o programa de diálise e transplante renal no Brasil situa-se ao redor de 1,4 bilhões de reais ao ano ${ }^{45,46}$.

No Brasil, estima-se que mais da metade de pacientes tem como causa determinante da disfunção renal o diabetes melito e a hipertensão arterial, reconhecidos fatores de risco cardiovascular ${ }^{45}$.

Inseridas no contexto do envelhecimento, são comuns as condições que ensejam a adoção de polifarmocoterapia, como o diabetes melito e a hipertensão arterial, conhecidos fatores de risco cardiovasculares e principais determinantes para a ocorrência da doença renal crônica. Nesse contexto, a crescente incidência de situações clínicas que, em última análise, determinam indicação de anticoagulação, como a fibrilação atrial não-valvar (FANV) e o tromboembolismo pulmonar (TEP) são frequentes no portador de disfunção renal, acrescendo complexidade de manejo clínico desses pacientes $45,48,51$.

Levando-se em conta dados norte-americanos, para cada paciente mantido em programa de diálise crônica havia cerca de 20 a 25 pacientes com algum grau de disfunção renal, ou seja, cerca 1,2 a 1,5 milhão de brasileiros com doença renal crônica. Trabalho populacional recente em Bambui-MG mostrou que a prevalência de creatinina sérica elevada foi de 0,48\% em adultos da cidade, chegando a 5,09\% na população mais idosa (>60 anos), o que projetaria a população brasileira com disfunção renal a cerca de 1,4 milhão de pessoas ${ }^{52,53,54}$.

A detecção precoce da doença renal e condutas terapêuticas apropriadas para o retardamento de sua progressão pode reduzir o sofrimento dos pacientes e os custos financeiros associados à DRC. Como as duas principais causas de insuficiência renal crônica são a hipertensão arterial e o diabetes melito, são os médicos clínicos gerais e médicos de família que trabalham na área de atenção básica à saúde que cuidam desses pacientes. Ao mesmo tempo, os portadores de disfunção renal leve apresentam quase sempre evolução progressiva, insidiosa e assintomática, dificultando o diagnóstico precoce da disfunção renal. Assim, a conscientização e vigilância do médico de cuidados primários à saúde são essenciais para o diagnóstico e encaminhamento precoce ao nefrologista e a instituição de diretrizes apropriadas para retardar a progressão da DRC, prevenir suas complicações, modificar 


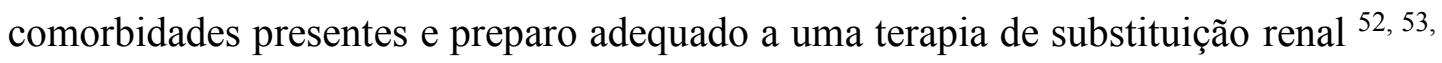
54 .

Segundo a definição da NKF (National Kidney Fundation), consolidada pela Sociedade Brasileira de Nefrologia, é portador de DRC o paciente adulto que, por um período superior a três meses, apresenta taxa de filtração glomerular (TFG) $<60$ $\mathrm{mL} / \mathrm{min} / 1,73 \mathrm{~m}^{2}$, ou que, nos casos com TFG $>60 \mathrm{~mL} / \mathrm{min} / 1,73 \mathrm{~m}^{2}$, apresente um marcador de lesão de estrutura renal (aumento na excreção de albumina urinária). A função renal pode ser avaliada direta ou indiretamente ${ }^{45}$.

Idealmente, o marcador da TFG deveria ser produzido endogenamente em taxas constantes, filtrado livremente no glomérulo, não metabolizado no tecido renal, barato e de fácil execução. Este marcador não existe. Utilizado em nível populacional, a mensuração da creatinina é a metodologia mais usada para estimar a TFG. Embora de fácil execução e barata, a creatinina sérica sofre influência da idade, do sexo, da massa muscular e dieta, além de ser secretada pelo túbulo renal (a taxa de secreção pode chegar a 50\% na DRC). Consideradas essas limitações, além de interferência técnica inerente à metodologia, é de se esperar inacurácia frequente com sua medida. De fato, a observância de valores considerados normais para a creatinina sérica em vigência de disfunção renal significativa é frequente na prática clínica, especialmente na população de idosos. Nessa população, a perda de massa muscular e a desnutrição são responsáveis pela observação acima descrita 45, 46, 48, 49 .

\subsubsection{Cálculo da Função Renal}

Qualquer que seja a razão, o mesmo valor de creatinina pode representar gradações diferentes de função renal e, portanto, valores normais desse marcador não excluem a presença de disfunção renal. Como complemento à mensuração direta de creatinina, a Taxa de Filtração Glomerular Estimada (TFGe) é utilizada, combinando valores de creatinina com variáveis demográficas como sexo, peso, altura, raça e idade, acrescentando maior acurácia na aferição da função renal. Já foram descritas na literatura mais de 20 equações para aferição da função renal, sendo mais utilizadas as fórmulas de Cockroft-Gault (C-G) e aquela derivada do estudo MDRD (Modification of Diet in Renal Disease) ${ }^{45,51,53}$. 
Diferentemente da equação do estudo MDRD, a fórmula C-G estima a depuração de creatinina e não é ajustada pela superfície corporal uma vez que utiliza o peso para o seu cálculo. A despeito de ser menos acurada na aferição da função renal de pacientes idosos e obesos, quando comparada à fórmula derivada do MDRD, a equação de Cockroft-Gault é aceita pelas diferentes sociedades nefrológicas, pois boa parte das recomendações posológicas de inúmeros fármacos foi respaldada com a sua utilização para a aferição do nível de função renal ${ }^{45,51,53}$.

A partir de 2009, o nomograma do CKD-EPI passa a ter papel relevante na estimativa da TFG, especialmente na detecção mais precoce da disfunção renal, sendo referendada por diversas Diretrizes em Nefrologia. Essa fórmula é de semelhante acurácia à do estudo MDRD, no subgrupo de pacientes com TFGe menor que $60 \mathrm{~mL} / \mathrm{min}$ e substancialmente mais acurada naqueles pacientes com taxa de filtração superior a $60 \mathrm{~mL} / \mathrm{min}$. A despeito da melhoria na aferição da função renal, essas equações estão relacionadas à utilização da creatinina como marcador da filtração glomerular supracitada ${ }^{51,53}$.

Alternativa à creatinina, a Cistatina $\mathrm{C}$, uma glicoproteína de $13 \mathrm{kDa}$ produzida por células nucleadas do organismo em taxa constante, passa a figurar como alternativa plausível como marcador da TFG. Em virtude de seu baixo peso molecular e à carga positiva, a Cistatina $\mathrm{C}$ é livremente filtrada pelo glomérulo renal, reabsorvida e metabolizada no túbulo renal proximal, não ocorrendo secreção renal ou extra renal ${ }^{55}$. Logo, a determinação da Cistatina $\mathrm{C}$ sérica reflete exclusivamente a filtração glomerular e seu aumento no soro significa uma redução dessa taxa de filtração. Adicionalmente, a dosagem e a interpretação podem ser feitas a partir de uma única dosagem aleatória. Com depuração extra renal mínima, a Cistatina $\mathrm{C}$ apresenta correspondência de $94 \%$ com a depuração do 51Cr-EDTA. A Cistatina C sérica sofre incremento com quedas da TFG abaixo de $80 \mathrm{~mL} / \mathrm{min}$, enquanto a creatinina sérica, muitas vezes, eleva-se somente com quedas menores de $40 \mathrm{~mL} / \mathrm{min}$ da TFG. Sua mensuração é de relevância, portanto, em pacientes com DRC leve a moderada, e a técnica utilizada não sofre as dificuldades metodológicas da creatinina. A adoção de fórmulas para a estimativa da TFG combinada à creatinina e à Cistatina C tem sido utilizada em alguns estudos e, embora requeira mais estudos para sua validação, pode determinar melhor calibração na avaliação da função renal ${ }^{48,50,51}$. 


\subsubsection{Estadiamento da Doença Renal Crônica}

Nos pacientes com doença renal crônica, o estágio da doença deve ser determinado com base no nível de função renal, independentemente do diagnóstico.

Para efeitos clínicos, epidemiológicos, didáticos e conceituais, a DRC é dividida em seis estágios funcionais, denominados de fases, de acordo com o grau de função renal do paciente, a saber: função normal sem lesão renal, lesão com função renal normal, fase de insuficiência renal funcional ou leve, insuficiência renal laboratorial ou moderada, insuficiência renal clínica ou severa, fase terminal de insuficiência renal crônica ${ }^{46}$.

Fase de função normal sem lesão renal: importante do ponto de vista epidemiológico, pois inclui pessoas integrantes dos chamados grupos de risco para o desenvolvimento da doença renal crônica (hipertensos, diabéticos, parentes de hipertensos, diabéticos e portadores de $\mathrm{DRC}$, etc.) que ainda não desenvolveram lesão renal ${ }^{46}$.

Fase de lesão com função renal normal: corresponde às fases iniciais de lesão renal com filtração glomerular preservada, ou seja, o ritmo de filtração glomerular está acima de $90 \mathrm{~mL} / \mathrm{min} / 1,73 \mathrm{~m}^{2} 46$.

Fase de insuficiência renal funcional ou leve: ocorre no início da perda de função dos rins. Nessa fase, os níveis de ureia e creatinina plasmáticos ainda são normais, não há sinais ou sintomas clínicos importantes de insuficiência renal e somente métodos acurados de avaliação da função do rim (métodos de depuração, por exemplo) irão detectar essas anormalidades. Os rins conseguem manter razoável controle do meio interno. Compreende a um ritmo de filtração glomerular entre $60 \mathrm{e}$ $89 \mathrm{ml} / \mathrm{min} / 1,73 \mathrm{~m}^{2}{ }^{46}$.

Fase de insuficiência renal laboratorial ou moderada: nessa fase, embora os sinais e sintomas de uremia possam estar presentes de maneira discreta, o paciente mantém-se clinicamente bem. Na maioria das vezes, apresenta somente sinais e sintomas ligados à causa básica (lúpus, hipertensão arterial, diabetes melito, infecções urinárias, etc.). Avaliação laboratorial simples já mostra, quase sempre, 
níveis elevados de ureia e de creatinina plasmáticos. Corresponde a uma faixa de ritmo de filtração glomerular compreendido entre 30 e $59 \mathrm{ml} / \mathrm{min} / 1,73 \mathrm{~m}^{2}{ }^{46}$.

Fase de insuficiência renal clínica ou severa: o paciente já se ressente de disfunção renal. Apresenta sinais e sintomas marcados de uremia. Dentre esses, a anemia, a hipertensão arterial, o edema, a fraqueza, o mal-estar e os sintomas digestivos são os mais precoces e comuns. Corresponde à faixa de ritmo de filtração glomerular entre 15 e $29 \mathrm{ml} / \mathrm{min} / 1,73 \mathrm{~m}^{2}{ }^{46}$.

Fase terminal de insuficiência renal crônica: como o próprio nome indica, corresponde à faixa de função renal na qual os rins perderam o controle do meio interno, tornando-se esse bastante alterado para ser incompatível com a vida. Nessa fase, o paciente encontra-se intensamente sintomático. Suas opções terapêuticas são os métodos de depuração artificial do sangue (diálise peritoneal ou hemodiálise) ou o transplante renal. Compreende a um ritmo de filtração glomerular inferior a $15 \mathrm{ml} / \mathrm{min} / 1,73 \mathrm{~m}^{2}{ }^{46}$.

A incidência de DRC em hipertensos é de cerca de 156 casos por milhão, em estudo de 16 anos com 332.500 homens entre 35 e 57 anos. O risco de desenvolvimento de nefropatia é de cerca de $30 \%$ nos diabéticos tipo 1 e de $20 \%$ nos diabéticos tipo 2. No Brasil, dentre 2.467 .812 pacientes com hipertensão e/ou diabetes cadastrados no programa Hiper Dia do Ministério da Saúde em 29 de março de 2004 , a frequência de doenças renais foi de $6,63 \%$ (175.227 casos $)^{45,46,55}$.

A doença renal crônica (DRC) é um dos maiores problemas atuais em saúde pública e está associada a arritmias cardíacas, entre elas a fibrilação atrial ${ }^{5}$.

A prevalência da FA em pacientes em programa de hemodiálise varia na literatura, podendo atingir 36\%, quando consideradas faixas etárias mais avançadas. Fatores de risco reconhecidos são idade avançada, sexo masculino, raça branca, obesidade, doença coronariana (DAC), IC, além da DM e valvulopatias ${ }^{2,3,4}$.

A Fibrilação Atrial (FA) aumenta o risco cardiovascular na população submetida à hemodiálise. Idade avançada, tempo de diálise, dilatação atrial esquerda, dentre outros fatores explicam o aumento da prevalência de FA nessa população. Fatores inerentes ao método dialítico, como a elevada ultrafiltração a que muitos 
pacientes são submetidos, podem predispor ao desenvolvimento de arritmias, incluindo a $\mathrm{FA}^{1,2,3}$.

A doença renal crônica (DRC) e fibrilação atrial (FA) configuram, portanto, doenças correlacionadas, apresentando importância relevante na qualidade de vida e na morbimortalidade ${ }^{5}$. Entretanto, existem poucos estudos sobre as características eletrocardiográficas e as consequências da prática terapêutica e, até o momento, nenhum estudo avaliando fatores preditores dessa arritmia no nefropata. A detecção precoce do risco e diagnóstico, além do comportamento dessa arritmia no paciente dialítico, se fazem relevantes na prática clínica como prevenção de fenômenos tromboembólicos, distúrbios cardiocirculatórios e metabólicos. Este estudo propôs avaliar os fatores preditores eletrocardiográficos da Fibrilação Atrial em pacientes renais crônicos durante o primeiro ano do processo dialítico. 


\section{OBJETIVOS}

\subsection{OBJETIVO PRIMÁRIO}

Detectar o momento de aparecimento de fatores preditores de Fibrilação Atrial em pacientes renais crônicos no primeiro ano de hemodiálise.

\subsection{OBJETIVOS SECUNDÁRIOS}

Analisar a relação dos fatores preditores de fibrilação atrial em pacientes renais crônicos no primeiro ano de hemodiálise com:

- as alterações elétricas de condução do miocárdio,

- as alterações metabólicas sanguíneas,

- as alterações estruturais,

- os dados sociodemográficos. 


\section{METODOLOGIA E CASUÍSTICA}




\section{METODOLOGIA E CASUÍSTICA}

O estudo foi submetido à Comissão de Ética em pesquisa da Faculdade de Medicina da Universidade São Paulo (FMUSP) e obtida aprovação CAAE 46893315.9.0000.0065. Todos os participantes assinaram o Termo de Consentimento Livre e Esclarecido (TCLE) antes da respectiva inclusão no estudo.

\subsection{DELINEAMENTO DE ESTUDO}

Estudo prospectivo, observacional, transversal, não randomizado.

\subsection{POPULAÇÃO}

Foram convidados todos os pacientes com DRC fase 5, em programa de diálise crônica, matriculados no programa de hemodiálise da Clínica UNASCO (Unidade Nefrológica de Osasco LTDA, sito à Avenida dos Autonomistas 2629, centro, Osasco/SP, Cep. 06090-020, telefone (11) 3685.3847/3683.3767), CNPJ: 47.653800/0001-01, CNES: 2806126 e do Hospital Municipal Central de Osasco (Hospital Antônio Giglio), sito à Rua Pedro Fioretti, 48, Centro, Osasco/SP, Cep. 06013-070, telefone (11) 2183.9333, CNPJ: 46.523.171/0003-68, CNES 008028, sem FA registrada até o momento da seleção. Período de março de 2016 a julho de 2019 integrantes do grupo 1 e de 2017 a 2019 integrantes do grupo 2.

Critérios de Inclusão: pacientes com DRC fase 5 (definidos pelo CKD-EPI), matriculados no programa de hemodiálise da Clínica UNASCO (Unidade Nefrológica de Osasco LTDA, sito à av. dos Autonomistas 2629, centro, Osasco/SP, Cep. 06090-020, telefone (11) 3685.3847/3683.3767, e no Hospital Municipal de 
Osasco Antônio Giglio sem FA registrada até o momento da seleção, com idade entre 20 e 80 anos.

Critérios de não Inclusão: pacientes com antecedentes de FA crônica e de AVC tromboembólico e pacientes em quem não se podia aplicar o Holter (problemas socioeconômicos) ou que não assinaram o TCLE.

Grupos: os pacientes foram divididos em 2 grupos:

Grupo 1: pacientes que estão no programa em até 06 (seis) meses.

Grupo 2: pacientes que estão no programa entre 07 (sete) meses e um ano.

\subsection{COLETA DE DADOS}

Dados sociodemográficos: os dados de anamnese, queixas, intercorrências, antecedentes pessoais, hábitos e dados de exames de sangue foram coletados do prontuário médico da Clínica de Hemodiálise da UNASCO e do Hospital Municipal Central de Osasco (Antônio Giglio). Foram eles: idade, sexo, raça, peso, hábitos pessoais (etilismo, tabagismo), escolaridade, estado civil, profissões, naturalidade (regiões), medicações em uso, doenças prévias (HAS, DM, ICC, IAM, DLP, TVP) e antecedentes familiares.

Dados de imagem cardiológica: em cada avaliação, realizou-se eletrocardiograma em repouso (ECG repouso) no ato, foram solicitados exames laboratoriais, Holter por 48 h. (aproveitando duas sessões de hemodiálise) e Ecocardiograma num prazo não superior a 15 dias. O ecocardiograma foi realizado ao longo do estudo (1 exame por paciente) nas dependências do Hospital Municipal Antônio Giglio/Osasco, no setor de ecocardiografia. A instalação e retirada do aparelho Holter foi executada por um profissional treinado e que exerce as funções tanto na Clínica de Hemodiálise (UNASCO), quanto no Hospital Municipal de Osasco. O convite para o estudo, a 
assinatura do TCLE, a coleta de dados do prontuário e dos aparelhos de avaliação cardíaca foram realizados pelo pesquisador com intervalo de tempo não superior a 15 dias entre eles. Os dados obtidos em cada exame cardiológico foram:

- Eletrocardiograma de repouso: foi analisado ritmo, Morfologia de P (características, amplitude, duração e polaridade) e complexos QRS aberrantes. Foram considerados como tipo de arritmia os exames que apresentavam extrassístoles ventriculares e supraventriculares, taquicardias ventriculares e supraventriculares. Todos os pacientes incluídos tinham ritmo de base sinusal. $\mathrm{O}$ aparelho foi um eletrocardiógrafo da marca Fukuda FX- 2122 e Mortara Eli 250 EKG/ECG.

- Eletrocardiografia dinâmica (sistema Holter): Aparelho Holter 24/48h digital DMS Brasil, modelo DMS 300-9 cedidos pela empresa DMS Brasil. Analisados os dados, (variabilidade da onda P (polaridade e intervalo PR), gatilhos eletrofisiológicos (extrassístoles atriais e ventriculares, taquicardias supra ventriculares e ventriculares), tempo de condução da onda P (duração e dispersão), força terminal de $\mathrm{P}$, alterações do intervalo QT).

- Ecocardiograma: analisados os parâmetros estruturais e funcionais do ventrículo esquerdo, estrutura anatômica do átrio direito e esquerdo, septo interatrial, análise dinâmica e funcional dos aparelhos valvares, medidas de pressões, volumes e diâmetros. Exames realizados nas dependências do Hospital Municipal Antônio Giglio/Osasco, no setor de ecocardiografia, com a responsabilidade técnica do Dr. Agnaldo Fernando Neto, CRM 66.161 e Dr. Diogo Freitas Cardoso de Azevedo, CRM 147147, com aparelho GE modelo Vividi7.

Dados e exames de laboratório sanguíneos: os exames de sangue foram coletados pré e pós hemodiálise (Creatinina e Ureia, Sódio $(\mathrm{Na})$, Potássio $(\mathrm{K})$, Cálcio $(\mathrm{Ca})$, Magnésio (Mg), Bicarbonato de Sódio (Bic de Na), Proteína-C-Reativa (PCR)). A metodologia dos exames metabólicos é especificada na tabela abaixo. Esses dados foram coletados do prontuário médico. 


\begin{tabular}{lllll}
\hline Exame & Material & Método & Referência & Observação \\
\hline Ureia & Soro/plasma & colorimétrico & 16 a $40 \mathrm{mg} / \mathrm{dl}$ & \\
Creatinina & Soro/plasma & Colorimétrico & 0,6 a $1,4 \mathrm{mg} / \mathrm{ml}$ & Reação de Jaffe \\
Sódio & Soro/plasma & Eletrodo íon seletivo & 135 a $145 \mathrm{mmol} / \mathrm{L}$ & Ap.C501-Roche \\
Potássio & Soro/plasma & Eletrodo íon seletivo & 3,5 a $5,0 \mathrm{mmol} / \mathrm{L}$ & Ap.C501-Roche \\
Cálcio & Soro/plasma & Colorimétrico & 8,5 a $10,2 \mathrm{mg} / \mathrm{dl}$ & \\
Magnésio & Soro/plasma & Colorimétrico & 1,7 a $2,6 \mathrm{mg} / \mathrm{dl}$ & \\
PCR & Soro/plasma & Aglutinação Látex & Até $10 \mathrm{mg} / \mathrm{dl}$ & \\
Gasometria & Sangue total & Potenciômetro & $\mathrm{pH}^{2} 7,35 \mathrm{a} 7,45$ & \\
arterial e venosa & em heparina & & $\mathrm{pCO}_{2}: 35-48 \mathrm{mmHg}$ & \\
Bicarbonato de & lítica & & $\mathrm{pO}_{2}: 83 \mathrm{a} 108 \mathrm{mmHg}$ & \\
Sódio & & & $\mathrm{HCO}_{3}: 22$ a $26 \mathrm{mEq} / \mathrm{L}$ & \\
\hline
\end{tabular}

Todos os exames foram realizados nas dependências da clínica UNASCO e no Hospital Municipal Antônio Giglio de Osasco- SP, seguindo a rotina de acompanhamento dos pacientes em hemodiálise.

\section{Categorização dos Dados}

Os dados coletados foram, conforme seguem, categorizados de forma binária (0 e 1) para as variáveis: dados sociodemográficos, eletrocardiograma de repouso, ecocardiograma transtorácico com doppler, sistema Holter com números absolutos com valores máximo e mínimo e médias para os dados laboratoriais nos momentos pré e pós hemodiálise dos grupos .

\section{Dados sociodemográficos:}

Idade: <60anos: 0; $>60$ anos:1

Sexo: Masculino: 0; Feminino:1

Escolaridade: Fundamental: 0; Outros: 1

Raça: Branca: 0; Outros: 1

Estado Civil: Solteiro: 0; Outros: 1 
Profissão: Ativo: 0; Outros: 1

Naturalidade: Sudeste: 0; Outras: 1

Região: Metropolitana: 0; Interior: 1

Antecedentes/morbidades: Até 2: 0; Mais de 2: 1

Preditores cardiovasculares: Até 2: 0; Mais de 2: 1

Medicações gerais: Até 2: 0; Mais que 2: 1

Medicações Cardiovasculares: Até 2: 0; Mais de 2: 1

\section{Dados ECG:}

Ritmo: Rítmico: 0; Arrítmico: 1

Morfologia da onda P: Normal: 0; Alterada: 1

Características da onda P: Normal: 0; Alterada: 1

Amplitude da onda P: Normal: 0; Alterada: 1

Duração da onda P: Normal: 0; Alterada: 1

Polaridade da onda P: Normal: 0; Alterada: 1

Tipo de Arritmia: Normal: 0; Alterada: 1

QRS Aberrante: Ausentes: 0; Presentes: 1

\section{Dados Ecocardiograma:}

Fração de Ejeção: Preservada: 0; Diminuída: 1

Átrio Esquerdo: Normal: 0; Alterada: 1

Átrio Direito: Normal: 0; Alterado: 1

Septo IA: Normal: 0; Alterado: 1

Volume sistólico: Normal: 0; Alterado: 1

Volume diastólico: Normal: 0; Alterado: 1 
Diâmetro sistólico: Normal: 0; alterado: 1

Diâmetro diastólico: Normal: 0; Alterado: 1

Válvulas Atrioventriculares: Sem alterações: 0; Com alterações: 1

Válvulas Semilunares: Sem alterações: 0; Com alterações:1

Contratilidade: Sem alterações: 0; Com alterações: 1

\section{Dados Holter:}

Ritmo: Rítmico: 0; Arrítmico: 1

Variabilidade Onda P (Polaridade): Normal: 0; Alterada: 1

Variabilidade Onda P (Intervalo pr): Até 200 ms: 0; Maior 200ms: 1

Gatilhos Eletrofisiológicos: Ausentes: 0; Presentes: 1

Duração Onda P: Até 120ms: 0; Maior 120ms: 1

Dispersão Onda P: Normal: 0; Alterada: 1

Força Terminal Onda P: Normal: 0; Alterada: 1

Intervalo QT: Normal: 0; Alterada: 1

\section{Dados Holter - Gatilhos Eletrofisiológicos}

ESV (extrassístoles ventriculares): Ausente: 0; Presente: 1

ESSV (extrassístoles supraventriculares): Ausentes: 0; Presentes: 1

TVNS (taquicardia ventricular não sustentada): Ausentes: 0; Presentes: 1

TVS (taquicardia ventricular sustentada): Ausente: 0; Presente: 1

TSVNS (taquicardia supra ventricular não sustentada): Ausente: 0; Presente: 1

TSVS (taquicardia supra ventricular sustentada): Ausentes: 0; Presentes: 1 


\section{Dados exames laboratoriais:}

Ureia: $\leq 100: 0 ; \geq 100: 1$

Creatinina: $\leq 4,0: 0 ; \geq 4,0: 1$

Sódio (Na): Normal: 0; Alterado: 1

Potássio (K): Normal: 0; Alterado: 1

Cálcio $\left(\mathrm{Ca}^{+2)}\right.$ : Normal: 0; Alterado: 1

Magnésio (Mg): Normal: 0; Alterado: 1

PCR: Normal: 0; Alterado: 1

Bicarbonato de Sódio (Bic Na): Normal: 0; Alterado: 1

\subsection{ANÁLISE ESTATÍSTICA:}

Os dados colhidos foram submetidos a análises descritivas. Os dados contínuos idade e peso foram analisados e testados quanto a sua normalidade (Kolgomorov e Smirnov) e homogeneidade (teste de Levene). Esses dados foram expressos por média, desvio padrão (DP) e testados posteriormente pelo teste $\mathrm{T}$ para amostras independentes.

Todas as covariáveis foram submetidas à categorização binária $\left(\begin{array}{lll}0 & \text { e } & 1\end{array}\right)$ conforme descrita acima. Esses dados categóricos dicotômicos foram expressos por porcentagem, máximos e mínimos, e analisou-se a associação das covariáveis através do teste Qui-quadrado estratificado segundo o tempo de diálise.

Posteriormente, os dados foram organizados sequencialmente para as análises de regressão logística. A sequência utilizada foi:

- escolha da variável dependente.

- análise da associação das covariáveis em relação à variável dependente pelo teste Qui-quadrado. 
- análise pela regressão logística binária univariada de cada covariável que obteve associação significativa $(\mathrm{p} \leq 0,05)$ no teste Qui-quadrado em relação à dependente escolhida;

- seleção das covariáveis significativas $(p \leq 0,20)$ ou de importância clínica nas análises de regressão univariada para serem submetidas à análise final pela regressão logística binária múltipla. A regressão binária logística múltipla foi realizada acrescentando cada fator a cada análise e retirandose os dados não significativos. Alguns dados de grande significância clínica foram mantidos.

As análises de regressão foram realizadas separadamente para cada variável dependente (regressão logística binária) sem dividir os participantes em grupos (tempo de diálise). As variáveis dependentes foram escolhidas de acordo com os objetivos deste projeto, critério clínico e incidência, a saber:

- alterações elétricas (Holter): gatilhos eletrofisiológicos, gatilhos ESV.

- alterações estruturais (ecocardiograma): átrio esquerdo, volume diastólico, volume sistólico, diâmetro diastólico, diâmetro sistólico, septo interventricular, válvula atrioventricular e, pela importância clínica, átrio direito.

As covariáveis foram todos os dados sociodemográficos, dos exames laboratoriais pré e pós hemodiálise, do ECG repouso, do ecocardiograma e alguns dados do Holter com exceção os que apresentavam baixa incidência (menos que 7 eventos em 73 análises). Os resultados das análises pelo teste Qui-quadrado foram expressos por porcentagem, máximos e mínimos e significância. Os valores das análises de regressão foram expressos em razão de chances, intervalo de confiança $95 \%$ e significância $5 \%$.

A significância escolhida para os testes foi $5 \%$, com exceção das covariáveis escolhidas para regressão logística binária múltipla em que se optou por significância de 0,20. O pacote estatístico foi o SPSS 20. 


\section{RESULTADOS}

Foram convidados para participar do estudo todos os pacientes que iniciaram a diálise no serviço da clínica UNASCO e no Hospital Municipal Antônio Giglio, no período de março de 2016 a julho de 2019, totalizando 77 pacientes. Desses, 1 não quis participar da pesquisa, 3 já apresentavam FA e assim não foram incluídos no estudo. No total de 73 pacientes, foram incluídos sendo 38 no grupo 1 ( 0 a 6 meses de início de hemodiálise) e 35 no grupo 2 ( 7 a 12 meses pós de hemodiálise). Figura 6.

\section{FLUXOGRAMA DE RECRUTAMENTO DE PACIENTES}

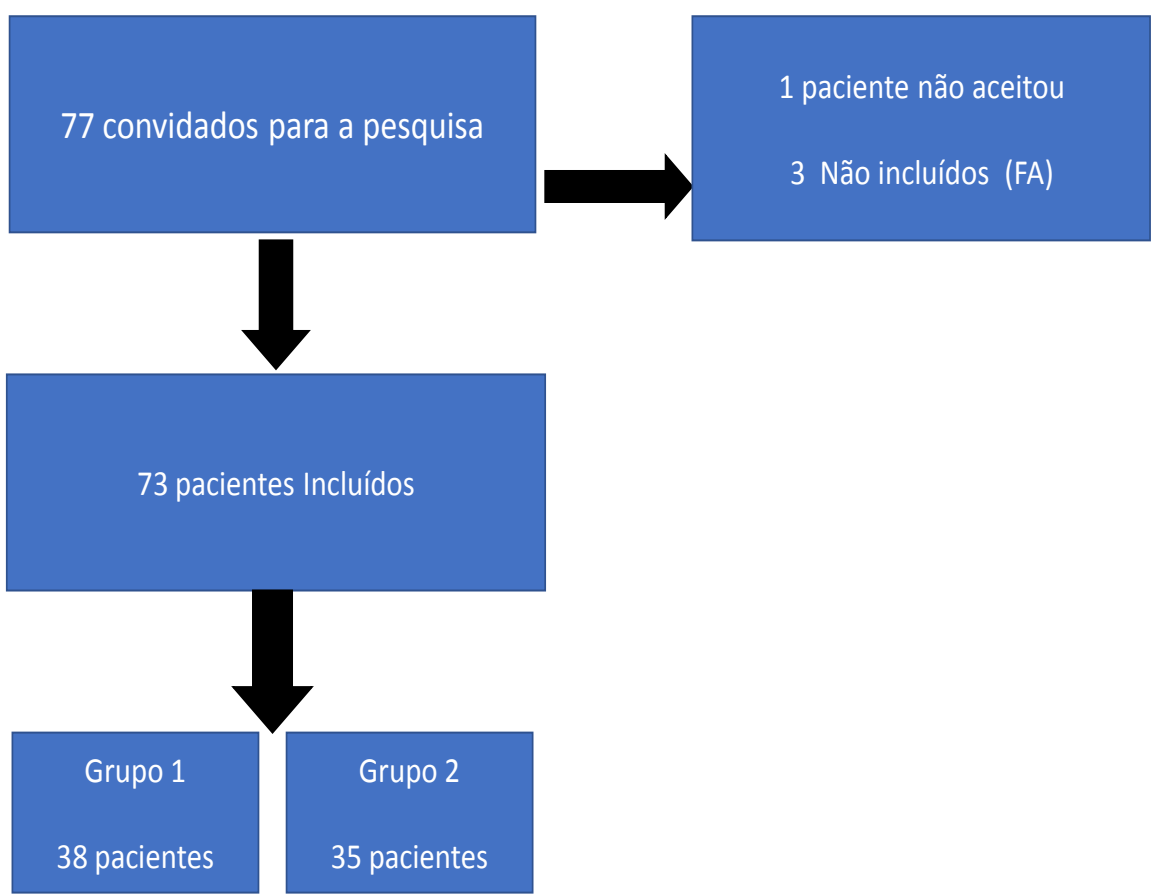

Figura 6 - Fluxograma de recrutamento de pacientes 
Apesar de não ser fator de inclusão, coincidentemente todos os participantes apresentavam hipertensão arterial sistêmica de longa data. Por serem dialíticos, todos os participantes apresentavam lesão de órgão alvo cardiovascular, que é a doença renal crônica, neste caso, terminal. Confirmou-se, assim, que todos os pacientes deste estudo apresentavam alto risco cardiovascular (1 fator de risco + lesão de órgão alvo) 56.

Os dados a seguir são referentes à Tabela 1; compreendem as variáveis sociodemográficas e morbidades entre os grupos de participantes da pesquisa. 
Tabela 1 - Variáveis Sociodemográficas

\begin{tabular}{|c|c|c|c|}
\hline VARIÁVEIS & $\begin{array}{c}\text { Grupo } 1 \\
\text { N (\%) }\end{array}$ & $\begin{array}{c}\text { Grupo } 2 \\
\text { N(\%) }\end{array}$ & $\mathbf{p}^{*}$ \\
\hline \multicolumn{4}{|l|}{ Sexo } \\
\hline Masculino & $22(57,90)$ & $27(77,14)$ & \multirow{2}{*}{0,080} \\
\hline Feminino & $16(42,10)$ & $8(22,86)$ & \\
\hline \multicolumn{4}{|l|}{ Escolaridade } \\
\hline Fundamental & $22(57,90)$ & $20(57,14)$ & \multirow{2}{*}{0,948} \\
\hline Outros & $16(42,10)$ & $15(42,86)$ & \\
\hline \multicolumn{4}{|l|}{ Raça } \\
\hline Branco & $26(68,42)$ & $23(65,72)$ & \multirow{2}{*}{0,806} \\
\hline Outros & $12(31,58)$ & $12(34,28)$ & \\
\hline \multicolumn{4}{|l|}{ Estado Civil } \\
\hline Solteiro & $9(23,69)$ & $6(17,14)$ & \multirow{2}{*}{0,490} \\
\hline Outros & $29(76,31)$ & $29(82,86)$ & \\
\hline \multicolumn{4}{|l|}{ Profissão } \\
\hline Ativo & $23(60,53)$ & $25(71,43)$ & \multirow{2}{*}{0,327} \\
\hline Outros & $15(39,48)$ & $10(28,57)$ & \\
\hline \multicolumn{4}{|l|}{ Natural (região) } \\
\hline Sudeste & $32(84,21)$ & $32(91,43)$ & \multirow{2}{*}{0,349} \\
\hline Outras & $6,0(15,79)$ & $3,0(08,57)$ & \\
\hline \multicolumn{4}{|c|}{ Natural (metro/int.)*** } \\
\hline Cidade & $27(71,05)$ & $31(88,57)$ & \multirow{2}{*}{0,064} \\
\hline Interior & $11(28,95)$ & $4(11,43)$ & \\
\hline \multicolumn{4}{|c|}{ Antecedentes/morbidades } \\
\hline Até 2 & $21(55,26)$ & $11(34,38)$ & \multirow{2}{*}{0,040} \\
\hline Mais 2 & $17(44,74)$ & $24(58,54)$ & \\
\hline \multicolumn{4}{|c|}{ Preditores C.v. **** } \\
\hline Até 2 & $35(92,10)$ & $21(37,50)$ & \multirow{2}{*}{0,001} \\
\hline Mais 2 & $3(7,90)$ & $14(82,35)$ & \\
\hline \multicolumn{4}{|c|}{ Medicações gerais } \\
\hline Até 2 & $16(42,10)$ & $5(23,81)$ & \multirow{2}{*}{0,009} \\
\hline Mais 2 & $22(57,90)$ & $30(57,69)$ & \\
\hline \multicolumn{4}{|c|}{ Medicações C.v. ***** } \\
\hline Até 2 & $29(76,31)$ & $18(38,30)$ & \multirow{2}{*}{0,027} \\
\hline Mais 2 & $9(23,69)$ & $17(65,38)$ & \\
\hline \multicolumn{4}{|l|}{ Idade } \\
\hline$<60$ anos & $28(73,68)$ & $10(28,57)$ & \multirow{2}{*}{0,007} \\
\hline \multirow[t]{2}{*}{$\geq 60$ anos } & $15(26,32)$ & $20(71,43)$ & \\
\hline & \multicolumn{2}{|c|}{ Média (dp) } & $\mathrm{p}^{* *}$ \\
\hline Idade & $50,00 \pm 13,82(22-74)$ & $58,57 \pm 13,2(23-69)$ & 0,009 \\
\hline Peso & $68,92 \pm 11,06(27-162)$ & $74,40 \pm 9,60(50-92)$ & 0,506 \\
\hline
\end{tabular}

Testes estatísticos utilizados *Qui-quadrado. **Teste t de Student. Valores expressos em números absolutos e porcentagem com desvio padrão, onde $\mathrm{n}=$ número de amostras, Significância $(\mathrm{p} 0,05) * * *$ metropolitana/interior, $* * * *$ preditores cardiovasculares, $* * * * *$ medicações cardiovasculares 
Percebe-se que os participantes deste estudo apresentam perfil predominante da raça branca, masculino, não solteiros, idade média na $5^{\circ}$ década e peso médio entre a $6^{\circ}$ e $7^{\circ}$ dezena, escolaridade até o ensino fundamental, ainda trabalham, moradores da região sudeste com predomínio de região metropolitana, multimorbidades com preditores de doenças cardiovasculares e em uso de polifarmácia. O grupo 2 apresenta perfil de participantes mais velhos, com mais peso e maior número de multimorbidades, polifarmácia e preditores cardiovasculares.

Os dados a seguir, referentes à Tabela 2, descrevem as variáveis pesquisadas no eletrocardiograma de repouso, realizado no início da pesquisa, após o convite de participação entre os grupos.

Tabela 2 - ECG de Repouso

\begin{tabular}{|c|c|c|c|c|}
\hline VARIÁVEIS & GRUPO 1 & n (\%) & GRUPO 2 & $\mathbf{p}^{*}$ \\
\hline \multicolumn{5}{|l|}{ ECG ritmo } \\
\hline Rítmico & $38(100)$ & & $35(100)$ & \multirow{2}{*}{---- } \\
\hline Arrítmico & $-(-)$ & & $-(-)$ & \\
\hline \multicolumn{5}{|c|}{ Morfologia Onda P } \\
\hline Normal & $38(100)$ & & $34(97)$ & \multirow{2}{*}{0,294} \\
\hline Alterada & $-(-)$ & & $1(3)$ & \\
\hline \multicolumn{5}{|c|}{ Característica Onda $\mathbf{P}$} \\
\hline Normal & $38(100)$ & & $34(97)$ & \multirow{2}{*}{0,294} \\
\hline Alterada & $-(-)$ & & $1(3)$ & \\
\hline \multicolumn{5}{|c|}{ Amplitude Onda P } \\
\hline Normal & $38(100)$ & & $33(94)$ & \multirow{2}{*}{0,135} \\
\hline Aumentada & $-(-)$ & & $2(6)$ & \\
\hline \multicolumn{5}{|c|}{ Duração Onda P } \\
\hline Normal & $38(100)$ & & $33(94)$ & \multirow{2}{*}{0,135} \\
\hline Aumentada & $-(-)$ & & $2(6)$ & \\
\hline \multicolumn{5}{|c|}{ Polaridade Onda $P$} \\
\hline Normal & $38(100)$ & & $34(97)$ & \multirow{2}{*}{0,294} \\
\hline Aumentada & $-(-)$ & & $1(3)$ & \\
\hline \multicolumn{5}{|l|}{ Tipo Arritmia } \\
\hline Rítmico & $36(94,74)$ & & $29(83)$ & \multirow{2}{*}{0,232} \\
\hline Arrítmico & $2(5,26)$ & & $6(17)$ & \\
\hline \multicolumn{5}{|c|}{ QRS Aberrantes } \\
\hline Ausentes & $38(100)$ & & $35(100)$ & \\
\hline Presentes & $-(-)$ & & $-(-)$ & \\
\hline
\end{tabular}

Valores expressos em números de pacientes e porcentagem, onde $\mathrm{n}=$ número de amostras, significância utilizada foi de $5 \% \mathrm{p}(0,05)$, teste estatístico foi o Qui-quadrado. * extrassístoles ventriculares 
Ambos os grupos apresentam no ECG de repouso ritmo sinusal de base e ausência de QRS aberrantes. Nos participantes do grupo 1, a única alteração detectada neste exame foram 2 pacientes com arritmias (ESV). Essa arritmia aumentou para 17\% dos pacientes do grupo 2. Apenas 2 pacientes do grupo 2 evidenciaram alterações em parâmetros de onda $\mathrm{P}$ (morfologia, amplitude, duração, polaridade).

Os dados referentes à Tabela 3 foram obtidos no exame de ecocardiograma transtorácico. 
Tabela 3 - Ecocardiograma

\begin{tabular}{|c|c|c|c|}
\hline VARIÁVEIS & $\begin{array}{c}\text { Grupo } 1 \\
\text { n (\%) }\end{array}$ & $\begin{array}{c}\text { Grupo } 2 \\
\text { n (\%) }\end{array}$ & $\mathbf{p}$ \\
\hline \multicolumn{4}{|l|}{ Fração ejeção } \\
\hline Preservada & $38,0(100)$ & $32,0(91,42)$ & \multirow{2}{*}{0,065} \\
\hline Diminuída & 0 & $3,0(8,57)$ & \\
\hline \multicolumn{4}{|l|}{ Átrio esquerdo } \\
\hline Normal & $38,0(100)$ & $22,0(62,86)$ & \multirow{2}{*}{$<0,001$} \\
\hline Alterado & 0 & $13,0(37,14)$ & \\
\hline \multicolumn{4}{|l|}{ Átrio direito } \\
\hline Normal & $38,0(100)$ & $29,0(82,85)$ & \multirow{2}{*}{0,080} \\
\hline Alterado & 0 & $6,0(17,14)$ & \\
\hline \multicolumn{4}{|l|}{ Septo Inter Atrial } \\
\hline Normal & $38,0(100)$ & $25,0(71,43)$ & \multirow{2}{*}{$<0,001$} \\
\hline Alterado & 0 & $10,0(28,57)$ & \\
\hline \multicolumn{4}{|l|}{ Volume Sistólico } \\
\hline Normal & $38,0(100)$ & $19,0(54,28)$ & \multirow{2}{*}{$<0,001$} \\
\hline Alterado & 0 & $16,0(45,72)$ & \\
\hline \multicolumn{4}{|l|}{ Volume Diastólico } \\
\hline Normal & $7,0(97,37)$ & $19,0(54,28)$ & \multirow{2}{*}{$<0,001$} \\
\hline Alterado & $1,0(2,63)$ & $16,0(45,72)$ & \\
\hline \multicolumn{4}{|l|}{ Diâmetro Sistólico } \\
\hline Normal & $38,0(100)$ & $26,0(74,28)$ & \multirow{2}{*}{0,001} \\
\hline Alterado & 0 & $9,0(25,72)$ & \\
\hline \multicolumn{4}{|l|}{ Diâmetro Diastólico } \\
\hline Normal & $37,0(97,37)$ & $24,0(68,57)$ & \multirow{2}{*}{0,001} \\
\hline Alterado & $1,0(2,63)$ & $11,0(31,43)$ & \\
\hline \multicolumn{4}{|c|}{ Válvulas atrioventriculares } \\
\hline Sem alterações & $38,0(100)$ & $28,0(80)$ & \multirow{2}{*}{0,044} \\
\hline Com alterações & 0 & $7,0(20)$ & \\
\hline \multicolumn{4}{|c|}{ Válvulas semilunares } \\
\hline Sem alterações & $38,0(100)$ & $33,0(94,28)$ & \multirow{2}{*}{0,135} \\
\hline Com alterações & 0 & $2,0(5,72)$ & \\
\hline \multicolumn{4}{|l|}{ Contratilidade } \\
\hline Sem alterações & $38,0(100)$ & $31,0(88,57)$ & \multirow{2}{*}{0,032} \\
\hline Com alterações & 0 & $4,0(11,43)$ & \\
\hline
\end{tabular}

Valores expressos em números pacientes e porcentagem, onde $\mathrm{n}=$ número de amostras, significância utilizada foi de $5 \%$ p $(0,05)$, teste estatístico foi o Qui-quadrado. 
Os participantes do grupo 1 apresentaram normalidade em quase todos os parâmetros ecocardiográficos. Apenas 1 participante do grupo apresentou alteração do volume e diâmetro diastólico. Houve alteração de todos os parâmetros ecocardiográficos em alguns pacientes do grupo 2, sendo alterações mais frequentes as relativas às câmaras esquerdas ( $\mathrm{AE}$, volume sistólico, volume diastólico, diâmetro diastólico, diâmetro sistólico de VE, válvulas atrioventriculares) com mais de $10 \%$ de eventos medidos ( $\geq 7$ eventos/73 eventos medidos) sendo que alterações dos volumes de VE atingiram quase metade dos eventos nesse grupo. Alterações de câmaras direitas e contratilidade estavam presentes em menos de $10 \%$ de eventos. Esses dados mostram que as alterações da estrutura e função global, de ambas as câmaras cardíacas, nos pacientes do estudo são mais frequentemente detectáveis pelo ecocardiograma transtorácico a partir do $6^{\circ}$ mês após início da hemodiálise e que as alterações estruturais mais expressivas correspondem às alterações das câmaras esquerdas, sugerindo grande influência do fator de risco cardiovascular HAS que todos os pacientes apresentavam.

Os dados a seguir são referentes aos dados obtidos no exame Holter (24-48h) realizado durante as sessões de hemodiálise; A Tabela 4 exibe os dados do Holter com exceção dos gatilhos eletrofisiológicos que foram incluídos na Tabela 5. 
Tabela 4 - Holter

\begin{tabular}{|c|c|c|c|}
\hline VARIÁVEIS & $\begin{array}{c}\text { Grupo } 1 \\
\text { N (\%) }\end{array}$ & $\begin{array}{c}\text { Grupo } 2 \\
\text { N(\%) }\end{array}$ & $\mathbf{p}$ \\
\hline \multicolumn{4}{|c|}{ HOLTER RITMO } \\
\hline Rítmico & $38(100)$ & $35(100)$ & \multirow{2}{*}{---} \\
\hline Arrítmico & $-(-)$ & $-(-)$ & \\
\hline \multicolumn{4}{|c|}{ HOLTERVARIAB ONDA P POLARIDADE } \\
\hline Normal & $38(100)$ & $35(100)$ & \multirow{2}{*}{---} \\
\hline Anormal & $-(-)$ & $-(-)$ & \\
\hline \multicolumn{4}{|c|}{ HOLTERVARIAB ONDA P INTERVPR } \\
\hline Até 20 & $38(100)$ & $35(100)$ & \multirow{2}{*}{---} \\
\hline$>20$ & $-(-)$ & $-(-)$ & \\
\hline \multicolumn{4}{|c|}{ HOLTER GATILHOS ELETRO FISIOL } \\
\hline Normal & $25(66)$ & $14(40,00)$ & \multirow{2}{*}{0,027} \\
\hline Anormal & $13(34)$ & $21(60,00)$ & \\
\hline \multicolumn{4}{|c|}{ HOLTER TEMPO DURAÇÃO ONDA P DURA } \\
\hline$<12$ & $38(100)$ & $34(97,00)$ & \multirow{2}{*}{0,294} \\
\hline$>12$ & $-(-)$ & $1(3,00)$ & \\
\hline \multicolumn{4}{|c|}{ HOLTER TEMPO DURAÇÃO ONDA P DIS } \\
\hline Normal & $38(100)$ & $34(97,00)$ & \multirow{2}{*}{0,294} \\
\hline Alterada & $-(-)$ & $1(3,00)$ & \\
\hline \multicolumn{4}{|c|}{ HOLTER FORÇA TERMINAL ONDA P } \\
\hline Normal & $38(100)$ & $34(97,00)$ & \multirow{2}{*}{0,294} \\
\hline Alterada & $-(-)$ & $1(3,00)$ & \\
\hline \multicolumn{4}{|c|}{ HOLTER INTERVALO QT } \\
\hline Normal & $28(74)$ & $21(60)$ & \multirow{2}{*}{0,214} \\
\hline Alterado & $10(26)$ & $14(40)$ & \\
\hline
\end{tabular}

Valores expressos em números de pacientes e porcentagem, onde $n=$ número de amostras, significância utilizada foi de $5 \%$, p $(0,05)$, teste estatístico foi o Qui-quadrado 
O Holter evidenciou que um pouco mais de $1 / 3$ dos pacientes do grupo 1 apresentaram algum tipo de arritmia considerada gatilho eletrofisiológico de FA e 1/4 alteração do intervalo QT. Os pacientes do grupo 2 apresentaram aumento expressivo dessas alterações elétricas $(2 / 3$ de gatilhos eletrofisiológicos, $p=0,027$ e quase $50 \%$ de alteração do intervalo QT, p=0,214). Os outros parâmetros foram ausentes em ambos os grupos com exceção de 1 paciente do grupo 2 que apresentou alterações de duração, dispersão e força terminal da onda $P$.

Tabela 5 - Holter Gatilhos-Eletrofisiológicos

\begin{tabular}{cccc}
\hline VARIÁVEIS & $\begin{array}{c}\text { Grupo 1 } \\
\text { n (\%) }\end{array}$ & $\begin{array}{c}\text { Grupo 2 } \\
\text { n (\%) }\end{array}$ & p \\
\hline ESV* & $10(26)$ & $14(40)$ & 0,025 \\
Presente & $28(74)$ & $21(56)$ & \\
Ausente & & & \\
ESSV** & $8(21)$ & $16(45)$ & 0,135 \\
Presente & $30(79)$ & $19(55)$ & \\
Ausente & & & 0,135 \\
TVNS*** & $0(0)$ & $0(0)$ & \\
Presente & $38(100)$ & $35(100)$ & 0,07 \\
Ausente & & & \\
TVS*** & $1(2)$ & $5(15)$ & \\
Presente & $37(98)$ & $30(85)$ & \\
Ausente & & $0(0)$ & \\
TSVNS***** & $1(3)$ & $35(100)$ & --334 \\
Presente & $37(97)$ & $-(-)$ & \\
Ausente & & $35(100)$ & \\
TSVS*** & $-(-)$ & & \\
Presente & $38(100)$ & & \\
Ausente & & & \\
\hline
\end{tabular}

Valores expressos em números de pacientes e porcentagem, onde $\mathrm{n}=$ número de amostras, significância utilizada foi de $5 \% \mathrm{p}(0,05)$, teste estatístico foi o Qui-quadrado, *extrassístoles ventriculares **extrassístoles supraventriculares ***taquicardia ventricular não sustentada ****taquicardia ventricular sustentada $* * * * *$ taquicardia supra ventricular não sustentada $* * * * * *$ taquicardia supraventricular sustentada

O gatilho eletrofisiológico mais prevalente foi ESV, presente em $1 / 3$ da amostra dos pacientes do grupo 1 e quase metade dos pacientes no grupo 2. O segundo gatilho eletrofisiológico em termos de frequência foi TVS presente em 1/6 dos pacientes do grupo 2. As outras arritmias foram ausentes ou inexpressivas em termos de frequência em ambos os grupos. Porém fica evidente que as arritmias 
ocorrem predominantemente no $2^{\circ}$ semestre do início de hemodiálise e que a ESV é a arritmia prevalente.

Como esperado, todas as medidas de Ureia e Creatinina estavam acima do normal, visto que os pacientes possuíam insuficiência renal terminal e eram submetidos à hemodiálise crônica. Após categorização dicotômica dos valores de Ureia (maior ou menor que 100) e creatinina (maior ou menor que 4,0) pré e pós hemodiálise (HD), foram testadas suas associações pelo teste Qui quadrado com tempo de hemodiálise que se mostrou não significativa. (Creatinina pré HD $p=0,858$; Ureia pré $\mathrm{HD} \mathrm{P}=0,639$; Creatinina pós $\mathrm{HD} \mathrm{p}=0,6$; Ureia pós $\mathrm{HD} \mathrm{p}=0,456$ ).

A tabela a seguir refere-se aos valores médios obtidos em exames laboratoriais nos pacientes dos grupos 1 e 2 realizados durante os momentos pré e pós-diálise com seus valores mínimo e máximo e valores de referência do método utilizado.

Tabela 6 - Exames Laboratoriais Plasmáticos

\begin{tabular}{|c|c|c|c|}
\hline VARIÁVEIS & \multicolumn{2}{|c|}{ média $(\min -M a x)$ n $(\%)$} & $\mathbf{V R}$ \\
\hline Creatinina $(\mathrm{mg} / \mathrm{dL})$ & $5,10(3,40-8,00)$ & $3,72(2,4-6,1)$ & $(0,6-1,2)$ \\
\hline Ureia $(\mathrm{mg} / \mathrm{dL})$ & $144,71(86,00-280,00)$ & $87,78(56-141)$ & $(16-40)$ \\
\hline $\mathrm{Na}(\mathrm{mmol} / \mathrm{l})$ & $141,55(133,00-146,00)$ & $138,81(135-144)$ & $(135-145)$ \\
\hline $\mathrm{K}(\mathrm{mmol} / \mathrm{l})$ & $5,47(3,90-6,50)$ & $4,63(3,3-5,7)$ & $(3,5-5,5)$ \\
\hline Cálcio (mg/dL) & $8,54(6,00-9,46)$ & $8,13(6,4-8,8)$ & $(8,5-10,2)$ \\
\hline Magnésio (mg/dL) & $2,1(1,5-2,5)$ & $1,82(1,5-2,5)$ & $(1,7-2,6)$ \\
\hline PCR (mg/dL) & $5,26(5,00-15,00)$ & $5,25(5-10,00)$ & (até 10) \\
\hline Bicarbonato (mEq/L) & $20,65(14,00-22,00)$ & $22,39(17,00-27,00)$ & $(22-26)$ \\
\hline VARIÁVEIS & \multicolumn{2}{|c|}{$\begin{array}{c}\text { Grupo } 2 * \text { Pré HD Grupo } 2 * * \text { Pós HD } \\
\text { média (min-máx.) n (\%) }\end{array}$} & $\mathbf{V R}$ \\
\hline Creatinina $(\mathrm{mg} / \mathrm{dL})$ & $6,42(2,4-11,9)$ & $4,19(1,4-7,9)$ & $(0,6-1,2)$ \\
\hline Ureia (mg/dL) & $194,17(64-344)$ & $96,8(34-202)$ & $(16-40)$ \\
\hline $\mathrm{Na}(\mathrm{mmol} / \mathrm{L})$ & $138,71(127-151)$ & $138,08(130-142)$ & $(135-145)$ \\
\hline $\mathrm{K}(\mathrm{mmol} / \mathrm{L})$ & $5,07(3,5-7,0)$ & $4,48(3,5-5,5)$ & $(3,5-5,5)$ \\
\hline Cálcio (mg/dL) & $8,68(6,9-11,4)$ & $8,41(7,00-9,5)$ & $(8,5-10,2)$ \\
\hline Magnésio (mg/dL) & $2,29(1,4-2,9)$ & $1,96(1,4-2,5)$ & $(1,7-2,6)$ \\
\hline PCR (mg/dL) & $8,23(1,9-17,3)$ & $7,54(4,03-15)$ & (até 10) \\
\hline Bicarbonato (mEq/L) & $19,18(12,5-25)$ & $19,42(10-22)$ & $(22-26)$ \\
\hline
\end{tabular}

Valores expressos em números absolutos decimais médios e valores mínimos e máximos, $\mathrm{n}=$ número de amostras e VR, valores de referência, * período pré hemodiálise, ** período pós hemodiálise, grupo 1; até 6 meses do início da hemodiálise; grupo 2; de 7 a 12 meses pós início de hemodiálise; Bicarbonato: -bicarbonato de sódio; PCR: proteína $\mathrm{C}$ reativa 
A tabela a seguir refere-se aos dados laboratoriais categorizados dicotomicamente normal e alterados de acordo com valores de referência nos momentos pré e pós-diálise entre os grupos.

Tabela 7 - Exames Laboratoriais Plasmáticos Categorizados Dicotomicamente

\begin{tabular}{|c|c|c|c|c|c|c|}
\hline \multirow{3}{*}{ VARIÁVEIS } & \multicolumn{2}{|c|}{ Pré HD } & \multicolumn{4}{|c|}{ Pós HD } \\
\hline & Grupo 1 & Grupo 2 & $\mathbf{p}$ & Grupo 1 & Grupo 2 & $\mathbf{p}$ \\
\hline & \multicolumn{2}{|c|}{ n $(\%)$} & \multicolumn{4}{|c|}{ n (\%) } \\
\hline \multicolumn{7}{|l|}{$\mathrm{Na}(\mathrm{mmol} / \mathrm{L})$} \\
\hline Normal & $35(92,1)$ & $29(82,9)$ & \multirow{2}{*}{0,23} & $38(100)$ & $32(91,43)$ & \multirow{2}{*}{0,13} \\
\hline Alterado & $3(7,9)$ & $6(17,10)$ & & $0(-)$ & $3(8,57)$ & \\
\hline \multicolumn{7}{|l|}{ K (mmol/L) } \\
\hline Normal & $24(63,16)$ & $29(82,95)$ & \multirow{2}{*}{0,059} & $36(94,7)$ & $35(100)$ & \multirow{2}{*}{0,17} \\
\hline Alterado & $14(36,84)$ & $6(17,1)$ & & $2(5,3)$ & $0(-)$ & \\
\hline \multicolumn{7}{|l|}{ Cálcio (mg/dL) } \\
\hline Normal & $29(76,32)$ & $22(62,9)$ & \multirow{2}{*}{0,212} & $13(34,2)$ & $23(65,71)$ & \multirow{2}{*}{0,007} \\
\hline Alterado & $9(23,68)$ & $13(37,1)$ & & $25(65,8)$ & $12(34,29)$ & \\
\hline \multicolumn{7}{|l|}{$\operatorname{PCR}(\mathrm{mg} / \mathrm{dL})$} \\
\hline Normal & $37(97,37)$ & $32(91,43)$ & \multirow{2}{*}{0,265} & $38(100)$ & $32(91,43)$ & \multirow{2}{*}{0,065} \\
\hline Alterado & $1(2,63)$ & $3(8,57)$ & & $0(-)$ & $3(8,57)$ & \\
\hline \multicolumn{7}{|c|}{ Bicarbonato $(\mathrm{mEq} / \mathrm{L})$} \\
\hline Normal & $14(36,84)$ & $4(11,43)$ & \multirow{2}{*}{0,012} & $24(63,2)$ & $5(14,29)$ & \multirow{2}{*}{$<0,001$} \\
\hline Alterado & $24(63,16)$ & $31(88,57)$ & & $14(36,8)$ & $30(85,71)$ & \\
\hline \multicolumn{7}{|c|}{ Magnésio (mg/dL) } \\
\hline Normal & $32(84,2)$ & $27(71,1)$ & \multirow{2}{*}{0,44} & $27(71,1)$ & $33(94,3)$ & \multirow{2}{*}{0,01} \\
\hline Alterado & $6(15,8)$ & $8(22,9)$ & & $11(28,9)$ & $2(5,7)$ & \\
\hline
\end{tabular}

Valores expressos em números de pacientes e porcentagem, onde $\mathrm{n}=$ número de amostras, a significância utilizada foi de $5 \%(\mathrm{p} 0,05)$, e o teste estatístico, Qui quadrado; Pré HD: pré hemodiálise; Pós HD: pós hemodiálise; grupo 1: até 6 meses do início da hemodiálise; grupo 2: de 7 a 12 meses pós início de hemodiálise; Na: sódio; K: potássio; Bicarbonato: bicarbonato de sódio; PCR: Proteína $\mathrm{C}$ reativa.

Observou-se, como esperado, que os pacientes de ambos os grupos apresentaram alterações dos exames pré-diálise e baixa função renal. Em geral, as alterações pré e pós-diálise foram mais expressivas no grupo 1. Os valores de cálcio, bicarbonato de sódio, magnésio e potássio, foram os mais alterados. Como esperado, os valores pós-diálise apresentaram-se em geral menos alterados, sugerindo 
eficiência do método dialítico e maior estabilidade metabólica nos pacientes do grupo 2 pós maior tempo de hemodiálise.

A seguir serão apresentadas as análises de pesquisa de preditores das variáveis dependentes pela Regressão Logística. As análises de regressão foram realizadas sem separação entre os grupos e executadas sequencialmente da seguinte forma: escolha da variável dependente, teste das covariáveis perante a variável dependente pelo teste Qui-quadrado, teste das variáveis significativas no teste Quiquadrado pela Regressão Logística Binária univariada e a seguir Regressão logística binária múltipla para ajuste dos fatores significativos conforme descrito em métodos. Algumas covariáveis não foram incluídas nas análises de regressão por sua baixa incidência (menos que 7 eventos por total de 73 análises por covariável). As covariáveis não incluídas foram: do ECG repouso (ritmo, $\mathrm{P}$ morfologia, $\mathrm{P}$ característica, $\mathrm{P}$ amplitude, $\mathrm{P}$ duração, $\mathrm{P}$ polaridade, QRS aberrantes), do Ecocardiograma (FE, Válvulas semilunares, contratilidade), do Holter (ritmo, P polaridade, PR intervalo, $\mathrm{P}$ duração, $\mathrm{P}$ dispersão, $\mathrm{P}$ onda terminal, ESSV, TVNS, TSVNS, TSVS).

As variáveis dependentes escolhidas de acordo com os objetivos deste projeto, critério clínico e incidência, foram, a saber,

- Alterações elétricas (Holter): gatilhos eletrofisiológicos, gatilhos ESV.

- Alterações estruturais (ecocardiograma): AE, volume diastólico, volume sistólico, diâmetro diastólico, diâmetro sistólico, septo interventricular, válvula atrioventricular e, pela importância clínica, átrio direito.

As análises, que seguem, testam as associações das covariáveis frente ao desfecho gatilhos Eletrofisiológicos.

A Tabela 8 , mostra os resultados significativos $(\mathrm{p} \leq 0,05)$ das análises pelo teste Qui-quadrado das covariáveis perante a variável Gatilhos Eletrofisiológicos. Os gatilhos ESV e TVS não foram testados por serem dependentes de gatilhos eletrofisiológicos. Os valores são expressos em significância. 
Tabela 8 - Relação Covariáveis e o Desfecho Gatilhos Eletrofisiológicos

\begin{tabular}{lc}
\hline VARIÁVEIS & $\mathbf{n} \mathbf{( 7 3 )}$ \\
\hline Dados Sociodemográfico & 0,027 \\
Tempo de diálise & 0,001 \\
Idade ( $\geq 60$ anos) & 0,023 \\
$\quad$ Total de Preditores Cardiovasculares & 0,017 \\
$\quad$ Total medicações Cardiovasculares & \\
Dados Exames Laboratoriais Pré e Pós Diálise & 0,014 \\
$\quad$ Cálcio pós & 0,06 \\
$\quad$ Magnésio pós & \\
Dados ECG repouso & 0,01 \\
$\quad$ Tipo Arritmia & \\
Dados Ecocardiográficos & 0,016 \\
$\quad$ Átrio Esquerdo & 0,06 \\
$\quad$ Átrio Direito & \\
Septo Interatrial & 0,023 \\
Volume Sistólico & 0,000 \\
Volume Diastólico & 0,001 \\
Diâmetro Sistólico & 0,007 \\
Diâmetro Diastólico & 0,031 \\
Válvula Atrioventricular & 0,003 \\
Dados Holter & \\
\hline Intervalo QT & 0,000 \\
\hline
\end{tabular}

Covariáveis estratificadas dicotômicas: Tempo de diálise: maior ou menor que 6 meses de início de Hemodiálise; idade: maior ou menor que 60 anos; exames de laboratório e imagem: normal e alterados. Ca pós= cálcio plasmático pós hemodiálise; $\mathrm{Mg}$ pós: magnésio plasmático pós hemodiálise; intervalo $\mathrm{QT}=$ duração do segmento QT no ECG (eletrocardiograma) obtido no Holter; teste Qui quadrado; significância 5\%.

A Tabela 8 mostra que, dos dados sociodemográficos obtidos, apenas tempo de hemodiálise, idade, comorbidades $\mathrm{CV}$ e medicações cardiovasculares apresentaram associação com o desfecho gatilhos eletrofisiológicos. Os fatores mais significantes foram idade e total medicação cardiovascular. Dos exames laboratoriais plasmáticos pré e pós-hemodiálise apenas Cálcio e Magnésio pós-hemodiálise apresentaram a associação com gatilhos eletrofisiológicos. No quesito ECG em repouso, apenas o tipo de arritmia apresentou associação com o desfecho gatilhos eletrofisiológicos. Em relação às alterações estruturais e função obtidos no Ecocardiograma, todos os parâmetros apresentaram associação com gatilhos eletrofisiológicos, sendo os de maior significância os volumes e diâmetros 
ventriculares. Em relação aos dados obtidos no Holter, apenas Intervalo QT apresentou a associação com gatilhos eletrofisiológicos.

A seguir, as covariáveis significativas nos testes Qui-quadrado avaliando a sua associação com o desfecho gatilhos eletrofisiológicos foram testadas pela Regressão Logística Binária Univariada. A variável dependente foi gatilhos eletrofisiológicos. Esses resultados são apresentados na Tabela 9.

Tabela 9 - Regressão Logística Binária Univariada. Variável Dependente Gatilhos Fisiológicos

\begin{tabular}{lcc}
\hline VARIÁVEIS & $\boldsymbol{\beta} \mathbf{( 9 5 \% \text { IC) }}$ & $\mathbf{p}$ \\
\hline Dados Sociodemográfico & & \\
$\quad$ Tempo de diálise & $2,885(1,113-7,474)$ & 0,029 \\
$\quad$ Idade & $5,38(1,95-14,88)$ & 0,001 \\
$\quad$ Total de Preditores Cardiovasculares $(\geq 2)$ & $3,709(1,148-11,987)$ & 0,029 \\
$\quad$ Total medicações Cardiovasculares & $3,33(1,22-9,09)$ & 0,019 \\
Dados Exames Laboratoriais & & \\
$\quad$ Ca pós & $0,305(0,117-0,798)$ & 0,016 \\
$\quad$ Mg pós & $0,281(0,07-1,12)$ & 0,07 \\
Dados ECG repouso & $242 .(00--)$ & \\
$\quad$ Tipo Arritmia & & 0,99 \\
Dados Ecocardiográficos & $5,0(1,246-20,069)$ & \\
$\quad$ Átrio Esquerdo & $6,55(0,725-59,174)$ & 0,023 \\
$\quad$ Átrio Direito & $5,69(1,117-29,013)$ & 0,094 \\
$\quad$ Septo Interatrial & $12,95(2,67-67,76)$ & 0,036 \\
$\quad$ Volume Sistólico & $8,4(2,153-32,77)$ & 0,001 \\
$\quad$ Volume Diastólico & $11,692(1,379-99166)$ & 0,002 \\
$\quad$ Diâmetro Sistólico & $4,32(1,062-17,56)$ & 0,024 \\
$\quad$ Diâmetro Diastólico & $23333 \ldots . .(0,00--)$ & 0,041 \\
$\quad$ Válvula Átrio- Ventricular & & 0,99 \\
Dados Holter & $74,45(9,618-656,4)$ & $<0,001$ \\
$\quad$ Intervalo QT & & \\
\hline
\end{tabular}

ECG: eletrocardiograma. Covariáveis estratificadas dicotomicamente: Tempo de diálise: maior ou menor que 6 meses de início de Hemodiálise; idade: maior ou menor que 60 anos; total preditores cardiovasculares= número de fatores de risco para doenças cardiovasculares maior ou menor de 2 fatores; exames de laboratório e imagem: normal e alterados. Ca pós= cálcio plasmático pós hemodiálise; $\mathrm{Mg}$ pós: magnésio plasmático pós hemodiálise. $\beta$ = razão de chances; 95\%IC: 95\% intervalo de confiança; $\mathrm{p}=$ =significância.

A Tabela 9 mostra que os fatores sociodemográficos preditores de gatilhos eletrofisiológicos mais importantes são idade, seguido de total preditores $\mathrm{CV}$ e 
medicações cardiovasculares. Tempo de hemodiálise também é fator de risco quase 3x maior para gatilhos eletrofisiológicos. ECG de repouso não apresenta dados preditores de gatilhos eletrofisiológicos. A maioria das alterações estruturais encontradas no ecocardiograma são preditores de gatilhos eletrofisiológicos. $O$ preditor de maior risco, atingindo o valor de quase $13 x$, é alteração do volume sistólico, seguido de alterações do diâmetro sistólico e volume diastólico. O intervalo QT é forte preditor de gatilhos eletrofisiológicos. O exame Cálcio sérico póshemodiálise é preditor protetor de gatilhos eletrofisiológicos.

Todos os dados das covariáveis sociodemográficas, ECG, Ecocardiograma, Holter e exames de laboratório pré e pós-hemodiálise que atingiram significância igual ou maior que 0,20 foram testados pela Regressão Logística Binária Múltipla para ajuste de fatores em relação ao desfecho gatilhos eletrofisiológicos. Os resultados dessa análise são mostrados na Tabela 10 .

Tabela 10 - Regressão Logística Binária Múltipla. Variável Dependente Gatilhos Fisiológicos

\begin{tabular}{lcc}
\hline $\begin{array}{l}\text { Regressão Multivariadas. } \\
\text { Dependente Gatilhos Eletrofisiológicos }\end{array}$ & $\boldsymbol{\beta}(\mathbf{9 5 \%}$ IC) & $\mathbf{p}$ \\
\hline Idade & $6,026(1,286-28,236)$ & 0,023 \\
Volume Diastólico & $9,849(1,609-60,275)$ & 0,013 \\
Intervalo QT Holter & $109,928(10,808-1118,078)$ & $<0,001$ \\
\hline
\end{tabular}

Covariáveis estratificadas dicotômicas: idade: maior ou menor que 60 anos; exames de imagem: normal e alterados. B - razão de chances; 95\%IC: 95\% intervalo de confiança; $p=$ significância.

Conclui-se que, após os ajustes das covariáveis, os 3 preditores de maior risco são intervalo QT pelo Holter seguido de volume diastólico e idade. Por serem todos os pacientes de alto risco cardiovascular, acreditamos que a idade talvez possa expressar não só o envelhecimento, mas também a evolução das doenças degenerativas cardiovasculares que, ao serem ajustadas para idade, mantém 95\% IC não significativo. 
Após testarmos a variável dependente gatilhos eletrofisiológicos, optamos por testar como variável dependente ESV (Extrassístole ventricular). Apresentamos, a seguir, as covariáveis testadas significativas pelo Qui-quadrado, frente a essa dependente. Posteriormente, apresentaremos a regressão logística binária univariada e múltipla frente a essas variáveis (Tabelas, 11, 12 e 13).

Tabela 11 - Associação Variável Dependente ESV e Covariáveis

\begin{tabular}{|c|c|c|}
\hline VARIÁVEIS & $n=73$ & $\mathbf{p}$ \\
\hline \multicolumn{3}{|l|}{ Dados Sociodemográficos } \\
\hline Tempo de diálise & & 0,025 \\
\hline Idade & & 0,009 \\
\hline Total medicações Cardiovasculares & & 0,001 \\
\hline \multicolumn{3}{|l|}{ Dados Ecocardiográficos } \\
\hline Átrio Esquerdo & & 0,002 \\
\hline Septo Interatrial & & 0,007 \\
\hline Volume Sistólico & & 0,001 \\
\hline Volume Diastólico & & 0,04 \\
\hline Diâmetro Sistólico & & 0,002 \\
\hline Diâmetro Diastólico & & 0,04 \\
\hline Válvula Atrioventricular & & 0,02 \\
\hline \multicolumn{3}{|l|}{ Dados Holter } \\
\hline Intervalo QT & & $<0,001$ \\
\hline
\end{tabular}

ESV: extrassístoles ventriculares; variáveis estratificadas dicotômicas: ESV: normal e alteradas. Tempo de diálise: maior ou menor que 6 meses de início de Hemodiálise; idade: maior ou menor que 60 anos; Total medicações cardiovasculares: maior ou menor que 2; exames de imagem: normal e alterados, dados ecocardiográficos e Holter estratificados como normais e alterados. Teste Qui quadrado; significância 5\%. 
Dos dados sociodemográficos e Holter, apenas idade, tempo de diálise, total de medicações cardiovasculares e intervalo QT apresentaram associação com ESV. Por outro lado, muitos parâmetros ecocardiográficos apresentam relação com a variável dependente ES.

Tabela 12 - Regressão Logística Binária Univariada. Variável Dependente ESV

\begin{tabular}{lcc}
\hline VARIÁVEIS & $\boldsymbol{\beta}(\mathbf{9 5 \%} \mathbf{~ I C )}$ & $\mathbf{p}$ \\
\hline Dados Sociodemográficos & $3,158(1,133-8,801)$ & 0,028 \\
$\quad$ Tempo de diálise & $3,778(1,355-10,536)$ & 0,011 \\
Idade & $5,758(1,986-16,694)$ & 0,001 \\
Total medicações Cardiovasculares & & \\
Dados Ecocardiográficos & $6,75(1,813-25,137)$ & 0,004 \\
$\quad$ Átrio Esquerdo & $6,314(1,463-27,253)$ & 0,014 \\
Septo Interatrial & $7,446(2,188-25,345)$ & 0,001 \\
Volume Sistólico & $3,075(1,002-9,435)$ & 0,05 \\
Volume Diastólico & $9,676(1,828-51,223)$ & 0,008 \\
Diâmetro Sistólico & $3,624(1,011-12,992)$ & 0,048 \\
Diâmetro Diastólico & $6,184(1,103-34,682)$ & 0,038 \\
Válvula Atrioventricular & & $<0,001$ \\
Dados Holter & $7,407(2,470-22,211)$ & \\
Intervalo QT & &
\end{tabular}

Variáveis estratificadas dicotomicamente: $\mathrm{ESV}=$ extrassístoles ventriculares estratificada como normal e alteradas. Tempo de diálise: maior ou menor que 6 meses de início de Hemodiálise; idade: maior ou menor que 60 anos; Total medicações cardiovasculares= número de medicações para doenças cardiovasculares maior ou menor de 2 fatores; exames de imagem: normal e alterados. $\beta$ = razão de chances; $95 \%$ IC: $95 \%$ intervalo de confiança; $p$ =significância. 
A regressão logística univariada evidencia que os maiores preditores sem ajuste de covariáveis para ESV são as alterações estruturais atingindo de fator de risco maior que 6,5 até 9,6 vezes. O dado de alterações elétricas relacionado foi intervalo QT com risco 7,4 vezes.

Tabela 13 - Regressão Logística Binária Múltipla. Variável Dependente ESV

\begin{tabular}{lcc}
\hline Dependente ESV & $\boldsymbol{\beta}(\mathbf{9 5 \%} \mathbf{I C})$ & $\mathbf{p}$ \\
\hline$*$,totalmedicaçõesCV & $5,117(1,425-18,370)$ & 0,012 \\
$* *$, Volume Sistólico & $6,838(1,642-28,471)$ & 0,008 \\
$* * *$, HolterIntervaloQT & $8,620(2,335-31,817)$ & 0,001 \\
\hline
\end{tabular}

Covariáveis estratificadas dicotômicas: teste Qui quadrado; significância 5\% total medicações cardiovasculares*, volume sistólico**, holter intervalo QT***, IC: intervalo de confiança

Concluiu-se que os fatores preditores da dependente ESV são polifarmácia $\mathrm{CV}$ (fator de risco 5x) que reflete o grau de severidade de comorbidades $\mathrm{CV}$, visto que todos os pacientes são de alto risco $\mathrm{CV}$, intervalo QT (fator de risco maior que $8 x$ ) e volume sistólico (fator de risco quase $7 x$ ), sendo o preditor mais importante 0 intervalo QT. 
Por ser a alteração do intervalo QT um dos maiores preditores de gatilhos eletrofisiológicos, optamos por checar quais eram os fatores de risco dessa alteração elétrica. Submetemos o dado obtido no Holter Intervalo QT às análises de QuiQuadrado, Regressão Logística Binária Univariada frente às covariáveis (Tabelas 14 e 15 respectivamente).

Tabela 14 - Associação de Intervalo QT Obtido pelo Holter e Covariáveis

\begin{tabular}{ll}
\hline VARIÁVEIS & $\mathbf{n = 7 3}$ \\
\hline Dados Sociodemográficos & $\mathbf{p}$ \\
\hline Idade & 0,03 \\
Sexo & 0,03 \\
Exames de Laboratório & \\
K pré & 0,04 \\
Cálcio pré & 0,02 \\
PCR pré & 0,02 \\
Cálcio pós & 0,03 \\
Ecocardiograma & \\
Volume Diastólico & 0,04 \\
Diâmetro Sistólico & 0,02 \\
\hline
\end{tabular}

Covariáveis estratificadas dicotomicamente: idade: maior ou menor que 60 anos; sexo: masculino e feminino; exames de laboratório e imagem: normal e alterados. K pré= potássio plasmático pré hemodiálise; Cálcio pré: cálcio plasmático pré hemodiálise; $\mathrm{PCR}$ pré: proteína $\mathrm{C}$ reativa plasmática pré hemodiálise; Cálcio pós= cálcio plasmático pós hemodiálise; teste Qui quadrado; significância 5\%. 
Relacionam-se com a variável dependente, com significância menor igual a 5\%, apenas idade, sexo, poucos exames eletrolíticos e, com as alterações estruturais, apenas volume diastólico e diâmetro sistólico, as quais foram submetidas à regressão univariada (Tabela 15).

Tabela 15 - Regressão Logística Binária Univariada. Variável Dependente Intervalo QT

\begin{tabular}{lcc}
\hline VARIÁVEIS & $\boldsymbol{\beta} \mathbf{( 9 5 \%}$ IC) & $\mathbf{p}$ \\
\hline Dados Sociodemográficos & & \\
$\quad$ Idade & $2,887(1,054-7,908)$ & 0,039 \\
$\quad$ Sexo & $0,29(0,086-0,978)$ & 0,046 \\
Exames de Laboratório & & \\
$\quad$ K pré & $0,269(0,07-1,032)$ & 0,056 \\
$\quad$ Cálcio pré & $0,226(0,059-0,861)$ & 0,029 \\
$\quad$ PCR pré & $0,226(0,059-0,861)$ & 0,029 \\
$\quad$ Cálcio pós & $0,345(0,124-0,958)$ & 0,041 \\
Ecocardiograma & & \\
$\quad$ Volume Diastólico & $3,075(1,002-9,435)$ & 0,05 \\
$\quad$ Diâmetro Sistólico & $5,111(1,153-22,66)$ & 0,032 \\
\hline
\end{tabular}

Covariáveis estratificadas dicotômicas: idade Maior e menor que 60 anos; sexo: masculino e feminino; exame de laboratório: exames plasmáticos normais e alterados; K pré: potássio sérico pré hemodiálise; Cálcio pré: cálcio sérico pré hemodiálise; PCR pré: proteína $\mathrm{C}$ reativa pré hemodiálise; Cálcio pós: cálcio sérico pós hemodiálise; ecocardiograma estratificado em normal e alterado. $\beta=$ razão de chances; 95\%IC: intervalo de confiança; $p=$ significância.

Observamos que são preditores de alteração do intervalo QT, avaliados pelo Holter, várias covariáveis sendo fatores protetores sexo masculino, cálcio préhemodiálise, PCR pré-hemodiálise. São fatores de risco positivos idade, volume diastólico e diâmetro sistólico, sendo esse último o maior fator de risco (mais de 5x). 
A Tabela 16 apresenta a análise Regressão Logística Binária Múltipla tendo como dependente diminuição do intervalo QT e covariáveis que apresentaram significância igual ou menos que 0,20 na análise do Qui-quadrado. Porém, nessa análise, nenhum dos fatores analisados apresentaram 95\% intervalo de confiança significativo.

Tabela 16 - Regressão Logística Binária Multivariada. Dependente: Diminuição do Intervalo QT

\begin{tabular}{lcc}
\hline \multicolumn{1}{c}{ Dependente intervalo QT } & $\boldsymbol{\beta}$ (95\%IC) & p \\
\hline Idade & $2,157(0,730-6,377)$ & 0,165 \\
Diâmetro Sistólico & $3,483(0,716-16,936)$ & 0,122 \\
\hline
\end{tabular}

Covariáveis estratificadas dicotômicas: idade: maior ou menor que 60 anos; Diâmetro sistólico: normal e alterados. $\beta=$ razão de chances; $95 \% \mathrm{IC}$ : $95 \%$ intervalo de confiança; $\mathrm{p}=$ significância.

Conclui-se que as preditoras, nas análises de regressão univariada, se equivalem quando é realizada a regressão múltipla para ajuste dos fatores.

Passamos agora a apresentar as análises de Regressão Logística tendo como variável dependente as alterações estruturais. As alterações estruturais escolhidas como dependentes e avaliadas separadamente foram as mais incidentes: AE (13/73), volume sistólico (16/73), volume diastólico (17/73), diâmetro diastólico (12/73), septo interatrial (10/73) e diâmetro sistólico (9/73), VAV (7/73) e AD (6/73). 
Seguem as análises estratificando como variável dependente átrio esquerdo.

A Tabela 17 apresenta as análises de associação pelo QUI ${ }^{2}$ da dependente átrio esquerdo frente às covariáveis.

Tabela 17 - Associação de Covariáveis e Átrio Esquerdo

\begin{tabular}{|c|c|c|}
\hline VARIÁVEIS & $n=73$ & $\mathbf{p}$ \\
\hline \multicolumn{3}{|l|}{ Dados Sociodemográficos } \\
\hline Tempo de Hemodiálise & & $<0,001$ \\
\hline Idade & & $<0,001$ \\
\hline Natural Região & & 0,04 \\
\hline Antecedentes & & 0,02 \\
\hline Total preditores cardiovasculares & & 0,004 \\
\hline Total medicações Cardiovasculares & & 0,03 \\
\hline \multicolumn{3}{|l|}{ Exames de Laboratório } \\
\hline Bicarbonato pós & & 0,01 \\
\hline ECG Repouso & & 0,00 \\
\hline Tipo Arritmia & & \\
\hline
\end{tabular}

Covariáveis estratificadas dicotômicas: Tempo de diálise: maior ou menor que 6 meses de início de Hemodiálise; idade: maior ou menor que 60 anos; exames de laboratório e imagem: normal e alterados. Bicarbonato pós = bicarbonato de sódio plasmático pós hemodiálise; ECG= eletrocardiograma; teste Qui quadrado; significância 
A Tabela 18 apresenta as análises de regressão logística binária univariada das covariáveis significativas no teste Qui-quadrado frente à variável dependente átrio esquerdo.

Tabela 18 - Regressão Logística Binária Univariada. Dependente: Átrio Esquerdo

\begin{tabular}{lcc}
\hline VARIÁVEIS & $\boldsymbol{\beta}(\mathbf{9 5 \%} \mathbf{I C})$ & $\mathbf{p}$ \\
\hline Dados Sociodemográficos & & 0,99 \\
Tempo de Hemodiálise & $954598791,169(0,00-)$ & 0,002 \\
Idade & $11,868(2,392-58,892)$ & 0,99 \\
Natural & & 0,036 \\
Região \#\# & $0,00(0,00$ & 0,007 \\
Antecedentes & $5,5(1,122-26,953)$ & 0,038 \\
Total preditores cv* & $5,833(1,615-21,075)$ & \\
Total medicações cv* & $3,733(1,074-12,983)$ & 0,064 \\
Exames de Laboratório & & \\
Bicarbonato pós & $4,5(, 918-22,071)$ & 0,003 \\
ECG Repouso & & $11,875(2,371-59,487)$ \\
$\quad$ Tipo Arritmia & & \\
\hline
\end{tabular}

Covariáveis estratificadas dicotomicamente, teste Qui quadrado; $\beta=$ razão de chances; $p=$ significância $*_{\mathrm{cv}}=$ cardiovasculares, \#natural (região geográfica-sudeste), \#\# região (metropolitana); exames de laboratório: exames plasmáticos estratificados em normal e alterado; bicarbonato pós: bicarbonato de sódio plasmático pós hemodiálise; tipo arritmia: arritmia detectada pós hemodiálise; ECG: eletrocardiograma 
Observamos que os fatores sociodemográficos idade, antecedentes, preditores cardiovasculares e total de medicações cardiovasculares são fatores de risco para alteração de $\mathrm{AE}$ como esperado. No quesito exames de laboratório, nenhum se mostrou preditor da dependente. No quesito ECG de repouso e Holter, as arritmias mostraram-se preditoras até quase $12 \mathrm{x}$ o risco para alteração de átrio esquerdo.

A Tabela 19 expressa os valores obtidos na Regressão Múltipla Binária Logística ajustando as covariáveis significativas $(\mathrm{p}>0,2)$ na regressão univariada perante a dependente alteração de átrio esquerdo.

Tabela 19 - Regressão Multivariada Logística Binária. Dependente Alteração de Átrio Esquerdo

\begin{tabular}{lcc}
\hline Dependente AE & $\boldsymbol{\beta}(\mathbf{9 5 \% \mathbf { I C } )}$ & $\mathbf{p}$ \\
\hline idade & $8,292(1,576-43,636)$ & 0,013 \\
Tipo arritmia & $5,873(1,041-33,129)$ & 0,045 \\
\hline
\end{tabular}

Covariáveis estratificadas dicotomicamente, teste Qui quadrado; $\beta=$ razão de chances; $p=$ significância $5 \%=$ índice de confiança; idade estratificada em maior ou menor que 60 anos; Tipo Arritmia: arritmia detectada no ECG repouso

Conclui-se que, após ajuste dos fatores, são fatores de risco de aumento de átrio esquerdo idade ( $>8 \mathrm{x}$ ) e tipos de arritmia (quase $6 \mathrm{x}$ ).

Passamos a apresentar as análises tendo como dependente volume diastólico.

Volume diastólico foi a variável estrutural mais presente em ambos os grupos (grupo 1=1; grupo 2=16). Também foi variável preditora (fator de risco) importante de gatilhos eletrofisiológicos. Portanto consideramos válido testar quais os preditores dessa alteração estrutural frente às covariáveis sociodemográficas, ECG repouso e exames de laboratório. 
A Tabela 20 expressa valores da associação testada pelo teste Qui-quadrado das covariáveis frente à dependente volume diastólico. As covariáveis dos dados obtidos por ecocardiogramas não foram testadas por serem dependentes entre si.

Tabela 20 - Associação Volume Diastólico e Covariáveis

\begin{tabular}{lc}
\hline VARIÁVEIS & $\mathbf{n = 7 3}$ \\
\hline Dados Sociodemográficos & $\mathbf{p}$ \\
$\quad$ Tempo de Hemodiálise & 0,00 \\
Idade & 0,02 \\
$\quad$ Total medicações Cardiovasculares & 0,008 \\
Laboratório & \\
$\quad$ Cálcio pós & 0,04 \\
$\quad$ Bicarbonato pós & 0,03 \\
\hline
\end{tabular}

Covariáveis estratificadas dicotômicas: Tempo de diálise: maior ou menor que 6 meses de início de Hemodiálise; idade: maior ou menor que 60 anos; exames de laboratório: normal e alterados. Ca pós = cálcio plasmático pós hemodiálise; Bicarbonato pós: bicarbonato de sódio plasmático pós hemodiálise. teste Qui quadrado; significância $5 \%$. 
As análises de regressão univariada foram aplicadas tendo como variável dependente a alteração estrutural volume diastólico e ajustes às variáveis significativas $(\mathrm{p} \leq 0,05)$ testadas pelo teste qui-quadrado nas Tabelas 20 e 21 .

Tabela 21 - Regressão Univariada Multivariada Binária Logística. Dependente Volume Diastólico

\begin{tabular}{lcc}
\hline VARIÁVEIS & $\begin{array}{c}\boldsymbol{\beta} \mathbf{( 9 5 \% \mathbf { I C } )} \\
\mathbf{n = 7 3}\end{array}$ & $\mathbf{p}$ \\
\hline Dados sociodemográficos & & \\
$\quad$ Tempo de Hemodiálise & $31,158(3,836-253,083)$ & 0,001 \\
$\quad$ Idade & $3,570(1,144-11,143)$ & 0,028 \\
$\quad$ Total preditores Cardiovasculares & $4,642(1,413-15,255)$ & 0,011 \\
Laboratório & & \\
$\quad$ Cálcio pós & $0,313(0,097-1,007)$ & 0,051 \\
$\quad$ Bicarbonato pós & $4,044(1,045-15,648)$ & 0,043 \\
\hline
\end{tabular}

Covariáveis estratificadas dicotomicamente, teste Qui quadrado; $\beta=$ razão de chances; $p=$ significância $5 \%$, IC = intervalo de confiança; idade estratificada entre maior ou menor que 60 anos; laboratório: exames plasmáticos estratificados em normal e alterado; ${ }^{*} \mathrm{CV}=$ cardiovasculares; Cálcio pós: cálcio plasmático pós hemodiálise; Bicarbonato pós $=$ bicarbonato de sódio plasmático pós hemodiálise.

O preditor mais importante de volume diastólico é tempo de hemodiálise (fator de risco 31x). Os outros fatores de risco oscilam entre 3 e 4x compondo-se de idade, total de preditores $\mathrm{CV}$ e bicarbonato pós hemodiálise. 
A Tabela 22 apresenta os valores da Regressão Logística Multivariada Binária tendo como dependente volume diastólico e covariáveis com significância maior que 0,2 na regressão univariada.

Tabela 22 - Regressão Multivariada Logística Binária. Dependente Volume Diastólico

\begin{tabular}{llc}
\hline VARIÁVEIS & $\mathbf{9 5 \%}$ IC & $\mathbf{p}$ \\
\hline Dependente Volume Diastólico & & \\
Tempo de Hemodiálise & $(3,836-253,083)$ & 0,001 \\
\hline
\end{tabular}

Covariáveis estratificadas dicotomicamente, teste Qui-quadrado; $\beta \mathrm{p}=$ significância $5 \%$, IC=intervalo de confiança, tempo de hemodiálise: 0 a 6 meses e 7 a 12 meses pós início de hemodiálise

Conclui-se que a única covariável, após o ajuste, que se manteve como preditora fator de risco foi tempo de hemodiálise com risco maior que 31x para alteração do volume diastólico. 
As tabelas seguintes apresentam as análises considerando-se dependente variável Volume sistólico. A Tabela 23 apresenta os dados significativos de associação pelo teste Qui-quadrado entre as covariáveis e a dependente escolhida.

Tabela 23 - Associação Covariáveis e Dependentes Volume Sistólico

\begin{tabular}{lc}
\hline VARIÁVEIS & $\mathbf{p}$ \\
\hline Dados sociodemográficos & 0,00 \\
$\quad$ Tempo de diálise & 0,00 \\
Idade & 0,004 \\
$\quad$ Total preditores Cardiovasculares & \\
Laboratório & 0,001 \\
$\quad$ Cálcio pós & 0,035 \\
$\quad$ Magnésio pós & 0,012 \\
$\quad$ Bicarbonato Pós & \\
ECG Repouso & 0,00 \\
\hline Tipo arritmia & \\
\hline
\end{tabular}

Covariáveis estratificadas dicotômicas: Tempo de diálise: maior ou menor que 6 meses de início de Hemodiálise; idade: maior ou menor que 60 anos; total preditores cardiovasculares: fatores de risco cardiovasculares maior ou menor que 2; exames de laboratório e imagem: normal e alterados. Ca pós= cálcio plasmático pós hemodiálise; Mg pós: magnésio plasmático pós hemodiálise; Bicarbonato pós= bicarbonato de sódio plasmático pós hemodiálise; ECG: eletrocardiograma; Tipo arritmia: arritmia detectada do ECG repouso. Teste Qui-quadrado; significância $5 \%$. 
A Tabela 24 apresenta as análises de Regressão Logística Binária Univariada considerando dependente volume sistólico e as covariáveis significativas $(\mathrm{p} \leq 0,05)$ no teste de associação Qui-quadrado.

Tabela 24 - Regressão Logística Binária Univariada. Dependente Volume Sistólico

\begin{tabular}{lcc}
\hline VARIÁVEIS & $\begin{array}{c}\boldsymbol{\beta}(\mathbf{9 5 \%} \mathbf{I C}) \\
\mathbf{n}=\mathbf{7 3}\end{array}$ & $\mathbf{p}$ \\
\hline Dados sociodemográficos & & 0,997 \\
Tempo de Hemodiálise & $1360399861(0,000)$ & 0,000 \\
Idade & $17,937(3,657-87,983)$ & 0,007 \\
$\quad$ Total preditores cv* & $5,333(1,588-17,908)$ & \\
Laboratório & $0,090(0,019-0,434)$ & 0,003 \\
$\quad$ Cálcio pós HD & $0,000(0,000)$ & 0,999 \\
$\quad$ Magnésio pós HD & $6,3(1,310-30,287)$ & 0,022 \\
$\quad$ Bicarbonato pós HD & & 0,002 \\
ECG Repouso & $16,5(2,907-93,665)$ & \\
$\quad$ Tipo arritmia & &
\end{tabular}

Covariáveis estratificadas dicotômicas; $\beta=$ razão de chances; $\mathrm{p}=$ significância $5 \% * \mathrm{CV}$ cardiovasculares, $\mathrm{IC}=$ índice de confiança; tempo de hemodiálise: 0 a 6 meses e 7 a 12 meses pós início de hemodiálise; idade: maior ou menor que 60 anos, HD: hemodiálise, Tipo arritmia: arritmia detectada no ECG repouso. 
Idade, total preditores $\mathrm{CV}$, bicarbonato pós-hemodiálise e tipos de arritmia são fatores de risco preditores de volume sistólico e foram submetidos à análise com ajuste de fatores por regressão logística multivariada binária (Tabela 25).

Tabela 25 - Regressão Binária Logística Multivariada Dependente Alteração de Volume

\begin{tabular}{lcc}
\hline VARIÁVEIS & $\boldsymbol{\beta}(\mathbf{9 5 \%} \mathbf{I C})$ & $\mathbf{p}$ \\
\hline dependente volume sistólico & & \\
$\quad$ Idade & $17,937(3,657-87,983)$ & 0,000 \\
\hline
\end{tabular}

Covariável estratificada dicotômica; $\beta=$ razão de chances; $\mathrm{p}=$ significância $5 \%$, IC = índice de confiança; idade categorizada como maior ou menor que 60 anos.

A Tabela 25 mostra que, na regressão Multivariada dependente volume sistólico, após ajuste de covariáveis, a única preditora é idade apresentando 17x fator de risco para esta alteração. 
A seguir são apresentadas as tabelas selecionando como variável dependente diâmetro sistólico. A Tabela 26 apresenta os valores significativos dos testes de associação pelo Qui-quadrado entre a dependente e as covariáveis.

Tabela 26 - Associação entre Alteração do Diâmetro Sistólico e as Covariáveis pelo Teste Qui-quadrado

\begin{tabular}{|c|c|c|}
\hline & $n=73$ & $\mathbf{p}$ \\
\hline \multicolumn{3}{|l|}{ Dados sociodemográficos } \\
\hline Tempo de diálise & & 0,001 \\
\hline Idade & & 0,002 \\
\hline Total preditores Cardiovasculares & & 0,014 \\
\hline Total medicações gerais & & 0,04 \\
\hline \multicolumn{3}{|l|}{ Laboratório } \\
\hline Cálcio pós & & 0,001 \\
\hline \multicolumn{3}{|l|}{ ECG repouso } \\
\hline Tipo arritmia & & 0,001 \\
\hline
\end{tabular}

Covariáveis estratificadas dicotômicas: Tempo de diálise: maior ou menor que 6 meses de início de Hemodiálise; idade: maior ou menor que 60 anos; exames de laboratório e imagem: normal e alterados. Ca pós= cálcio plasmático pós hemodiálise; Mg pós: magnésio plasmático pós hemodiálise; Tipo arritmia: arritmia detectada no ECG repouso; N= valores absolutos de dados; teste Qui quadrado; significância 5\%. 
A Tabela 27 apresenta as análises da Regressão Univariada Logística Binária das covariáveis significativas pelo teste de associação da tabela L frente à dependente diâmetro sistólico.

Tabela 27 - Regressão Univariada Logística Binária Dependente Alteração Diâmetro Sistólico

\begin{tabular}{lcc}
\hline VARIÁVEIS & $\boldsymbol{\beta}(\mathbf{9 5 \%} \mathbf{I C})$ & $\mathbf{p}$ \\
\hline Dados sociodemográficos & $\mathbf{N}=\mathbf{7 3}$ & \\
$\quad$ Tempo de Hemodiálise & & 0,998 \\
Idade & $559202827,4(0,000)$ & 0,013 \\
Total preditores Cardiovasculares & $15,273(1,794-130,056)$ & 0,023 \\
$\quad$ Total medicações gerais & $5,417(1,262-23,253)$ & 0,998 \\
Laboratório & $338122624,923(0,000)$ & 0,998 \\
$\quad$ Cálcio pós & $0,000(0,000)$ & \\
ECG Repouso & & 0,003 \\
$\quad$ Tipo arritmia & $12,000(2,283-63,063)$ & \\
\hline
\end{tabular}

Covariáveis estratificadas dicotômica; $\beta=$ razão de chances; $p=$ significância $5 \% * \mathrm{CV}=$ cardiovasculares: tempo de hemodiálise: 0 a 6 meses e 7 a 2 meses do início da hemodiálise, idade: maior e menor que 60 anos; total preditores e medicações estratificadas maior ou menor que 2 fatores; cálcio pós: cálcio sérico pós hemodiálise; Tipo arritmia: arritmia detectada no ECG de repouso.

Foram preditoras de diâmetro sistólico idade (15x risco aumentado), total preditores CV (5x risco aumentado) e tipo arritmia (ESV -12x fator de risco).

Foram selecionadas da Tabela 27 as covariáveis idade, total preditoras $\mathrm{CV}, \mathrm{P}$ amplitude e tipo de arritmias para testar a regressão múltipla frente à variável diâmetro sistólico. 
A Tabela 28, apresenta estes resultados.

Tabela 28 - Regressão Múltipla Binária Logística com Dependente Alteração do Diâmetro Sistólico

\begin{tabular}{lcc}
\hline VARIÁVEIS & $\boldsymbol{\beta}(\mathbf{9 5 \%} \mathbf{I C})$ & $\mathbf{p}$ \\
\hline Dependente Diâmetro Sistólico & & \\
$\quad$ Idade & $10,058(1,101-91,865)$ & 0,041 \\
$\quad$ Tipo arritmia & $5,746(0,982-33,605)$ & 0,052 \\
\hline
\end{tabular}

Covariáveis estratificadas dicotômicas; $\beta=$ razão de chances; $p=$ significância $5 \%$, IC = índice de confiança; idade: maior ou menor que 60 anos; Tipo arritmia: arritmia detectada no ECG de repouso.

Conclui-se que, após ajuste de fatores, a única preditora de risco para alteração de diâmetro sistólico é idade com risco de 10x. A covariável tipo de arritmia pelo ECG de repouso atingiu valores limítrofes de significância para risco da dependente. 
As análises seguintes mostram os valores das covariáveis associadas à dependente de alteração estrutural diâmetro diastólico. A Tabela 29 apresenta os resultados dos testes de qui-quadrado entre as covariáveis e a dependente.

Tabela 29 - Associação entre Covariáveis Significativas e a Dependente Alteração do Diâmetro Diastólico

\begin{tabular}{|c|c|c|}
\hline VARIÁVEIS & $\mathrm{n}=73$ & $\mathbf{p}$ \\
\hline \multicolumn{3}{|c|}{ Dados sociodemográficos } \\
\hline Tempo de diálise & & 0,001 \\
\hline Idade & & 0,049 \\
\hline \multicolumn{3}{|l|}{ Laboratório } \\
\hline Bicarbonato pós & & 0,015 \\
\hline \multicolumn{3}{|l|}{ ECG repouso } \\
\hline Tipo arritmia & & 0,001 \\
\hline
\end{tabular}

Covariáveis estratificadas dicotômicas: Tempo de diálise: maior ou menor que 6 meses de início de Hemodiálise; idade: maior ou menor que 60 anos; exames de laboratório; bicarbonato pós: bicarbonato sérico pós hemodiálise; Tipo arritmia: arritmia detectada pós hemodiálise; $\mathrm{N}=$ valores absolutos de dados; teste Qui quadrado; significância 5\% 
A Tabela 30 apresenta os valores obtidos na regressão univariada entre a dependente alteração do diâmetro diastólico e as covariáveis significativas obtidas no teste Qui-quadrado.

Tabela 30 - Regressão Univariada Dependente Alteração do Diâmetro Diastólico

\begin{tabular}{lcc}
\hline VARIÁVEIS & $\boldsymbol{\beta}(\mathbf{9 5 \%} \mathbf{I C})$ & $\mathbf{p}$ \\
\hline Dados sociodemográficos & $\mathbf{N}=\mathbf{7 3}$ & 0,009 \\
$\quad$ Tempo de diálise & & 0,058 \\
$\quad$ Idade & $16,958(2,055-139,958)$ & \\
Laboratório & $3,545(0,958-13,128)$ & 0,038 \\
$\quad$ Bicarbonato pós & & \\
ECG Repouso & $9,333(1,134-76,841)$ & 0,002 \\
$\quad$ Tipo Arritmia & $13,810(2,700-70,631)$ & \\
\hline
\end{tabular}

Covariáveis estratificadas dicotômica; $\beta=$ razão de chances; $p=$ significância $5 \%$, IC = intervalo de confiança; Bicarbonato pós: bicarbonato sérico pós hemodiálise; Tipo arritmia: arritmia detectada no ECG de repouso; ECG: eletrocardiograma

Todas as covariáveis testadas na regressão univariada (tempo de diálise, idade, bicarbonato pós HD e tipo de arritmia) foram preditoras de diâmetro diastólico, sendo a de maior risco o tempo de hemodiálise (quase 17x maior risco). 
Todas essas preditoras preencheram critérios de preditoras a serem testadas pela regressão Múltipla $(\mathrm{p}<0,2)$ com dependente alteração de diâmetro diastólico. Esses resultados são mostrados na Tabela 31.

Tabela 31 - Regressão Múltipla Logística Binária. Dependente Alteração do Diâmetro Diastólico

\begin{tabular}{lcc}
\hline VARIÁVEIS & $\boldsymbol{\beta}(\mathbf{9 5 \%} \mathbf{I C})$ & $\mathbf{p}$ \\
\hline $\begin{array}{l}\text { Dependente Diâmetro Diastólico } \\
\quad \text { Bicarbonato pós }\end{array}$ & $10,169(1,053-98,206)$ & 0,045 \\
$\quad$ Tipo arritmia & $15,078(2,387-95,241)$ & 0,004 \\
\hline
\end{tabular}

Covariáveis estratificadas dicotômica; $\beta=$ razão de chances; $p=$ significância 5\%; Bicarbonato pós= bicarbonato sérico pós hemodiálise; Tipo arritmia: arritmia encontrada no ECG de repouso; ECG: eletrocardiograma; IC= intervalo de confiança.

Conclui-se que, após ajuste das covariáveis, apenas bicarbonato pós Hemodiálise e Tipo de arritmia no ECG de repouso são preditoras de alteração de diâmetro diastólico. 
A seguir testamos covariável dependente alteração do septo interatrial. A Tabela 32 apresenta os testes de associação pelo qui-quadrado das covariáveis com a dependente escolhida.

Tabela 32 - Associação Covariáveis com Dependente Alteração do Septo Interatrial

\begin{tabular}{|c|c|c|}
\hline VARIÁVEIS & $n=73$ & $\mathbf{p}$ \\
\hline \multicolumn{3}{|l|}{ Dados sociodemográficos } \\
\hline Tempo de diálise & & 0,00 \\
\hline Idade & & '0,007 \\
\hline Total medicações Cardiovasculares & & 0,08 \\
\hline \multicolumn{3}{|l|}{ Laboratório } \\
\hline Cálcio pós & & 0,03 \\
\hline Bicarbonato pós & & 0,04 \\
\hline \multicolumn{3}{|l|}{ ECG Repouso } \\
\hline Tipo Arritmia & & 0,002 \\
\hline
\end{tabular}

Covariáveis estratificadas dicotômicas: Tempo de diálise: maior ou menor que 6 meses de início de Hemodiálise; idade: maior ou menor que 60 anos; exames de laboratório e imagem: normal e alterados. Ca pós $=$ cálcio plasmático pós hemodiálise; Mg pós: magnésio plasmático pós hemodiálise; Bicarbonato pós: bicarbonato de sódio sérico pós hemodiálise; Tipo arritmia: arritmia detectada no ECG repouso; ECG: eletrocardiograma; N= valores absolutos de dados; teste Qui quadrado, significância 5\%. 
A Tabela 33 apresenta os resultados dos dados das análises de regressão univariada logística binária das covariáveis significativas no teste Qui-quadrado frente à variável alteração do septo interatrial.

Tabela 33 - Regressão Univariada entre Covariáveis e Dependente Alterações do Septo Interatrial

\begin{tabular}{lcc}
\hline VARIÁVEIS & $\begin{array}{c}\boldsymbol{\beta}(\mathbf{9 5 \%} \mathbf{I C}) \\
\mathbf{N}=\mathbf{7 3}\end{array}$ & $\mathbf{p}$ \\
\hline Dados sociodemográficos & & \\
$\quad$ Tempo diálise & $646189933,537(0,000)$ & 0,998 \\
$\quad$ Idade & $7,455(1,455-38,191)$ & 0,016 \\
$\quad$ Total medicações CV* & $3,225(0,818-12,715)$ & 0,094 \\
Laboratório & & \\
$\quad$ Cálcio pós HD** & $0,200(0,039-1,018)$ & 0,053 \\
$\quad$ Bicarbonato pós HD*** & $7,200(0,860-60,279)$ & 0,069 \\
ECG repouso & & 0,006 \\
$\quad$ Tipo Arritmia & $9,833(1,945-49,715)$ & \\
\hline
\end{tabular}

Covariáveis estratificadas dicotomicamente, $C V=$ cardiovasculares; $p=$ significância $5 \%(p \leq 0,05), \beta=$ razão de chance, $\mathrm{IC}=$ intervalo de confiança; **álcio sérico pós hemodiálise; *** bicarbonato de sódio sérico pós hemodiálise; ECG: eletrocardiograma; Tipo Arritmia: arritmia detectada no ECG de repouso.

Foram preditoras de SIA a covariável idade (7,5x risco aumentado) e tipo de arritmia (quase 10x risco aumentado) 
Foram selecionadas as covariáveis com significância maior ou igual a 0,2 para regressão múltipla com a dependente septo interatrial. Esses resultados são apresentados na Tabela 34 .

Tabela 34 - Regressão Múltipla Binária Logística. Variável Dependente Septo Interatrial

\begin{tabular}{lcc}
\hline VARIÁVEIS & $\boldsymbol{\beta}(\mathbf{9 5 \%} \mathbf{m})$ & $\mathbf{p}$ \\
\hline Regressão múltipla SIA & & \\
$\quad$ idade & $6,502(1,232-34,326)$ & 0,027 \\
$\quad$ Bicarbonato pós & $5,983(0,683-52,382)$ & 0,106 \\
\hline
\end{tabular}

Covariáveis estratificadas dicotômica; $\beta=$ razão de chances; $p=$ significância $5 \%$; SIA= septo interatrial; IC: intervalo de confiança.

A única preditora de risco de alterações de septo interatrial é idade com fator de risco de 6x para alterações do septo interatrial. 
A seguir são apresentadas as análises de associação pelos testes Qui-quadrado e regressão tendo como variável dependente alterações de átrio direito

A Tabela 35 apresenta as análises de associação das covariáveis e a dependente alterações de átrio direito.

Tabela 35 - Associação Covariáveis e a Dependente Alterações de Átrio Direito

\begin{tabular}{lc}
\hline VARIÁVEIS & $\mathbf{n = 7 3}$ \\
\hline Dados sociodemográficos & $\mathbf{p}$ \\
$\quad \begin{array}{l}\text { Tempo diálise } \\
\text { Idade }\end{array}$ & 0,008 \\
Laboratório & 0,002 \\
$\quad$ Cálcio pós & 0,01 \\
ECG repouso & \\
$\quad$ Tipo Arritmia & 0,001 \\
\hline
\end{tabular}

Covariáveis estratificadas dicotômicas: Tempo de diálise: maior ou menor que 6 meses de início de Hemodiálise; idade: maior ou menor que 60 anos; exames de laboratório e imagem: normal e alterados. Ca pós= cálcio plasmático pós hemodiálise; Mg pós: magnésio plasmático pós hemodiálise. $\mathrm{N}=$ valores absolutos de dados; teste Qui quadrado; significância 5\%; AD- átrio direito 
Os resultados significativos no teste Qui-quadrado foram submetidos a análises de regressão logística univariada logística binária em relação a átrio direito (Tabela 36).

Tabela 36 - Regressão Univariada. Dependente Átrio Direito

\begin{tabular}{lcc}
\hline VARIÁVEIS & $\boldsymbol{\beta}(\mathbf{9 5 \%} \mathbf{I C})$ & $\mathbf{p}$ \\
\hline $\begin{array}{l}\text { Dados sociodemográficos } \\
\text { Tempo diálise }\end{array}$ & & \\
$\quad$ Idade & $334236173,771(0,000)$ & 0,998 \\
Laboratório & $403868723,803(0,000)$ & 0,997 \\
$\quad$ Cálcio pós & $0,000(0,000)$ & 0,998 \\
ECG repouso & & \\
$\quad$ Tipo Arritmia & $12,400(1,966-78,196)$ & 0,007 \\
\hline
\end{tabular}

Covariáveis estratificadas dicotômicas: Tempo de diálise: maior ou menor que 6 meses de início de Hemodiálise; idade: maior ou menor que 60 anos; exames de laboratório e imagem: normal e alterados. Ca pós= cálcio plasmático pós hemodiálise; $\mathrm{Mg}$ pós: magnésio plasmático pós hemodiálise. $\mathrm{N}=$ valores absolutos de dados; teste Qui quadrado; significância 5\%.

A única covariável que é preditora é tipo de arritmia com risco maior de $12 \mathrm{x}$ para alterações de átrio direito. 
Nas análises que se seguem são apresentados os resultados das associações e regressão tendo como dependente VAV.

A Tabela 37 apresenta os resultados significativos do teste qui-quadrado entre a dependente VAV e as covariáveis.

Tabela 37 - Associação Covariáveis e Dependente VAV

\begin{tabular}{lc}
\hline VARIÁVEIS & $\mathbf{n = 7 3}$ \\
\hline Dados sociodemográficos & $\mathbf{p}$ \\
$\quad \begin{array}{l}\text { Tempo diálise } \\
\text { Idade }\end{array}$ & 0,04 \\
Laboratório & 0,01 \\
$\quad$ Cálcio pós & 0,005 \\
$\quad$ Bicarbonato pós & 0,024 \\
ECG repouso & \\
Tipo Arritmia & 0,00 \\
\hline
\end{tabular}

Covariáveis estratificadas dicotômicas: Tempo de diálise: maior ou menor que 6 meses de início de Hemodiálise; idade: maior ou menor que 60 anos; exames de laboratório e imagem: normal e alterados. Ca pós= cálcio plasmático pós hemodiálise; $\mathrm{Mg}$ pós: magnésio plasmático pós hemodiálise. $\mathrm{N}=$ valores absolutos de dados; teste Qui quadrado; significância 5\%. 
A seguir a Tabela 38 apresenta os resultados da regressão univariada logística binária das covariáveis significativas nos testes Qui-quadrado em relação à dependente VAV.

Tabela 38 - Regressão Univariada Logística Binária das Covariáveis Significativas nos Testes Qui-quadrado em Relação a Dependente VAV

\begin{tabular}{lcc}
\hline VARIÁVEIS & $\boldsymbol{\beta}(\mathbf{9 5 \%} \mathbf{I C})$ & $\mathbf{p}$ \\
\hline Dados sociodemográficos & $\mathbf{n}=\mathbf{7 3}$ & \\
$\quad$ Tempo diálise & & 0,998 \\
$\quad$ Idade & $403868714,213(0,000)$ & 0,997 \\
Laboratório & $491666266,456(0,000)$ & \\
$\quad$ Cálcio pós & & 0,998 \\
$\quad$ Bicarbonato pós & $0,000(0,000)$ & 0,998 \\
ECG repouso & $305630360,7(0,000)$ & \\
$\quad$ Tipo Arritmia & & 0,001 \\
\hline
\end{tabular}

Covariáveis estratificadas dicotômicas: Tempo de diálise: maior ou menor que 6 meses de início de Hemodiálise; idade: maior ou menor que 60 anos; exames de laboratório e imagem: normal e alterados. Ca pós= cálcio plasmático pós hemodiálise; Mg pós: magnésio plasmático pós hemodiálise. $\mathrm{N}=$ valores absolutos de dados; teste Qui quadrado; significância 5\%.

Conclui-se que a única preditora foi tipo de arritmia detectada pelo ECG de repouso com risco 20 vezes para alterações de VAV. 
A Tabela 39 apresenta o resumo dos resultados das análises de regressão logística binária multivariada.

Tabela 39 - Variáveis Dependentes e Fatores de Risco

\begin{tabular}{|c|c|c|}
\hline Variável Dependente & Covariável & $\beta(95 \% \mid C)$ \\
\hline \multicolumn{3}{|l|}{ Alterações Elétricas } \\
\hline \multirow[t]{3}{*}{ Gatilhos Eletrofisiológicos } & Idade & $6,026(1,286-28,236)$ \\
\hline & Vol diastólico & $9,849(1,609-60,275)$ \\
\hline & Intervalo QT & $109,928(10,808-1118,078)$ \\
\hline \multirow[t]{3}{*}{ Extra-Sístole Ventricular } & Total Med CV & $5,117(1,425-18,370)$ \\
\hline & Vol Sistólico & $6,838(1,642-28,471)$ \\
\hline & Intervalo QT & $8,62(2,335-31,817)$ \\
\hline \multirow[t]{2}{*}{ Intervalo QT } & Idade & $2,157(, 730-6,377)$ \\
\hline & Diâmetro Sistólico & $3,483(, 716-16,936)$ \\
\hline \multicolumn{3}{|l|}{ Alterações Estruturais } \\
\hline \multirow[t]{2}{*}{ Átrio Esquerdo } & Idade & $8,292(1,576-43,636)$ \\
\hline & Tipo Arritmia & $5,873(1,041-33,129)$ \\
\hline Volume Diastólico & Idade & $31,158(3,836-253,083)$ \\
\hline Volume Sistólico & Idade & $17,937(3,657-87,983)$ \\
\hline \multirow[t]{2}{*}{ Diâmetro Sistólico } & Idade & $10,058(1,101-91,865)$ \\
\hline & Tipo Arritmia & $5,746(, 982-33,605)$ \\
\hline \multirow[t]{2}{*}{ Diâmetro Diastólico } & Bicarbonato Pós HD & $10,169(1,053-98,206)$ \\
\hline & Tipo Arritmia & $15,078(2,387-95,241)$ \\
\hline \multirow[t]{2}{*}{ Septo Interatrial } & Idade & $6,502(1,232-34,326)$ \\
\hline & Bicarbonato Pós HD & $5,983(, 683-52,382)$ \\
\hline Átrio Direito & Tipo Arritmia & $12,400(1,966-78,196)$ \\
\hline Válvula Átrio Ventricular & Tipo Arritmia & $20,667(3,394-125,832)$ \\
\hline
\end{tabular}

Covariáveis estratificadas dicotômica; $\beta=$ razão de chances; $p=$ significância 5\%; IC: Intervalo de confiança.

Conclui-se que, após os ajustes de covariáveis, para gatilhos de FA os preditores mais relevantes são idade, alterações estruturais de volume e intervalo QT. Para alteração do intervalo QT, idade e alteração de diâmetro. Para as alterações estruturais, os preditores mais relevantes e frequentes após o ajuste das covariáveis são idade, tipo de arritmia e bicarbonato pós-hemodiálise. O preditor comum a todas as variáveis dependentes analisadas foi idade mais avançada. 
5 DISCUSSÃO 


\section{DISCUSSÃO}

Este estudo sugere que, na população analisada, os pacientes com função renal crônica terminal, quando iniciam hemodiálise, são detectáveis em sua maioria, função e estrutura cardíaca normal, evoluindo para sinais de degeneração estrutural e elétrica com aparecimento de preditores de FA entre o $7^{\circ}$ e o $12^{\circ}$ mês de hemodiálise. Esses sinais degenerativos são percebidos, predominantemente, na modificação da estrutura dos ventrículos, da força de contração e relaxamento, atingindo a função sistólica e diastólica do miocárdio e o aparecimento de arritmias caracterizadas por gatilhos eletrofisiológicos em especial ESV.

Optamos por estudar um grupo de pacientes não aleatórios de um serviço público de terapia de reposição renal. Fizemos essa opção por ser o serviço público o principal responsável pelo tratamento dialítico a longo prazo no Brasil e no mundo. Convidamos todos os pacientes que iniciaram hemodiálise no serviço da clínica de diálise UNASCO e no Hospital Municipal Antônio Giglio localizados em Osasco, na grande São Paulo, no período de recrutamento do projeto, portanto não se trata de uma amostra e sim da população total do serviço com essas características. Totalizamos quase 80 pacientes e esse número dependeu do acesso dos pacientes ao serviço. Ocorreu limitação desse acesso em função de medidas de políticas públicas de saúde que reduziram os gastos governamentais com este tratamento no período de março de 2016 a julho 2019, incluído no período de recrutamento de pacientes para o projeto. Assim, a amostra estudada é não aleatória. Apesar de trabalhos com populações randômicas terem maior evidência científica que os não probabilísticos, eles ocorrem com mais frequência e podem contribuir com dados significativos para a prática clínica, como evidenciado por trabalhos nacionais e internacionais semelhantes aos nossos na literatura ${ }^{80,81}$.

Embora não fosse fator de inclusão, coincidentemente todos os participantes apresentavam hipertensão arterial de longa data e, por serem dialíticos, apresentavam lesão de órgão alvo cardiovascular que é a doença renal crônica, nesse caso terminal. Por outro lado, a presença de FA no recrutamento de pacientes foi inexpressiva 
atingindo menos de meio por cento da população. Confirmou-se, assim, que a FA é arritmia que se desenvolve predominantemente após o início da terapia de reposição renal e que todos os pacientes deste estudo apresentavam alto risco cardiovascular ( 1 fator de risco + lesão de órgão alvo), dados esses semelhantes aos da literatura nacional e internacional, por ser a doença hipertensiva uma das causas mais frequentes de falência renal terminal ${ }^{1,2,56}$.

Ambos os grupos analisados eram predominantemente do sexo masculino, brancos, não solteiros, quinquagenários, com peso médio entre a $6^{\mathrm{a}}$ e $7^{\mathrm{a}}$ dezena, trabalhadores em atividade, que estudaram até o ensino fundamental, moradores na região sudeste, especialmente da área metropolitana, com alto risco cardiovascular, multimorbidades e em uso de polifarmacia (mais de duas medicações). O grupo 2 apresenta perfil de participantes um pouco mais velhos, com maior peso e número de multimorbidades, polifarmácia e preditores cardiovasculares.

A população brasileira e de São Paulo, segundo o IBGE em 2018, apresenta discreto predomínio de mulheres na faixa etária de 50 a 54 anos (Brasil: homens 2,82\% e mulheres 3,08\% da população brasileira; São Paulo: homens 2,96\% e mulheres 3,27\%). Importante destacar, nesse sentido, que a população do estudo, cuja maioria pertence a São Paulo, não espelha a população em geral, sugerindo predominância de doença renal vascular terminal na população masculina dessa faixa etária ${ }^{74}$. De fato, em relação aos pacientes hipertensos e vasculopatas, o estudo Saúde Brasil 2018 do Ministério da Saúde revelou maior predominância do sexo masculino, com taxa de crescimento anual de $2,2 \%$ e de $2 \%$ para o sexo feminino. A raça predominante também aponta um perfil de $3 / 4$ da população masculina, em torno de 55 anos, branca, com ensino fundamental e má adesão à medicação e a consultas médicas, com alto risco de doenças vasculares ${ }^{75}$. O Inquérito Brasileiro de Diálise Crônica realizada em 2016 mostrou ser a população dialítica brasileira predominantemente masculina (57\%), entre 20 e 65 anos (65,7\%). Dos 39.714 pacientes, que iniciaram diálise em 2016, 98\% recebiam o método hemodiálise, a maioria pertencia ao SUS, apresentavam hipertensão e diabetes como morbimortalidades mais frequentes, em uso de polifarmácia e $48 \%$ atendidos por serviços da região sudeste, em especial São Paulo. Esses dados estão em consonância com os dados obtidos nesta pesquisa assinalando que os pacientes estudados 
espelham a população brasileira em procedimentos hemodialíticos. De fato, o perfil dos pacientes atendidos pelo Serviço da UNASCO e Hospital Municipal Antônio Giglio localizados em Osasco, na grande São Paulo, desde a sua fundação, são em sua quase totalidade masculinos, entre 50 e 60 anos, hipertensos e vasculopatas com insuficiência renal crônica e pertencentes aos SUS, em atendimento hemodialítico. Optamos por incluir somente pacientes com estabilidade hemodinâmica durante o estudo na tentativa de controlar e homogeneizar a população e sua variabilidade. No entanto, sabemos ser possível que vários outros fatores possam ter interferido nos resultados obtidos e não somente os dados coletados e analisados neste estudo, como o tempo e alterações estruturais e metabólicas ocorridos devido ao início da hemodiálise. Esses fatores são comuns em estudos clínicos observacionais nos quais grande parte das covariáveis não podem ser controladas. É importante também destacar que o desenho transversal deste estudo e os testes aplicados não permitem relação causal e sim de associação. Os resultados, portanto, devem ser interpretados à luz dessas limitações e deve-se ter cuidado para transportá-los para a prática clínica. Porém, mesmo com esses vieses, este estudo sinaliza claramente que a progressão da degeneração cardíaca para fibrilação atrial em pacientes portadores de doença renal crônica terminal submetidos à hemodiálise pode ser diagnosticada precocemente através dos fatores preditores da FA.

O eletrocardiograma de repouso não mostrou ser um bom exame para a detecção precoce de fatores preditores de FA pois, em ambos os grupos da pesquisa, os resultados apresentaram-se pouco expressivos quanto às suas alterações. No grupo 1, observou-se, como alteração preditora, apenas ESV com 5\% de prevalência. Por outro lado, chamou-nos atenção o aumento dessa variável nos pacientes do grupo 2 que apresentaram $17 \%$ de alterações para ESV. Apenas no grupo 2, observaram-se, ainda, alterações elétricas supraventriculares quanto à morfologia, amplitude e duração da onda P menores de $2 \%$ da amostra.

O exame de eletrocardiografia dinâmica (Holter) mostrou ser superior ao do ECG de repouso para evidenciar precocemente as alterações de polaridade de membrana miocárdica e condução elétrica durante o $1^{\circ}$ ano de hemodiálise, já sinalizadas no $1^{\circ}$ semestre da terapia de reposição renal. Um pouco mais de $1 / 3$ dos pacientes do grupo 1 apresentou algum tipo de arritmia considerada gatilho 
eletrofisiológico de FA e 1/4 alteração do intervalo QT. Já nos pacientes do grupo 2, houve aumento expressivo dessas alterações elétricas; gatilhos eletrofisiológicos e alterações do intervalo QT se fizeram presentes em mais da metade dos pacientes. Os outros parâmetros mostraram-se inexpressivos ou ausentes em ambos os grupos. $\mathrm{O}$ gatilho eletrofisiológico mais prevalente foi ESV, presente em $1 / 3$ da amostra dos pacientes do grupo 1 e em quase metade dos pacientes do grupo 2. O segundo gatilho eletrofisiológico, em termos de frequência, foi TVS, que se fez presente em 1/6 dos pacientes do grupo 2. As outras arritmias foram inexpressivas ou ausentes em termos de frequência em ambos os grupos. Porém fica evidente que as arritmias ocorrem, predominantemente, no segundo semestre do início de hemodiálise e que a ESV é a arritmia mais prevalente. A condução elétrica ventricular durante a terapia dialítica está associada a risco aumentado de eventos arrítmicos ventriculares com potencial maligno consequente do aumento do intervalo QT e da dispersão do QT, traduzindo diferenças na despolarização e repolarização ventricular, podendo funcionar como preditoras de futuras arritmias ventriculares ou morte súbita cardíaca ${ }^{79,83,84}$. Nossos dados evidenciaram o aumento progressivo da presença de ESV no grupo 2, o maior tempo de terapia de dialítica nos pacientes desse grupo e com constantes alterações de despolarização e repolarização ventricular podem favorecer nesta população tal fenômeno. A presença de ESV nessa população, apesar de ser um forte preditor de FA, pode ser reflexo do remodelamento ventricular relacionado à doença hipertensiva visto em toda a população do estudo e confirmado nos dados do ecocardiograma. Essas alterações, muito provavelmente em função de sobrecargas ventriculares crônicas devido à própria hipertensão arterial e hipervolemia nestes pacientes, acabam modificando toda a ultraestrutura neuromuscular, facilitando processos arritmogênicos ventriculares. ${ }^{82}$.

De acordo com a literatura e estudos com populações semelhantes ao nosso estudo, pacientes com doença renal crônica em terapia de substituição renal no início do processo apresentam um perfil eletrocardiográfico semelhante a este estudo: a maioria apresenta alterações do intervalo QT em pacientes também submetidos à terapia dialítica há mais de 6 meses ${ }^{76,77,83}$.

O intervalo QT é observado no ECG de repouso entre o início da onda Q do

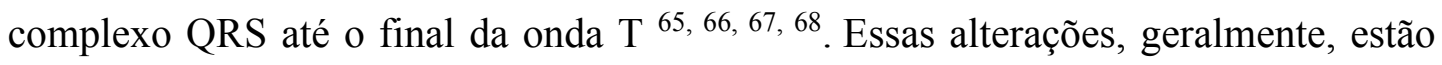


ligadas a eventos eletrolíticos no período de repolarização celular, participam desse processo o sódio, potássio, cálcio e magnésio na maior parte do evento. Em nosso estudo, não se observou essa alteração no exame de eletrocardiograma de repouso, fato que, provavelmente, se explica porque os pacientes, em sua maioria, eram provenientes de ambulatórios e no início de tratamento e estavam, portanto, compensados do ponto de vista clínico e dialítico.

No ecocardiograma, os participantes do grupo 1 apresentaram normalidade em quase todos os parâmetros. Por outro lado, alterações de todos os parâmetros do ecocardiograma foram mais prevalentes no grupo 2. As alterações mais frequentes foram as relativas às câmaras esquerdas ventriculares, alcançando quase metade da população a partir do sétimo mês de terapia dialítica. As alterações funcionais, volumes, átrio direito e contratilidade estavam pouco presentes. Esses dados mostram que as alterações da estrutura e função global de ambas as câmaras cardíacas são mais precocemente e frequentemente detectáveis pelo ecocardiograma transtorácico a partir do sexto mês após início da hemodiálise. O corpo de evidências indica o extraordinário papel da ecodopplercardiografia na melhora da qualidade da avaliação clínica global do paciente com DRC em diálise. A literatura e a prática clínica atuais têm realçado a utilidade do método no diagnóstico da disfunção cardíaca subclínica, no refinamento do diagnóstico clínico de insuficiência cardíaca, na predição do risco cardiovascular e no direcionamento e acompanhamento das estratégias de tratamento 78,82 . Os desfechos ecodopplercardiográficos têm sido comprovados como marcadores substitutos úteis para estudos de prognóstico e intervenção. Diretrizes norte-americanas ${ }^{78}$ recomendam o ecodopplercardiograma para todos os pacientes de diálise, um a três meses após o início da terapia renal substitutiva e em intervalos de três anos subsequentemente a despeito dos sintomas. Portanto é consenso que todo paciente iniciando a terapia dialítica deva ser submetido ao ecocardiograma 77, 78, 82, 86. Nossos dados apontam a importância de realizar o exame no início e no $2^{\circ}$ semestre, porque as alterações estruturais prevalecem no $2^{\circ}$ período, intervalos menores entre os exames podem ser de valor clínico em condutas individualizadas. Está comprovado que o acompanhamento com ecocardiogramas seriados adiciona valor prognóstico além do exame basal, possibilitando a monitorização da regressão das alterações do $\operatorname{VE}^{78,82}$. Futuramente, 
novos métodos ecodopplercardiográficos com a propriedade de investigar doença miocárdica subclínica, como strain, strain rate e caracterização ultrassônica tecidual, poderão beneficiar ainda mais esse grupo de pacientes sob excessivo risco cardiovascular 77, 78, 82, 86. Esses dados contribuem para instituir medidas preventivas individuais e coletivas da FA em pacientes renais crônicos em hemodiálise, permitindo-se assim melhora da qualidade clínica para esses pacientes e economia para os cofres públicos. Como descrito anteriormente, todos os pacientes já eram hipertensos de longa data e com tratamento clínico irregular, ocasionando lesão de órgão alvo (coração com hipertrofia ventricular presente), por isso nossos pacientes apresentaram maior alteração ventricular do que atrial.

Como esperado, todas as medidas de ureia e creatinina estavam acima do normal, já que todos os pacientes possuíam insuficiência renal crônica terminal e eram submetidos à hemodiálise crônica. Ficou claro, no entanto, que as alterações eletrolíticas e metabólicas foram mais expressivas pré-diálise no grupo 1, evidenciando ainda sinais de instabilidade metabólica dos pacientes renais crônicos em início de hemodiálise. Os valores pós-diálise apresentaram-se, em geral, menos alterados, também conforme se previa. O que sugeriu, sim, eficiência do método dialítico, maior estabilidade metabólica e melhora dos parâmetros eletrolíticos pós maior tempo de hemodiálise nesses pacientes.

Optamos por categorizar dicotomicamente os valores de ureia (acima de 100 $\mathrm{mg} / \mathrm{dL}$ ) e creatinina (acima de 4,0 mg/dL). Essa estratificação foi baseada na relação de clareamento da creatinina e taxa de filtração glomerular que não é linear e sim uma exponencial. O clareamento de creatinina e ureia pelo rim depende de vários fatores como raça, IMC, hábitos alimentares e metabolismo $45,46,47,53$. Porém valores de creatinina acima de 4,0 apresentam função renal em torno de $10 \%$ e, por isso, refletem a população dialítica analisada. Entendemos que todos os pacientes apresentariam função renal abaixo de $30 \%$ e, por serem crônicos, tiveram a indicação de hemodiálise de manutenção. Entendemos também que a retenção de escórias entre $30 \%$ e abaixo de $10 \%$ é diferente, tornando o organismo suscetível a distúrbios metabólicos, celulares e elétricos distintos, com maior vulnerabilidade quanto menor for a taxa de filtração glomerular; justificando, portanto, termos estratificado os valores de ureia e creatinina nesses níveis. Outro ponto a ser considerado é se as 
alterações metabólicas no início do processo dialítico afetariam de forma igual ou diferente a condução elétrica miocárdica após a estabilização desses parâmetros no $2^{\circ}$ semestre de terapia de reposição renal, as análises de associações com tempo de hemodiálise que se mostraram significativas foram o bicarbonato de sódio e o potássio, no instante pré-diálise e cálcio sérico, bicarbonato de sódio e magnésio no instante pós-diálise.

Todos os participantes do estudo apresentavam HAS de longa data, com lesão de órgão alvo e alto risco cardiovascular. A lesão crônica, principalmente no coração e rins, induz os mecanismos de compensação tanto da função cardíaca quanto da renal e metabólica haja visto que são pacientes com quadro de acidose constante, acarretando inúmeros efeitos adversos sobre o funcionamento celular. O cálcio, potássio e bicarbonato estão diretamente associados à despolarização e repolarização do cardiomiócito, sendo K relacionado aos canais rápidos de despolarização, o cálcio aos canais lentos e ao bicarbonato, refletindo acidose, com a funcionalidade de gap junctions responsáveis pela passagem rápida da transmissão elétrica cardíaca. $O$ bicarbonato de sódio é um dos principais tampões corpóreos sanguíneos. As alterações eletrolíticas e de bicarbonato são comuns em pacientes renais crônicos, porque o sistema renal é o responsável por regenerar e reabsorver esse tampão e trazê-lo de volta à circulação sanguínea. Essa capacidade é ineficiente no paciente portador de nefropatia terminal e é reconstituída na hemodiálise por cálculo e infusão endovenosa durante o procedimento. Este cálculo nunca é fisiológico e, assim, apesar de se aproximar do normal, dificilmente atinge a normalidade. Alterações de $\mathrm{pH}$ por distúrbios metabólicos ocorridas no nefropata atingem polaridade de membrana e a função mecânica da fibra cardíaca. A contração de actina e miosina é feita com alto consumo de ATP. Em situações de acidose, o miócito cardíaco pode ter acometimento de gap junctions e de consumo do ATP para a contração mecânica comprometendo dessa forma sua função. Além disso, associam-se as alterações de volemia e HAS dos pacientes nefropatas, que podem facilitar a alteração do diâmetro diastólico ventricular, ultrapassando a lei de Starling, levando a desacoplamento de fibras de actina e miosina e disfunção ventricular ${ }^{85}$. Nas análises que fizemos, o bicarbonato associou-se ao tempo de hemodiálise, sendo níveis mais alterados no primeiro semestre do início do procedimento. Não foi preditor de sinais preditores de 
FA. O potássio associou-se a alterações no $1^{\circ}$ semestre de início HD. De fato, tivemos maior instabilidade eletrolítica sanguínea nesse período e assim com maior risco CV. O cálcio alterado (baixo) associou-se ao período do $2^{\circ}$ semestre pós- início de HD. Esse dado está em consonância com a literatura pela estabilização dos níveis de cálcio abaixo da normalidade "toleráveis" pelo paciente portador de insuficiência renal crônica dialítica. No entanto, quando inseridos nas análises de predição, as alterações eletrolíticas e de bicarbonato (indiretamente $\mathrm{pH}$ ) não se mostraram como fatores de risco para preditores de FA. Acreditamos que os efeitos deletérios da acidose, representados pelo consumo de bicarbonato e de potássio no $1^{\circ}$ semestre e do cálcio no $2^{\circ}$ semestre pós-início da $\mathrm{HD}$, estejam presentes na maioria da população analisada impedindo que sua participação na alteração elétrica da fibra miocárdica fosse evidenciada pela metodologia de regressão logística a qual se baseia na comparação entre fatores (população com e sem os preditores de FA). Essa proposta tem consonância na literatura ${ }^{85}$.

Vários fatores sociodemográficos, estruturais e elétricos foram preditores e fatores de risco de gatilhos eletrofisiológicos de FA na análise univariada como idade, preditores cardiovasculares, medicações cardiovasculares e tempo de diálise. A maioria das alterações estruturais de maior risco foram do volume sistólico e do diâmetro sistólico e volume diastólico, intervalo QT, ECG de repouso não apresentou dados preditores de gatilhos eletrofisiológicos. Entretanto, após o ajuste das covariáveis, somente 3 preditores permaneceram como fatores de risco: idade, intervalo QT (pelo Holter) e volume diastólico, volume sistólico, total medicações $\mathrm{CV}$.

O preditor mais frequente para as alterações estruturais e elétricas cardíacas foi a idade, presente com risco de 6 vezes para gatilhos eletrofisiológicos e 8 vezes para alteração de átrio esquerdo. É possível também que esse dado esteja indiretamente inserido na covariável total medicação cardiovascular, risco 5x para ESV e tempo de hemodiálise, risco 20 vezes para alteração de volume diastólico, por serem fatores interdependentes. Acreditamos que idade reflita o alto risco cardiovascular que todos os pacientes exibiam por serem todos hipertensos e apresentarem lesão de órgão alvo (doença renal crônica terminal) ${ }^{56}$ e já na década sexagenária. Sabemos que a degeneração cardiovascular em pacientes com alto risco, 
em especial os dialíticos, por já apresentarem lesão de órgãos alvo, é um contínuo associado à idade e a fatores de risco como hipertensão, diabetes, tabaco, álcool, uso de polifarmácia (mais de 4 medicações) e controle clínico ${ }^{46,56}$. Nesse contexto, interpretamos que, provavelmente, o tempo de diálise, multimorbidades e polifarmácia cardiovascular, que foram fatores preditores em algumas análises de regressão univariada e desapareceram na análise multivariada, possam estar contidos na covariável idade. A multimorbidade e polifarmácia são fatores muito importantes para a degeneração cardiovascular, mas que, nos pacientes analisados, já compunham o respectivo perfil, não podendo, portanto, ser mensurado seu fator de risco nessa população pela análise comparativa de regressão. Relembramos que a regressão logística analisa predição de um fator (Y, variável dependente) em relação a outro (variável independente X ou covariável). Essas análises são realizadas escolhendo-se o padrão para a comparação. $\mathrm{Na}$ análise binária, a comparação é da apresentação (covariáveis) e não do desfecho (variável dependente, no caso, as alterações elétricas ou estruturais analisadas). Nas covariáveis, a comparação se dá em relação à presença ou não de fator de risco cardiovascular. Neste sentido, é difícil estratificar o peso de cada fator de risco cardiovascular separadamente, uma vez que esses fatores são interdependentes e estavam presentes em todos os participantes do estudo.

O intervalo QT, foi o maior fator de risco obtido para gatilhos eletrofisiológicos (mais que 100 vezes). Pacientes renais crônicos dialíticos apresentam aumento da resistência vascular periférica total e sobrecarga ventricular esquerda em decorrência da hipertrofia ventricular esquerda. Esses pacientes, por terem maior massa cardíaca e aumento da volemia, apresentam uma condução elétrica mais lentificada, acarretada por períodos de despolarização e repolarização prolongados refletindo um intervalo QT alterado ${ }^{82,83,84,86 .}$

Os achados estatísticos pós ajustes das covariáveis se mostraram em consonância com a literatura, pois nossos resultados confirmam que as alterações estruturais e elétricas em indivíduos mais idosos têm o caráter preditor de arritmias cardíacas, como a fibrilação atrial.

Apesar de tempo de diálise ser um marcador de divisão de um período para melhor evidenciar sinais de alterações estruturais e elétricas pelos métodos estudados 
em pacientes hipertensos e portadores de nefropatia terminal, sabemos que as alterações são progressivas, com início assintomático e não pontuais, limitadas a um período. Segundo o estudo - CORDIAL ${ }^{75}$, Prevalência de fatores de risco cardiovasculares em pacientes em hemodiálise (abril 2014), a idade avançada proporciona risco cardiovascular que se assemelha à relação descrita na população geral - há uma prevalência crescente de idosos na população em hemodiálise em todo o mundo. No censo brasileiro de diálise de 2009 a 2018, o perfil dos pacientes em diálise mostra que $35 \%$ dos dialíticos têm mais de 65 anos e outros dados sugerem que fatores mórbidos cardiovasculares não interferem nos gatilhos, porém todos os pacientes já apresentavam alto risco cardiovascular não se podendo estratificar maior risco perante este estudo ${ }^{75}$.

Na regressão com dependente, a arritmia ESV, são preditoras as alterações elétricas, estruturais e polifarmácia de morbidades cardiovasculares. Nesse caso, destaca-se a alteração do intervalo QT com risco 8,6 vezes. Entendemos que o intervalo QT nesta população, como comentado anteriormente, retarda a transmissão de estímulo no VE hipertrofiado pela hipertensão e predispondo ao aparecimento de ectopias ventriculares. Polifarmácia para morbidades cardiovasculares também reflete a gravidade das doenças degenerativas progressivas miocárdicas nesses pacientes com alto risco cardiovascular. O volume sistólico alterado também reflete o acometimento do VE nesses pacientes. Interessante comentar que o volume diastólico foi o fator de risco estrutural preponderante para a covariável gatilhos eletrofisiológicos e para ESV foi o volume sistólico. É possível que para ESV o componente hipertrófico ventricular seja mais importante que o componente de dilatação das fibras miocárdicas. Esses dados confirmam o grau de comprometimento miocárdico secundário principalmente à hipertensão nesses pacientes. Essa proposta está em consonância com a literatura. Além disso, de acordo com a literatura, tal fenômeno também pode ser explicado pelas alterações estruturais associadas a diversas outras situações mantidas nesses pacientes, como distúrbios hidroeletrolítico, hormonais e uso de drogas arritmogênicas $1,2,4,6$.

A população do nosso estudo apresenta um alto risco cardiovascular pelos critérios de Framingham, principalmente por serem todos HAS e a maioria também 
ter DM e fazerem uso de polifarmácia e apresentarem em seus dados alterações elétricas, metabólicas e da estrutura cardíaca.

Analisamos também os fatores de risco para intervalo QT. Muitos fatores foram preditores na análise univariada como a idade $(2 \mathrm{x})$ e alterações estruturais como volume diastólico $(3 \mathrm{x})$ e diâmetro sistólico $(5 \mathrm{x})$ de câmaras esquerdas. Os eletrólitos cálcio pré e pós-hemodiálise impactaram de forma protetora sobre o intervalo QT, porém de forma mais discreta (menor que 1), a significância desses preditores desapareceu após ajuste de covariáveis na análise multivariada. Isso mostra que essas variáveis independentes significativas nas análises univariadas são equivalentes no impacto das alterações do intervalo QT.

O intervalo QT é muito comum na prática clínica como medida, pois corresponde ao período que vai desde o início da despolarização ventricular, início da onda $Q$, até o final da repolarização ventricular, final da onda $T$ no eletrocardiograma, traduzindo fisiologicamente a polaridade de membrana. A duração dessa variável eletrofisiológica avaliada pelo eletrocardiograma (ECG) é definida pelo ponto de convergência entre a tangente que passa pela porção mais íngreme da fase final da onda $\mathrm{T}$ e a reta que passa pela linha de base e, em nossa prática, seu valor é dado em milissegundos com valores de normalidade entre 340 e $440 \mathrm{~ms}{ }^{65,67}$. Os canais de potássio são a maior e mais complexa família de canais iônicos, representada por pelo menos 70 locus do genoma humano, a magnitude dos canais de potássio de retificação retardada do tipo rápido e lento, na fase de repolarização do potencial de ação cardíaco. Nesse contexto, a heterogeneidade eletrofisiológica pode ser considerada importante característica miocárdica na determinação de mecanismos de arritmogênicos. A passagem de íons através da membrana celular dos miócitos é regulada por canais iônicos específicos, que provocam despolarização e repolarização cíclica da célula, denominada potencial de ação. O potencial de ação de um miócito ordinário inicia-se quando a célula é despolarizada de seu potencial transmembrana diastólico de $-90 \mathrm{mV}$ para um potencial de cerca de $-50 \mathrm{mV}$. Nesse potencial limiar, abrem-se os canais rápidos de sódio dependentes de voltagem, causando despolarização rápida mediada por influxo de sódio por seu alto gradiente de concentração. O canal rápido de sódio é rapidamente inativado, interrompendo o influxo de sódio, mas abrem-se outros 
canais iônicos dependentes de tempo e voltagem, permitindo a entrada de cálcio pelos canais lentos de cálcio (um evento despolarizante) e a saída de potássio através dos canais de potássio (um evento repolarizante)" $83,84,87$.

Em nosso estudo, observamos apenas as alterações do intervalo QT detectadas pelo Holter, no teste do Qui-quadrado refletindo os dados apurados nos exames iniciais da pesquisa. Já, quando associamos a outras variáveis, principalmente aos dados metabólicos, não enxergamos essas alterações. Esse dado reforça, em nossa opinião, que o controle eficaz dos eletrólitos durante a diálise corrobora para o controle da condução elétrica normalizando as alterações do intervalo QT e, provavelmente, diminuindo as possibilidades de acarretar arritmias cardíacas, em especial, a FA.

O tipo de arritmia foi fator de risco para alterações estruturais. Relembramos que tipo de arritmia no ECG de repouso reflete a presença de extrassístole supraventricular e ventricular. Entendemos ser este fator um dado genérico e pouco específico do ECG de repouso, porém pode se tornar um exame interessante que, associado ao exame físico em paciente renal crônico no $2^{\circ}$ semestre de HD, seria um sinal de fácil aquisição e alertaria que alterações elétricas, metabólicas e estruturais estão instaladas a ponto de serem detectadas, permitindo que medidas de tratamento para controle de fatores de risco e de remodelação cardíaca fossem aplicadas e checadas em termos de adesão pelo paciente.

Em pacientes dialíticos, as arritmias cardíacas tanto supraventriculares como ventriculares têm um importante papel, em virtude de esses pacientes disporem de uma maior morbimortalidade associada às doenças cardiovasculares e constituírem a principal causa de mortalidade nesse grupo. São mecanismos complexos e parecendo estar relacionados às alterações da estrutura cardíaca, distúrbios eletrolíticos, ácidobase, hiperatividade simpática, toxinas urêmicas além de fatores associados como a idade e desnutrição ${ }^{88}$.

As alterações dos volumes ventriculares impactaram como fator de risco de gatilhos eletrofisiológicos em nosso estudo mesmo após ajustes das covariáveis. A população analisada é composta por pacientes hipertensos com alto risco cardiovascular. Assim, optamos por avaliar quais seriam os preditores das alterações 
de câmaras esquerdas para discernirmos o impacto da HAS de longa data no miocárdio nesta população. Analisamos o volume diastólico final e alterações de átrio esquerdo. Após ajuste de fatores, obtivemos que novamente a idade apresentava fator de risco 8x maior para alteração de átrio esquerdo e tempo de hemodiálise fator de risco 10x maior para alteração de volume diastólico, confirmando que as degenerações cardiovasculares crônicas progressivas ao longo do tempo são os fatores que mais impactam no miocárdio dessa população.

A população do nosso estudo apresenta um alto risco cardiovascular pelos critérios de Framingham, principalmente por serem todos HAS e a maioria também ter DM, fazer uso de polifarmácia e apresentar em seus dados alterações elétricas, metabólicas e da estrutura cardíaca.

A dilatação do átrio esquerdo é atribuída à diminuição da circulação sanguínea diastólica do AE para o VE, em função do aumento da rigidez ventricular esquerda. Ocorre um aumento da sobrecarga no átrio esquerdo, influenciado pela lei de Frank-Starling, distendendo suas fibras para a câmara exercer a função de reservatório, levando à deterioração estrutural. Em grandes estudos prospectivos tem sido estabelecido que o aumento do AE é um fator de risco independente para o desenvolvimento de FA ${ }^{82,}{ }^{89}$. Sabemos também que a prevalência da FA está relacionada diretamente ao aumento da idade e, em indivíduos acima de 65 anos, essa prevalência aumenta substancialmente ${ }^{1}$.

O preditor mais importante de volume diastólico é tempo de hemodiálise. Os outros fatores de risco como idade, total de preditores cardiovasculares e bicarbonato de sódio pós-hemodiálise tiveram resultados pouco expressivos. Conclui-se, assim, que a única covariável, após o ajuste, que se manteve como preditora fator de risco foi tempo de hemodiálise para alteração do volume diastólico.

A disfunção diastólica, diagnosticada pela alteração do volume diastólico, produzida por alterações do relaxamento e da complacência ventricular causa o aumento das pressões de enchimento. Em fases avançadas, esse aumento da pressão diastólica contribui fortemente para manifestações de insuficiência cardíaca. Pacientes dialíticos apresentam estado urêmico frequente, o que pode causar fibrose miocárdica elevando as pressões de enchimento, alterações de fatores neuro- 
humorais também contribuem para o aumento da rigidez e a diminuição do relaxamento levando à exacerbação de volemia sobre o enchimento do $\mathrm{VE}^{83}$.

A disfunção sistólica do VE é fator de risco para ESV na população analisada. Este é um importante indicador de prognóstico desfavorável para indivíduos dialíticos. Mecanismos multifatoriais como DAC, anemia, hiperparatireoidismo, toxinas urêmicas, má nutrição e sobrecarga hemodinâmica prolongada têm efeito adverso sobre disfunção sistólica. Independente da massa ventricular esquerda, essas alterações estão diretamente ligadas a desfechos cardiovasculares de risco máximo, quando associadas a doentes renais crônicos dialíticos ${ }^{82,86}$.

Notamos aqui também que as alterações da estrutura miocárdica têm um papel importante no quesito referente à disfunção sistólica do VE, e o fato de esses pacientes já apresentarem em sua fase inicial HAS e alguma repercussão miocárdica contribui diretamente para essas alterações.

A incidência de alteração de $\mathrm{AD}$ foi baixa (menor que $10 \%$ ), predominando no $2^{\mathrm{o}}$ semestre. Devido a sua baixa incidência, não submetemos esses dados a análises de fatores de risco. Porém este trabalho sinalizou a baixa incidência de alterações estruturais no $1^{\mathrm{o}}$ ano de hemodiálise. A quase ausência de arritmias supraventriculares nos dois grupos suporta esses dados.

A literatura mostra que a FA se associa mais frequentemente a alterações estruturais atriais ${ }^{1,2}$, porém este projeto mostrou que as alterações de estrutura preditoras de gatilhos de FA foram, principalmente, às relacionadas com alterações de volume e diâmetros ventriculares. Esse dado deve ser interpretado à luz da população analisada. Acreditamos que as alterações estruturais refletiram mais as alterações das comorbidades de base (HAS e IRC terminal com sobrecarga de volume) do que alterações estruturais específicas para FA 1, 2,3, 7, 56, 78 .

A diástole inicia-se com o fechamento da valva aórtica e termina com o fechamento da valva mitral e início da sístole ventricular. Ela é composta por quatro fases: relaxamento isovolumétrico, enchimento rápido, diástase e contração atrial. A função diastólica do ventrículo esquerdo é determinada por relaxamento ventricular (um processo que consome energia), enchimento da cavidade, propriedades elásticas 
passivas do ventrículo e frequência cardíaca, a qual tem importância fundamental, uma vez que seu aumento reduz desproporcionalmente o tempo de enchimento diastólico. A disfunção diastólica caracteriza-se por aumento das pressões de enchimento, resultando em dispneia, inicialmente na realização de esforços, podendo tornar-se progressiva até quadros de insuficiência cardíaca diastólica. $\mathrm{O}$ aumento do volume diastólico está ligado à incomplacência, à insuficiência e à dilatação do ventrículo. Essas alterações são mais frequentes em pacientes portadores de miocardiopatias dilatadas e de distúrbio da condução elétrica por modificação celular e molecular do miócito alterando o acoplamento de actina e miosina e sua polaridade de membrana ${ }^{82}$.

A remodelação cardíaca é definida como um conjunto de mudanças moleculares, celulares e intersticiais cardíacas, que se manifestam clinicamente por alterações no tamanho, massa, geometria e função do coração em resposta à determinada agressão. Esse processo resulta em mau prognóstico, pois está associado à progressão da disfunção ventricular e arritmias malignas ${ }^{86}$. Interessantemente alterações estruturais de $\mathrm{AD}$ pouco foram encontradas o que parece se contrapor à literatura que aponta ser o AD forte risco para FA. As alterações estruturais mais encontradas em nossos pacientes foram as de câmaras esquerdas, enfatizando o maior comprometimento do coração pela longa epidemiologia hipertensiva dos pacientes e queda da função renal do que especificamente alterações de câmaras direitas. A hipertensão arterial é o fator de risco mais prevalente e modificável para FA $^{1,2}$. A hipertensão arterial sistêmica (HAS) aumenta a pressão diastólica final do ventrículo esquerdo (VE) e induz a disfunção diastólica do VE, o que, posteriormente, aumenta a pressão do átrio esquerdo (AE) e em cujas paredes provoca estresse. A sobrecarga de pressão no átrio esquerdo induz alterações fisiopatológicas, as quais provocam uma remodelação estrutural e funcional. Essas mudanças alteram as características eletrofisiológicas do VE e aumentam a atividade atrial ectópica culminando no início dos ataques de fibrilação atrial paroxística (FAP). O aumento da morbidade e mortalidade da FA requer a previsão dessa arritmia nas fases iniciais da doença. A câmara do AE não é apenas um simples espaço de transporte, mas também uma estrutura dinâmica. A função do AE inclui a expansão do $\mathrm{AE}$ durante a sístole do $\mathrm{VE}$ (fase de reserva), esvaziamento atrial 
esquerdo passivo (fase condutiva) e ativo (fase contrátil ou de propulsão) durante a diástole precoce e tardia do $\mathrm{VE}^{5,9}$. Imagens de Doppler tecidual e bidimensional têm sido utilizadas com sucesso em diferentes fases do ciclo cardíaco para medir o volume e as diversas outras funções do $\mathrm{AE}^{10,11}$. O volume e a dimensão do $\mathrm{AE}$ têm sido apontados como preditores da FA ${ }^{12,14}$. Além disso, a função do $\mathrm{AE}$ pode deteriorar-se antes do aumento do AE. Nosso estudo mostrou que a população estudada já apresentava, em sua maioria, HAS e que, muito provavelmente, já recebia influência desses fatores de interferência em câmaras atriais, principalmente no átrio esquerdo, ainda que não tenham sido detectados em exames iniciais como ECG de repouso e ecocardiograma.

Limitações do estudo: o fato de este estudo ter sido realizado numa população em terapia renal de substituição (hemodiálise) até um ano poderia ter sido um fator de limitação nos resultados, já que nesses pacientes os fatores preditores vistos na literatura poderiam ter sido mascarados por alguns mecanismos de compensação. No entanto esse era o objetivo deste projeto no intuito de abrir uma possibilidade real para que os gatilhos eletrofisiológicos como arritmias, alterações estruturais, metabólicas e sociodemográficas (principalmente pacientes mais idosos), fossem observados e tratados precocemente em pacientes dialíticos. Outros fatores contribuíram para a limitação da pesquisa: a escassez de vagas SUS em clínicas e serviços hospitalares em razão de mudanças nas políticas de saúde ocorridas entre 2017 e 2018, a não concordância pelos pacientes em realizar o Holter por 48h (entre 2 sessões de diálise) e, principalmente, pela baixa rotatividade de pacientes novos nos serviços utilizados.

O presente estudo sugere novas propostas de acompanhamento do paciente renal crônico - realização, no início da terapia, de ecocardiograma no $1^{\circ}$ e $2^{\circ}$ semestres, acompanhamento detalhado através de ECG de repouso frequente, a fim de visualizar episódios de arritmias ventriculares tipo ESV, além de possível implantação de estudo com Holter 24 a $48 \mathrm{~h}$ no primeiro ano da terapia substitutiva renal.

Alterações estruturais, elétricas e metabólicas comuns no paciente renal crônico dialítico podem, de fato, ser diagnosticadas precocemente no $1^{\mathrm{o}}$ ano de 
hemodiálise e controladas, segundo os resultados e impressões percebidos durante este estudo, minimizando as possibilidades de futuras sequelas, sobretudo de ordem embólica, suscitadas por arritmas, notadamente, a Fibrilação Atrial (FA).

A continuidade do estudo faz-se fundamental para melhor compreensão dessas arritmias em pacientes dialíticos, pela necessidade de se determinar a positividade de outras variáveis, portanto imprescindível na elaboração de propostas preventivas de atuação do profissional médico. 


\section{CONCLUSÕES}




\section{CONCLUSÕES}

Os dados desse estudo sugerem que, na população analisada, os pacientes com função renal crônica terminal, no primeiro ano de início de terapia hemodialítica, mostram que o momento de aparecimento de fatores preditores de Fibrilação Atrial ocorre preferentemente durante o $7^{\circ}$ e o $12^{\circ}$ mês pós-início de hemodiálise.

\section{Preditores Elétricos:}

- $\quad$ - ESV foi a arritmia preditora de FA mais frequente em ambos os grupos.

- $\quad$ - A prevalência de ESV dobra no $2^{\circ}$ semestre atingindo quase metade dos pacientes pós início de hemodiálise.

- - O aumento do intervalo QT é a segunda alteração mais frequente, atingindo $25 \%$ dos pacientes no $1^{\circ}$ semestre e $40 \%$ dos pacientes no $2^{\circ}$ semestre de início de hemodiálise.

- - O melhor exame para detectar precocemente preditores de FA é o Holter e deve ser indicado, principalmente, no $2^{\circ}$ semestre pós-início de hemodiálise, o ECG não é um bom exame para diagnóstico precoce de preditores de FA.

\section{Preditores Estruturais:}

As alterações estruturais cardíacas ocorreram predominantemente no $2^{\circ}$ semestre do início da hemodiálise, tendo as ventriculares alcançado quase $50 \%$ dos participantes no período entre 7 e 12 meses pós-início de hemodiálise. Até 6 meses do início da hemodiálise os pacientes apresentaram, em sua maioria, estrutura cardíaca normal. 
- A alteração estrutural mais frequente associada aos gatilhos eletrofisiológicos foram as ventriculares esquerdas, caracterizadas por alteração dos volumes diastólicos e sistólicos ventriculares, sugerindo relação também com a HAS de base do paciente e a Cardiopatia urêmica. Elas ocorrem predominantemente a partir do $7^{\circ}$ mês de início da terapia dialítica e são fatores de risco de até 10 vezes para gatilhos de FA.

- As alterações dos diâmetros ventriculares tanto diastólicos quanto sistólicos atingiram até $1 / 3$ da população analisada no $2^{\circ}$ semestre pós-hemodiálise e foram fatores de risco de quase 4x para alteração elétrica do intervalo QT.

\section{Preditores sociodemográficos:}

- Idade foi o fator de risco mais forte e mais prevalente perante os gatilhos eletrofisiológicos. Acreditamos que esse fator espelha o tempo de degeneração contínua e silente cardiovascular secundária à hipertensão e à vasculopatia.

- Tempo de diálise foi fator de risco para gatilhos eletrofisiológicos nas análises univariadas. Porém, após ajuste de fatores, esse fator não se caracterizou como preditor, perdendo sua significância frente ao ajuste com a variável idade e volume ventricular. Acreditamos que esse fator possa estar mascarado pelo fator idade e morbidades cardiovasculares, visto que a terapia dialítica traduz lesão de órgão alvo no caso da HAS.

- A amostra do estudo foi por conveniência, porém traz dados que suportam a evidência que o $2^{\circ}$ semestre pós-início de hemodiálise é o período adequado para diagnóstico precoce de alterações de preditores de FA, alterações de condução elétrica, em especial intervalo QT, e alterações estruturais cardíacas, provavelmente, secundárias

à

HAS

crônica.

\section{Laboratoriais:}

Os eletrólitos Cálcio, bicarbonato e magnésio foram alterados principalmente pré 
hemodiálise no $1^{\circ}$ semestre do início do procedimento sugerindo a eficácia do método dialítico.

Nenhum eletrólito se manteve como fator de risco para gatilhos eletrofisiológicos após o ajuste de covariáveis. 
7 ANEXOS 


\title{
APROVAÇÃO DO PROFESSOR TITULAR DO DEPARTAMENTO DE CLÍNICA MÉDICA-FMUSP
}
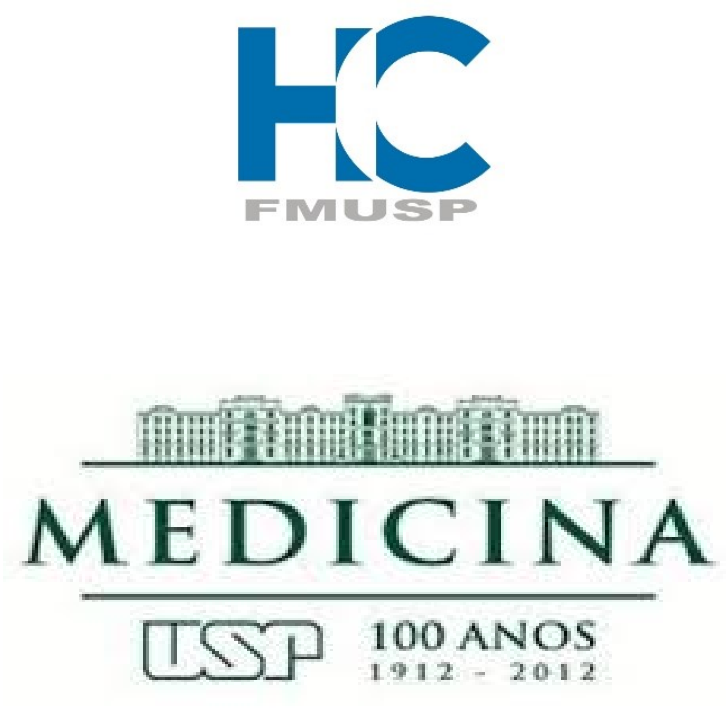

Declaração

Declaro que li e aprovo o estudo " Alterações eletrocardiográficas preditoras de fibrilação atrial (FA) em pacientes com doença renal crônica que iniciaram programa de hemodiálise. Estudo longitudinal de 1 ano do Dr. Silvio Luiz Priori, sob orientação da Profa Dra Maria Lúcia Bueno Garcia, no período de março de 2015 e dezembro de 2016, a ser desenvolvido no Serviço de Clínica Geral do HCFMUSP.

São Paulo, 25 de fevereiro de 2015

\author{
Prof Dr Milton Arruda Martins \\ Professor Titular \\ Disciplina de Clínica Geral
}

Faculdade de Medicina da Universidade de São Paulo 
$26 / 10 / 2020$

Janus - Sistema Administrativo da Pós-Graduação

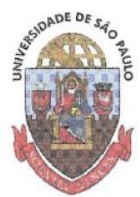

Universidade de São Paulo

Faculdade de Medicina

FICHA DO ALUNO

5165 - 10577097/1 - Silvio Luiz Priori

Email:

silvio.priori@fm.usp.br

Data de Nascimento:

16/12/1963

Cédula de Identidade: $\quad$ RG - 13.015.691-7 - SP

Local de Nascimento: $\quad$ Estado de São Paulo

Nacionalidade: Brasileira

Graduação: $\quad$ Médico - Universidade do Oeste Paulista - São Paulo - Brasil - 1993

Curso: $\quad$ Mestrado

Programa: $\quad$ Ciências Médicas

Área:

Processos Inflamatórios e Alérgicos

Data de Matrícula:

22/08/2017

Início da Contagem de Prazo: $\quad$ 22/08/2017

Data Limite para o Depósito: 18/02/2021

Orientador:

Prof(a). Dr(a). Sergio Paulo Bydlowski - 22/08/2017 até 05/10/2017. Email: spbydlow@usp.br

Orientador:

Prof(a). Dr(a). Maria Lucia Bueno Garcia - 06/10/2017 até o presente. Email: maria.garcia@fm.usp.br

Proficiência em Línguas:

Inglês, Aprovado em 22/08/2017

Data de Aprovação no Exame de

Qualificação:

Aprovado em 12/02/2019

Data do Depósito do Trabalho:

Título do Trabalho:

Data Máxima para Aprovação da

Banca:

Data de Aprovação da Banca:

Data Máxima para Defesa:

Data da Defesa:

Resultado da Defesa:

Histórico de Ocorrências:

Primeira Matrícula em 22/08/2017

Aluno matriculado no Regimento da Pós-Graduação USP (Resolução nº 6542 em vigor de 20/04/2013 até 28/03/2018).

Última ocorrência: Matrícula de Acompanhamento em 27/07/2020

Impresso em: 26/10/2020 12:23:36 
$26 / 10 / 2020$

Janus - Sistema Administrativo da Pós-Graduação

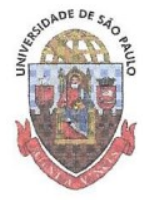

Universidade de São Paulo

Faculdade de Medicina

FICHA DO ALUNO

5165 - 10577097/1 - Silvio Luiz Priori

\begin{tabular}{|c|c|c|c|c|c|c|c|c|c|}
\hline Sigla & Nome da Disciplina & Início & Término & $\begin{array}{l}\text { Carga } \\
\text { Horária }\end{array}$ & Cred. & Freq. & Conc. & Exc. & Situação \\
\hline$\underset{4 / 1}{\text { MCM588- }}$ & Bioestatística I & 06/03/2018 & $30 / 04 / 2018$ & 120 & 8 & 100 & A & N & Concluída \\
\hline$\underset{2 / 4}{\operatorname{MCM} 5901-}$ & Avaliação Didática de Projetos & $02 / 04 / 2018$ & $15 / 07 / 2018$ & 60 & 4 & 100 & A & N & Concluída \\
\hline $\begin{array}{l}\text { MAN5739- } \\
1 / 2\end{array}$ & $\begin{array}{l}\text { Gestão e Desenvolvimento de Estudos } \\
\text { Multicêntricos em Pesquisa Clínica: Normas } \\
\text { Regulatórias e Aplicação Prática }\end{array}$ & $01 / 05 / 2018$ & $14 / 05 / 2018$ & 30 & 2 & 100 & A & $\mathrm{N}$ & Concluída \\
\hline$\underset{3 / 4}{\operatorname{MCM} 5884-}$ & $\begin{array}{l}\text { Educação Médica: Avaliação de Habilidades e } \\
\text { Atitudes }\end{array}$ & $14 / 05 / 2018$ & $10 / 06 / 2018$ & 60 & 0 & - & - & $\mathrm{N}$ & $\begin{array}{l}\text { Matrícula } \\
\text { cancelada }\end{array}$ \\
\hline$\underset{5 / 3}{\operatorname{MPR} 5720-}$ & Estudos Epidemiológicos Transversais & $06 / 08 / 2018$ & 09/09/2018 & 45 & 0 & - & - & N & $\begin{array}{l}\text { Matrícula } \\
\text { cancelada }\end{array}$ \\
\hline$\underset{6 / 3}{\operatorname{MCM} 5745-}$ & Pesquisa Avançada em Doença Renal Crônica & $07 / 08 / 2018$ & $03 / 09 / 2018$ & 60 & 4 & 100 & A & $\mathrm{N}$ & Concluída \\
\hline $\begin{array}{l}\text { MGT5771- } \\
2 / 1\end{array}$ & $\begin{array}{l}\text { Redação de Trabalho Cientifico em } \\
\text { Gastroenterologia: da Idéia à Publicação }\end{array}$ & $13 / 08 / 2018$ & $26 / 08 / 2018$ & 60 & 4 & 100 & A & $\mathrm{N}$ & Concluída \\
\hline
\end{tabular}

\begin{tabular}{|c|c|c|c|}
\hline & \multicolumn{2}{|c|}{ Créditos mínimos exigidos } & \multirow{2}{*}{\begin{tabular}{|l|} 
Créditos obtidos \\
\end{tabular}} \\
\hline & Para exame de & o da dissertação & \\
\hline Disciplinas: & 8 & 16 & 22 \\
\hline \multicolumn{4}{|l|}{ Estágios: } \\
\hline Total: & 8 & 16 & 22 \\
\hline
\end{tabular}

Créditos Atribuídos à Dissertação: 80

Conceito a partir de 02/01/1997:

A - Excelente, com direito a crédito; B - Bom, com direito a crédito; C - Regular, com direito a crédito; R - Reprovado; T Transferência.

Um(1) crédito equivale a 15 horas de atividade programada.

Última ocorrência: Matrícula de Acompanhamento em 27/07/2020

Impresso em: 26/10/2020 12:23:36 


\section{FACULDADE DE MEDICINA DA UNIVERSIDADE DE SÃO PAULO TERMO DE CONSENTIMENTO LIVRE E ESCLARECIDO}

\section{DADOS DE IDENTIFICAÇÃO DO SUJEITO DA PESQUISA OU RESPONSÁVEL LEGAL}

1. NOME:

DOCUMENTO DE IDENTIDADE $\mathrm{N}^{\circ}$ SEXO: $\mathrm{M}(\quad) \mathrm{F}($ )

DATA NASCIMENTO:

ENDEREÇO:

BAIRRO:

CIDADE:

CEP:

TELEFONE: DDD (

2. RESPONSÁVEL LEGAL:

NATUREZA (grau de parentesco, tutor, curador etc.):

DOCUMENTO DE IDENTIDADE: SEXO: M ( ) F ( )

DATA NASCIMENTO:

ENDEREÇO:

BAIRRO:

CIDADE:

CEP:

TELEFONE: DDD

\section{DADOS SOBRE A PESQUISA}

1. TÍTULO DO PROTOCOLO DE PESQUISA: Alterações Eletrocardiográficas preditoras de fibrilação atrial, em pacientes com doença renal crônica que iniciaram programa de hemodiálise. Estudo longitudinal de 1 ano.

2. PESQUISADOR: SLVIO LUIZ PRIORI

CARGO/FUNÇÃO: MÉDICO MEDICINA No 79180

INSCRIÇÃO CONSELHO REGIONAL

UNIDADE DO HCFMUSP: Departamento de Eletrocardiograma do HCFMUSP 
3. AVALIAÇÃO DO RISCO DA PESQUISA:

\begin{tabular}{|c|c|}
\hline RISCO MÍNIMO ( X ) & RISCO MÉDIO \\
\hline RISCO BAIXO ( ） & RISCO MAIOR \\
\hline
\end{tabular}

4. DURAÇÃO DA PESQUISA: 1 (um) ano 


\section{FACULDADE DE MEDICINA DA UNIVERSIDADE DE SÃO PAULO}

1. Essas informações estão sendo fornecidas para sua participação voluntária neste estudo, que visa verificar o risco de arritmias cardíacas relacionado com a sessão de hemodiálise;

2. Será instalado o aparelho de Holter, através de eletrodos (adesivos) no tórax, onde serão acoplados cabos (fios) a uma caixa contendo um gravador. Este aparelho será instalado no dia da sessão de hemodiálise e retirado após o término da sessão seguinte de hemodiálise. O procedimento ocorrerá durante 2(dois) dias $(48$ h) - período em que o aparelho ficará instalado. Será realizado antes e depois da sessão de hemodiálise eletrocardiograma de 12 derivações - exame sem riscos realizado com paciente deitado, conectado com fios a um aparelho gerador, que fornecerá traçados (desenhos) em um papel sulfite.

3. A coleta de sangue seguirá a rotina da unidade de diálise e os dados serão coletados para a pesquisa. Será realizado um exame de ecocardiograma: exame não invasivo que capta imagem ultrassonográfica do coração, através de um transdutor (cabo), sem riscos à integridade do paciente.

4. O desconforto com os eletrodos e cabos instalados no tórax é mínimo e não impede a movimentação e as atividades diárias. Será impedido apenas o banho e também dormir de bruços (de barriga para baixo).

5. A coleta de sangue se dará por punção venosa (tirar sangue) de veias periféricas (preferencialmente do braço), com agulhas finas e riscos mínimos ao paciente.

6. O participante poderá se beneficiar em caso de presença de arritmia cardíaca que necessite tratamento específico, além de ter o coração avaliado através do ecocardiograma, o qual poderá auxiliar no manejo terapêutico.

7. Em qualquer etapa do estudo, você terá acesso aos profissionais responsáveis pela pesquisa para esclarecimento de eventuais dúvidas. O principal investigador é o Dr. Silvio Luiz Priori. Se você tiver alguma consideração ou dúvida sobre a ética da pesquisa, entre em contato com o Comitê de Ética em 
Pesquisa da Faculdade de Medicina da Universidade de São Paulo (CEPFMUSP): Av. Dr. Arnaldo, 251 - Cerqueira César - São Paulo - SP -21º andar - sala 36- CEP: 01246-000 Tel: 3893-4401/4407 E-mail: cep.fm@usp.br

8. É garantida a liberdade da retirada de consentimento a qualquer momento e desistência de participação no estudo, sem qualquer prejuízo à continuidade de seu tratamento na Instituição;

9. Direito de confidencialidade: as informações obtidas serão analisadas em conjunto com outros pacientes, não sendo divulgada a identificação de nenhum paciente;

10. Direito de ser mantido atualizado sobre os resultados parciais das pesquisas, quando em estudos abertos, ou de resultados que sejam do conhecimento dos pesquisadores;

11. Despesas e compensações: não há despesas pessoais para o participante em qualquer fase do estudo, incluindo exames e consultas. Também não há compensação financeira relacionada à sua participação. Se existir qualquer despesa adicional, ela será absorvida pelo orçamento da pesquisa.

12. Compromisso do pesquisador de utilizar os dados e o material coletado somente para esta pesquisa.

Acredito ter sido suficientemente informado a respeito das informações que li ou que foram lidas para mim, descrevendo o estudo "Preditores Eletrocardiográficos de Fibrilação Atrial em pacientes com Insuficiência Renal Crônica terminal relacionados à sessão de hemodiálise"

Eu discuti com o Dr. Silvio Luiz Priori sobre a minha decisão em participar deste estudo. Ficaram claros para mim quais são os propósitos do estudo, os procedimentos a serem realizados, os desconfortos e riscos, as garantias de confidencialidade e de esclarecimentos permanentes. Ficou claro também que minha participação é isenta de despesas e que tenho garantia do acesso a tratamento hospitalar quando necessário. Concordo voluntariamente em participar deste estudo e poderei retirar o meu 
consentimento a qualquer momento, antes ou durante o mesmo, sem penalidades, prejuízo ou perda de qualquer benefício que eu possa ter adquirido no meu atendimento neste Serviço.

Assinatura do paciente/representante legal

Data

11

Assinatura da testemunha

Data

Para casos de pacientes menores de 18 anos, analfabetos, semi-analfabetos ou portadores de deficiência auditiva ou visual.

(Somente para o responsável do projeto)

Declaro que obtive de forma apropriada e voluntária o Consentimento Livre e Esclarecido deste paciente ou representante legal para a participação neste estudo. 


\section{chly}

UNIDADE DE NEFROLOGIA DE OSASCO

Dr. Washington Luiz Correia

CRM 19.729

A Unasco

(Unidade de Nefrologia de Osasco)

Autoriza aos Drs. Silvio Luiz Priopi

E Ronaldo Rabello, a realizarem

Estudos de doenças cardiovasculares

Nos nossos pacientes portadores de

Doença Renal Crônica em programa

De Hemodiálise

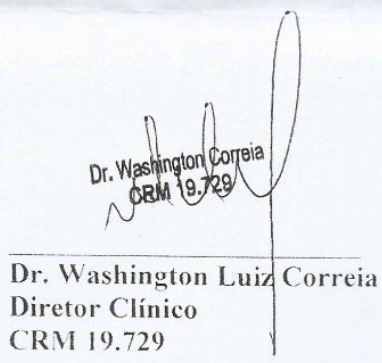

Watter M. Arteage Nefrotogitas CRM 20025

Dr. Washington Luiz Correia

Dr. Walter Martinez Arteaga

CRM 19.729

Coordenador Médico

CRM 100.225 


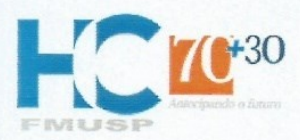

\author{
INSTITUTO CENTRAL \\ HOSPITAL DAS CLÍNICAS DA \\ FACULDADE DE MEDICINA DA UNIVERSIDADE DE SÃo PAULO \\ AV. DR. ENÉAS DE CARVALHO AGUIAR, 255 \\ CEP 05403-900 SĀO PAULO - BRASIL
}

\title{
DECLARAÇÃO
}

Declaro para os devidos fins que o Serviço de Eletrocardiografia do HCFMUSP está em anuência com o Dr. Silvio Luiz Priori com a cessão de aparelhos Holter, na Pesquisa Clínica Alteraçōes Eletrocardiográficas preditoras de Fibrilação Atrial (FA) em pacientes com doença renal crônica.

Durante a vigência do estudo. O pesquisador terá todo apoio necessário para sua realização, conforme previamente acordado.

Atenciosamente,

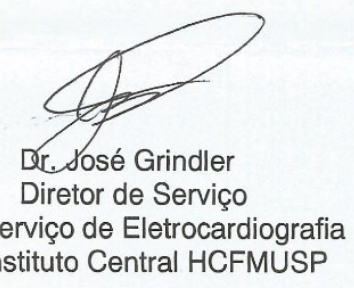




\section{PREFEITURA DO MUNICÍPIO DE OSASCO}

SECRETARIA DA SAÚDE

HMCO

HOSPITAL MUNICIPAL CENTRAL DE OSASCO

RUA PEDRO FIORETTI, 48 - CENTRO - OSASCO / SP CEP 06013-070

TEL. 2183-9300 FAX. 2183-9367

Osasco, março de 2015.

D E C L A R A Ç Â O D E A N UÊ N C I A

Eu, Dr. Aguinaldo Fernando Neto - CRM 66.161 - Coordenador do setor de Ecocardiografia do Hospital Municipal Antonio Giglio (HMAG), declaro para devidos fins, que realizarei os exames de ecocardiograma dos pacientes da pesquisa Fibrilação Atrial em Pacientes Renal Crônico em Programa de Hemodiálise, realizada pelos doutores, Silvio Luiz Priori e Ronaldo Rabelo.

Atenciosamente

Dr. Aguinaldo Fernando Neto

Coordenador do setor de Ecocardiografia

HMAG 


\section{REFERÊNCIAS}




\section{REFERÊNCIAS}

1. Zimerman LI, Fenelon G, Martinelli Filho M, Grupi C, Atié J, Lorga Filho A, D’Ávila A, Paola A, Peres AK, Moreira D, Saad E, Sosa E, Sternick E, God EMG, Darrieux F, Pachón JC, Oliveira JC, Silva LB, Magalhães L, Montera M, Fagundes M, Silva MA, Scanavacca M, Alkimin R, Rassi S, Maciel W. Sociedade Brasileira de Cardiologia. Diretrizes Brasileiras de Fibrilação Atrial. Arq Bras Cardiol. 2009;92(6 supl.1):1-39.

2. Magalhães LP, Figueiredo MJO, Cintra FD, Saad EB, Kuniyoshi RR, Teixeira RA, Lorga Filho AM, D’Avila A, de Paola AAV, Kalil CA, Moreira DAR, Sobral Filho DC, Sternick EB, Darrieux FCC, Fenelon G, Lima GG, Atié J, Mateos JCP, Moreira JM, Vasconcelos J. II Diretrizes Brasileiras de Fibrilação Atrial. Arq Bras Cardiol. 2016;106(4Supl.2):1-22.

3. Wanderley APB, Rigolon LPJ. Atualizações em fibrilação atrial - 2016. Blog Medportal. Disponível em www.medportal.com.br/bloq

4. Fenelon G, De Paola AAV. Novas ideias sobre os mecanismos eletrofisiológicos da fibrilação atrial e suas implicações terapêuticas. Reblampa. Revista Brasileira e Latino-Americana de Marcapasso e Arritmia. 2000;13(1):5-12.

5. Peres LAB, Luiz AA, Espiga MC, Spivakoski CS. Fibrilação atrial em pacientes crônicos em hemodiálise. Rev Bras Clin Med. São Paulo, 2012;10(6):4825.

6. Lordsleem A, Gueiros APS, Gueiros JEB, Markman Filho B, Victor EG. Avaliação cardiológica de pacientes portadores de doença renal crônica: quais as lições?.J Bras Nefrol. 2012;34(1):8-15.

7. Lip GYH. Chronic renal disease and stroke in atrial fibrillation: balancing the prevention of thromboembolism and bleeding risk. Europace. 2010;13(2):145-8. 
8. McMichael J. History of atrial fibrillation 1628-1819 - Harvey - de Senac Laennec. Br Heart J. 1982;48(3):193-7.

9. Laennec RTH. De 1'auscultationmédiate. Paris: Brosson \& Chaudé; 1819.

10. Vulpian A. Note sur les effets de la faradisationdirecte des ventriculae du coeur chez le chien. Arch Physiol Normale Pathol. 1847;6:975.

11. MacKenzie J. The venous and liver pulses and the arrhythmic contraction of the cardiac cavities. J Pathol Bact. 1894;2:84-254.

12. Silverman ME. From rebellious palpitation to the discovery of auricular fibrillation: contributions of Mackenzie, Lewis and Einthoven. Am J Cardiol. 1994;73(5):384-9.

13. Hering HE. Analysedespulsusirregularisperpetuus. Prager Med Wchnschr. 1903;38:377-81.

14. Lewis T. Evidences of auricular fibrillation, treated historically. Br Med J. 1912;13:57-60.

15. Rensma PL, Allessie MA, Lammers WJ, Bonke FI, Schalij MJ. The length of the excitation wave and susceptibility to reentrant atrial arrythmias in normal conscious dogs. Circ Res. 1988;62(2):395-410.

16. Fenelon G, Brugada P. What can be learned from electrophysiological studies of atrial fibrillation? Eur JCPE. 1995;5:97-100.

17. Kannel WB, Wolf PA, Benjamin EJ, Levy D. Prevalence, incidence, prognosis, and predisposing conditions for atrial fibrillation: population-based estimates. Am J Cardiol. 1998;82(8A):2N-9N.

18. Moe GK. Abildskov JA. Atrial fibrillation as a self sustaining arrhythmia independent of focal discharge. Am Heart J. 1959;58(1):59-70. 
19. Falk R. Etiology and complications of atrial fibrillation: insights from pathology studies. Am J Cardiol. 1998;82:10N-17N.

20. Li D, Fareh S, Leung TK, Nattel S. Promotion of atrial fibrillation by heart failure in dogs: atrial remodeling of a different sort. Circulation. 1999;100(1):87-95.

21. de Paola AAV, Veloso HH, Figueiredo E, Melo WDS. Fibrilação atrial. Rev Soc Cardiol Estado de São Paulo. 1998;8(1):46-56.

22. Rensma P, Allessie MA, Lammers WJ, Bonke FI, Schalij MJ. Length of the excitation wave and susceptibility to reentrant atrial arrhythmias in normal conscious dogs. Circ Res. 1988;62(2):395-410.

23. Gallagher M, Camm J. Classification of atrial fibrilation. Am J Cardiol. $1998 ; 82(8 \mathrm{~A}): 18 \mathrm{~N}-28 \mathrm{~N}$.

24. Wijffels MC, Kirchhof C, Dorland R, Allessie MA. Atrial fibrillation begets atrial fibrillation. A study in awake chronically instrumented goats. Circulation. 1995;92(7):1954-68.

25. Tieleman RG, De Langen C, Van Gelder IC, de Kam PJ, Grandjean J, Bel KJ, Wijffels MC, Allessie MA, Crijns HJ. Verapamil reduces tachycardia-induced electrical remodeling of the atria. Circulation. 1997;95(7):1945-53.

26. Heinisch RH, Leal FM, Heinisch LMM. Atualização em fibrilação atrial. Arquivos Catarinenses de Medicina. 2013;42(2):93-99.

27. Daoud EG, Knight BP, Weiss R, Bahu M, Paladini W, Goyal R, Man KC, Strickberger SA, Morady F. Effect of verapamil and procainamide on atrial fibrillation-induced electrical remodeling in humans. Circulation. 1997;96(5):154250. 
28. Tieleman RG, Van Gelder IC, Crijns HJ, De Kam PJ, Van Den Berg MP, Haaksma J, Van Der Woude HJ, Allessie MA. Early recurrences of atrial fibrillation after electrical cardioversion: a result of fibrillation-induced electrical remodeling of the atria? J Am Coll Cardiol. 1998;31(1):167-73.

29. Sanfilippo AJ, Abascal VM, Sheehan M, Oertel LB, Harrigan P, Hughes RA, Weyman AE. Atrial enlargement as a consequence of atrial fibrillation. A prospective echocardiographic study. Circulation. 1990;82(7):792-7.

30. Goette A, Honeycutt C, Langberg JJ. Electrical remodeling in atrial fibrillation. Time course and mechanisms. Circulation. 1996;94(11):2968-74.

31. Kopecky S, Gersh B, McGoon M, Whisnant JP, Holmes DR Jr, Iilstrup DM, Frye RL. The natural history of lone atrial fibrillation: A population-based study over three decades. N Engl J Med. 1987;317(11):669-74.

32. Scherf D. Studies on auricular tachycardia caused by aconitine administration. Proc Soc Exp Biol Med. 1947;64(2):233-9.

33. Jais P, Haissaguerre M, Shah DC, Chouari S, Gencel L, Hocini M, Clémenty J. A focal source of atrial fibrillation treated by discrete radiofrequency ablation. Circulation. 1997;95(3):572-6.

34. Haissaguerre M, Jais P, Shah D, Takahashi A, Hocini M, Quiniou G, Garrigue S, Le Mouroux A, Le Métayer P, Clémenty J. Spontaneous initiation of atrial fibrillation by ectopic beats originating in the pulmonary veins. N Engl J Med. 1998;339(10):659-66.

35. Stambler B S. Shepard R K. Turner D A. Fenelon G. Chronic atrial dilatation induces prolongation of atrial refractoriness and atrial tachyarrhythmias. J Am Coll Cardiol. 1997;29:63A(Abstract). 
36. Fenelon G. Shepard RK. Turner DA. et al. Evidence of a focal origin as the mechanism of atrial tachycardia in dogs with ventricular pacing-induced congestive heart failure. PACE 1997;20:1095(Abstract).

37. Coumel P. Neural aspects of paroxysmal atrial fibrillation. In: Falk R, Podrid PJ, ed. Atrial Fibrillation: Mechanisms and Management. New York: Raven Press; 1992. p.109-26.

38. Frustaci A, Chimenti C, Bellocci F, Morgante E, Russo MA, Maseri A. Histologic substrate of atrial biopsies in patients with lone atrial fibrillation. Circulation. 1997;96(4):1180-4.

39. Wijffels MC, Kirchhof C, Dorland R, Allessie MA. Atrial fibrillation begets atrial fibrillation. A study in awake chronically instrumented goats. Circulation. 1995;92(7):1954-68.

41. Wiener N. Rosenblueth A. The mathematical formulation of the problem of conduction of impulses in a network of connected excitable elements, specifically in cardiac muscle. Arch Inst Cardiol Mex. 1946;16(3):205-65.

40. Kirchhof P, Lip GY, Van Gelder IC, Bax J, Hylek E, Kaab S, Schotten U, Wegscheider K, Boriani G, Brandes A, Ezekowitz M, Diener H, Haegeli L, Heidbuchel H, Lane D, Mont L, Willems S, Dorian P, Aunes-Jansson M, Blomstrom-Lundqvist C, Borentain M, Breitenstein S, Brueckmann M, Cater N, Clemens A, Dobrev D, Dubner S, Edvardsson NG, Friberg L, Goette A, Gulizia M, Hatala R, Horwood J, Szumowski L, Kappenberger L, Kautzner J, Leute A, Lobban T, Meyer R, Millerhagen J, Morgan J, Muenzel F, Nabauer M, Baertels C, Oeff M, Paar D, Polifka J, Ravens U, Rosin L, Stegink W, Steinbeck G, Vardas P, Vincent A, Walter M, Breithardt G, Camm AJ. Comprehensive risk reduction in patients with atrial fibrillation: emerging diagnostic and therapeutic options - a report from the 3rd Atrial Fibrillation Competence NETwork/European Heart Rhythm Association consensus conference. Europace. 2012;14(1):8-27. 
42. Dagres N, Anastasiou-Nana M. Atrial fibrillation and obesity. J Am Coll Cardiol. 2010;55(21):2328-9.

43. Tedrow UB, Conen D, Ridker PM, Cook NR, Koplan BA, Manson JE, Buring JE, Albert CM. The long- and short-term impact of elevated body mass index on the risk of new atrial fibrillation the WHS (women's health study). J Am Coll Cardiol. 2010;55(21): 2319-27.

44. Baranchuk A. Sleep apnea, cardiac arrhythmias, and conduction disorders. J Electrocardiol. 2012;45(5):508-12.

45. National Kidney Foundation. K/DOQI clinical practice guidelines for chronic kidney disease. Am J Kidney Dis. 2002;39(2 Suppl 1):S1-S246.

46. Romão Junior JE. Doença renal crônica: definição, epidemiologia e classificação. J Bras Nefrol. 2004;26(3 Suppl 1):1-3.

47. Romão Jr JE, Pinto SWL, Canziani ME, Praxedes JN, Santello JL, Moreira JCM. Censo SBN 2002: Informações epidemiológicas das unidades de diálise do Brasil. J Bras Nefrol. 2003;25:188-99.

48. Ministério da Saúde do Brasil, Secretaria de Assistência à Saúde. Estudo epidemiológico brasileiro sobre terapia renal substitutiva. Brasília (DF): Ministério da Saúde; 2002.

49 Zatz R, Romão Jr JE, Noronha IL. Nephrology in Latin America, with emphasis on Brazil. Kidney Int. 2003;63(Suppl 83):S131-S134.

50. Bastos MG, Kirsztajn GM. Doença renal crônica :importância do diagnóstico precoce, encaminhamento imediato e abordagem interdisciplinar estruturada para melhora do desfecho em pacientes ainda submetidos a diálise. J Bras Nefrol. 2011;33(1):93-108. 
51. Ministério da Saúde do Brasil, Programa HiperDia. Disponível em: http://hiperdia.datasus.gov.br, 29/03/2004.

53. National Kidney Foundation. K/DOQI clinical practice guidelines for chronic kidney disease. Am J Kidney Dis. 2002; 39(Suppl 1):S1-S246.

54. Bastos MG; Bregman R, Kirsztajn GM. Doença renal crônica: frequente e grave, mas também prevenível e tratável. Rev Assoc Med Bras. 2010;56(2):248-53.

55. Passos VMA, Barreto SM, Lima-Costa MFF; Bambui Health and Ageing Study (BHAS) Group. Detection of renal dysfunction based on serum creatinine levels in a Brazilian community. The Bambuí Health and Ageing Group. Braz J Med Biol Res. 2003;36(3):393-401.

56. Malachias MVB, Gomes MAM, Nobre F, Alessi A, Feitosa AD, Coelho EB. $7^{\mathrm{a}}$ Diretriz Brasileira de Hipertensão Arterial. Arq Bras Cardiol. 2016;107(3 Sup. 3):17-19.

57. Lip GYH, Beevers DG. ABC of atrial fibrillation. History, epidemiology and importance of atrial fibrillation. Br Med J. 1995;311(7016):1361-3.

58. McMichael J. History of atrial fibrillation 1628-1819 - Harvey - de Senac Laënnec. Br Heart J. 1982;48(3):193-7.

59. Castro-Torres Y, Carmona-Puerta R, Chavez-Gonzales E. Razão entre duração máxima e mínima da onda $\mathrm{P}$ (Pmax/Pmin): um novo preditor eletrocardiográfico para fibrilação atrial em pacientes com infarto agudo do miocárdio com supradesnivelamento ST. In J Cardiovasc Sci. 2016;29(5):370-7.

60. Salah A, Zhou S, Liu Q, Yan H. Índices de onda P na predição de recorrência de fibrilação atrial após isolamento da veia pulmonar. Arq Bras Cardiol. 2013;101(6): 519-27. 
61. Silva RMFL, Kazzaz NM, Torres RM, Moreira MCV. Dispersão da onda P e índice de volume do átrio esquerdo como preditores na insuficiência cardíaca. Arq Bras Cardiol. 2013;100(1):67-74.

62. United States Renal Data System (USRDS) - 2001 Annual Data Report. Am J Kidney Dis. 2002;37:S1-S189.

63. Moeller S, Gioberge S, Brown G. ESRD patients in 2001: Global overview of patients, treatment modalities and development trends. Nephrol Dial Transplant. 2002;17(12):2071-6.

64. Batista MC. Doença renal e fibrilação atrial não valvar. Encarte Científico da Bristol-Myers Squibb; 2014.

65. Friedmann AA, Grindler J. ECG. Eletrocardiologia básica. São Paulo: Sarvier; 2000.

66. Friedmann AA, Grindler J, Oliveira CAR. Diagnóstico diferencial no eletrocardiograma. São Paulo: Manole; 2007.

67. Friedmann AA. Eletrocardiograma em 7 aulas. Temas avançados e outros métodos. São Paulo: Manole; 2010.

68. Grindler J, Cardoso AF, Fonseca AJ, Oliveira CAR. Holter - 50 casos. São Paulo: Manole; 2016.

69. Benseñor I, Lotufo P. Epidemiologia clínica: abordagem prática. 2a edição. São Paulo: Sarvier; 2005.

70. Shahbaba B. Biostatistics with R: an introduction to statistics through biological data. 1a edição. New York: Springer; 2012.

71. Morettin P, Bussab W. Estatística Básica. 6a edição revista e atualizada. São Paulo: Editora Saraiva; 2014. 
72. Ross S. Probabilidade: um curso moderno com aplicações. 8a edição. Porto Alegre: Bookman; 2010.

73. Lip GYH, Beevers DG. ABC of atrial fibrillation. History, epidemiology and importance of atrial fibrillation. Br Med J. 1995;311:1361-3.

74. Brugada R, Tapscott T, Czernuszewicz GZ, Marian AJ, Iglesias A, Mont L, Brugada J, Girona J, Domingo A, Bachinski LL, Roberts R. Identification of a genetic locus for familial atrial fibrillation. N Engl J Med. 1997;336(13):905-11.

75. Burmeister JE, Mosmann CB, Costa VB, Saraiva RT, Grandi RR, Bastos JP, Gonçalves LP, Rosito GA. Estudo Cordial. Prevalência de Fatores de Risco Cardiovascular em Pacientes com Hemodiálise. Arq Bras Cardiol. 2014; 102(5):47380 .

76. Pastore CA, Pinho JA, Pinho C, Samesima N, Pereira-Filho HG, Kruse JCL, Paixão A, Pérez-Riera AR, Ribeiro AL, Oliveira CAR, Gomes CIG, Kaiser E, Galvão F, Darrieux FCC, França FFAC, Feitosa-Filho G, Germiniani H, Aziz JL, Leal MG, Molina M, Oliveira NMT, Oliveira PA, Sanches PCR. III Diretrizes da Sociedade Brasileira de Cardiologia sobre Análise e Emissão de Laudos Eletrocardiográficos. Arq Bras Cardiol. 2016;106(4 supl.1):1-38.

77. Bignotto LH, Kallás ME, Djouki RJT, Sassaki MM, Voss GO, Soto CL, Frattini F, Medeiros FS. Achados eletrocardiográficos em pacientes com doença renal crônica em hemodiálise. J Bras Nefrol. 2012;34(3):235-42.

78. Barberato SH, Pecoits-Filho R. Alterações ecocardiográficas em pacientes com insuficiência renal crônica em programa de hemodiálise. Arq Bras Cardiol. 2010;94(1):140-6.

79. Valentim B, Pereira A, Coelho P, Pereira T. Estudo da sístole elétrica ventricular nos insuficientes renais crônicos hemodialisados. Arq Bras Cardiol. 2013;100(3):261-8. 
80. Piccolli AP, Nascimento MM, Riella MC. Prevalência da doença renal crônica em uma população do sul do Brasil (estudo Pro-Renal). Braz J Nephrol. (J. Bras. Nefrol.) 2017;39(4):384-90.

81. Marinho AWGB, Penha AP, Silva MT, Galvão TF. Prevalência de doença renal crônica em adultos no Brasil: revisão sistemática da literatura. Cad Saúde Colet. Rio de Janeiro, 2017;25(3):379-88.

82. Araujo S, Lemes HP, Cunha DA, Queiroz VS, Nascimento DD, Ferreira Filho SR. Morfologia e função cardíacas em pacientes renais crônicos, com ou sem diurese residual, em tratamento hemodialítico. J Bras Nefrol. 2011;33(1):74-81.

83. Bignotto LH, Kallás ME, Djouki RJ, Sassaki MM, Voss GO, Soto CL, Frattini F, Medeiros FS. Alterações eletrocardiográficas em pacientes nefropatas crônicos em hemodiálise. Bras Nefrol. 2012;34(3):235-42.

84. Barcellos GA, Barcellos PT. Manifestações eletrocardiográficas de doenças não cardíacas. Revista da Sociedade de Cardiologia do Estado do Rio Grande do Sul. $2011 ; 19(21): 1-7$.

85. Rocha PN. Uso de bicarbonato de sódio na acidose metabólica do paciente gravemente enfermo. J Bras Nefrol. 2009;31(4):297-306.

86. Ammirati AL, Canziani MEF. Fatores de risco da doença cardiovascular nos pacientes com doença renal crônica. J Bras Nefrol. 2009;31(1 suppl.1):43-8.

87. Souto Maior A, Barbosa PRB, Barbosa Neto O, Mota GR, Marocolo Junior M. Canais iônicos de potássio associados à síndrome do QT longo adquirido. Rev Bras Cardiol. 2011;24(1):42-51.

88. Bonato FOB, Canziani MEF. Arritmia ventricular em pacientes com doenças renal crônica. J Bras Nefrol. 2017;39(2):186-95. 
89. Tenekecioglu E, Agca FV, Ozluk OA, Karaagac K, Demir S, Peker T, Kuzeytemiz M, Senturk M, Yilmaz M. Função atrial esquerda prejudicada associada com a fibrilação atrial paroxística na hipertensão. Arq Bras Cardiol. 2014;102(3):253-62. 


\section{APÊNDICES}




\section{PLANILHA 1 - IDENTIFICAÇÃO E DADOS PESSOAIS}

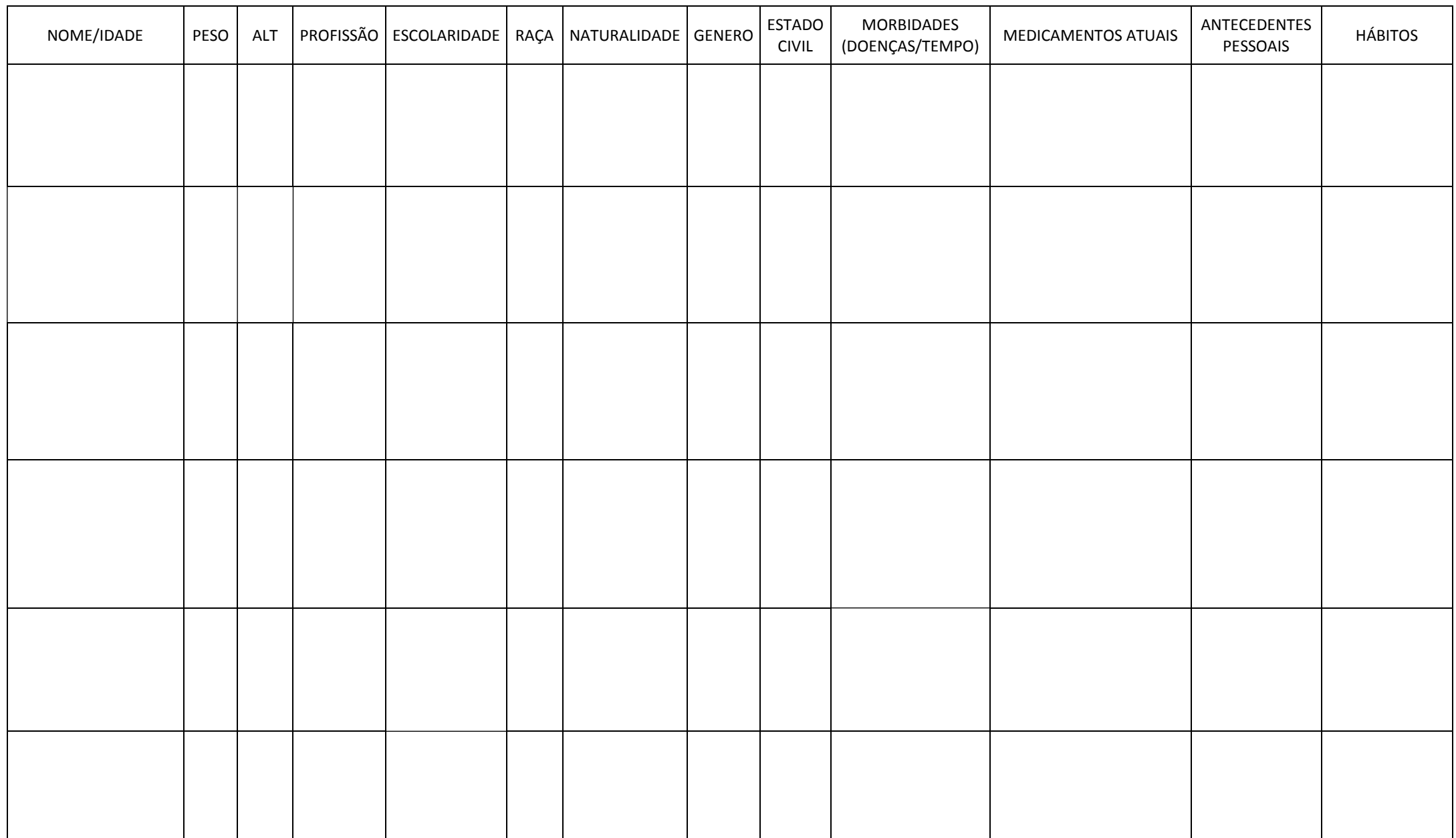


PLANILHA 2 - EXAMES

\begin{tabular}{|c|c|c|c|c|c|c|c|c|c|c|c|c|}
\hline \multicolumn{13}{|l|}{ NOME: } \\
\hline & \multicolumn{9}{|c|}{ BIOQUIMICOS } & \multicolumn{3}{|c|}{ CARDIOLOGICO } \\
\hline & CL.CREAT & UREIA & NA & $\mathrm{K}$ & CA & $\mathrm{P}$ & PTH & PCR & $\begin{array}{l}\text { GASOMETRIA } \\
\text { ART/VEM }\end{array}$ & ECG & ECOCARDIOGRAMA & HOLTER \\
\hline \multicolumn{13}{|l|}{ PRE HD 1ำ sessão } \\
\hline \multicolumn{13}{|l|}{ PÓS HD-1 SESSÃO } \\
\hline \multicolumn{13}{|l|}{ Pré HD- 6 MESES } \\
\hline PÓS HD - 1 ANO & & & & & & & & & & & & \\
\hline & & & & & & & & & & & & \\
\hline
\end{tabular}


PLANILHA DO ELETROCARDIOGRAMA

\begin{tabular}{|c|c|c|c|c|c|}
\hline NOME & RITMO & MORF. DE P & ONDAS F & ALT. RITMOS & QRS ABER \\
\hline & & & & & \\
\hline & & & & & \\
\hline & & & & & \\
\hline & & & & & \\
\hline & & & & & \\
\hline & & & & & \\
\hline & & & & & \\
\hline & & & & & \\
\hline & & & & & \\
\hline & & & & & \\
\hline & & & & & \\
\hline & & & & & \\
\hline & & & & & \\
\hline & & & & & \\
\hline & & & & & \\
\hline & & & & & \\
\hline & & & & & \\
\hline & & & & & \\
\hline & & & & & \\
\hline & & & & & \\
\hline & & & & & \\
\hline & & & & & \\
\hline & & & & & \\
\hline & & & & & \\
\hline & & & & & \\
\hline & & & & & \\
\hline & & & & & \\
\hline & & & & & \\
\hline
\end{tabular}

TABELA DE ELETROCARDIOGRAMA

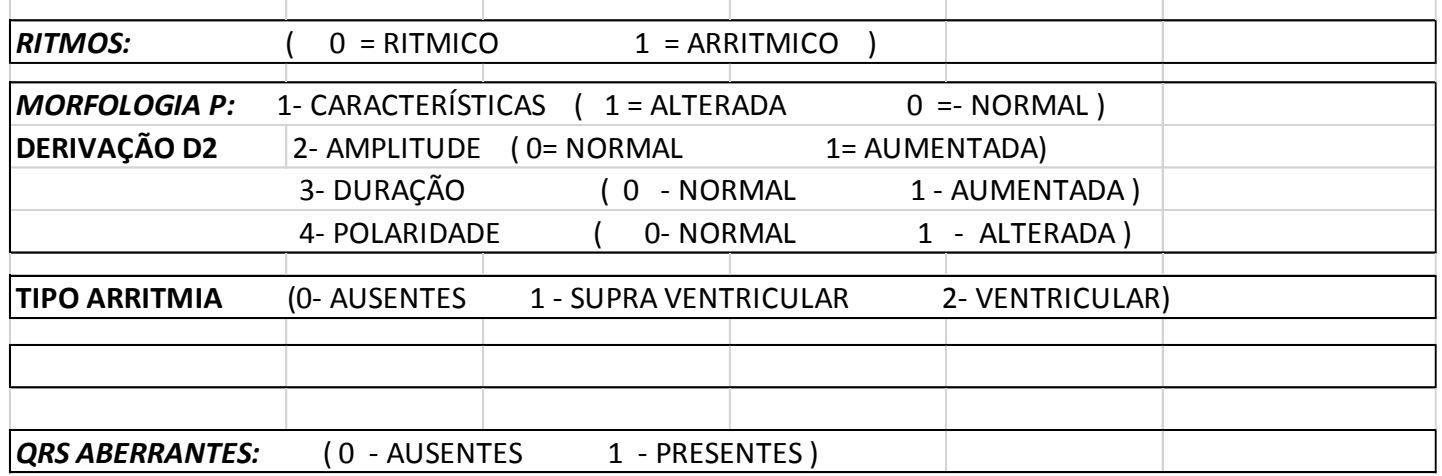


PLANILHA DO HOLTER

\begin{tabular}{|c|c|c|c|c|c|c|}
\hline NOME & RITMO & VAR. $P$ & GATILHOS & DURAÇÃOO & FORÇA TER & QTI \\
\hline & & & & & & \\
\hline & & & & & & \\
\hline & & & & & & \\
\hline & & & & & & \\
\hline & & & & & & \\
\hline & & & & & & \\
\hline & & & & & & \\
\hline & & & & & & \\
\hline & & & & & & \\
\hline & & & & & & \\
\hline & & & & & & \\
\hline & & & & & & \\
\hline & & & & & & \\
\hline & & & & & & \\
\hline & & & & & & \\
\hline & & & & & & \\
\hline & & & & & & \\
\hline & & & & & & \\
\hline & & & & & & \\
\hline & & & & & & \\
\hline & & & & & & \\
\hline & & & & & & \\
\hline & & & & & & \\
\hline & & & & & & \\
\hline & & & & & & \\
\hline & & & & & & \\
\hline & & & & & & \\
\hline & & & & & & \\
\hline & & & & & & \\
\hline
\end{tabular}

TABELA HOLTER:

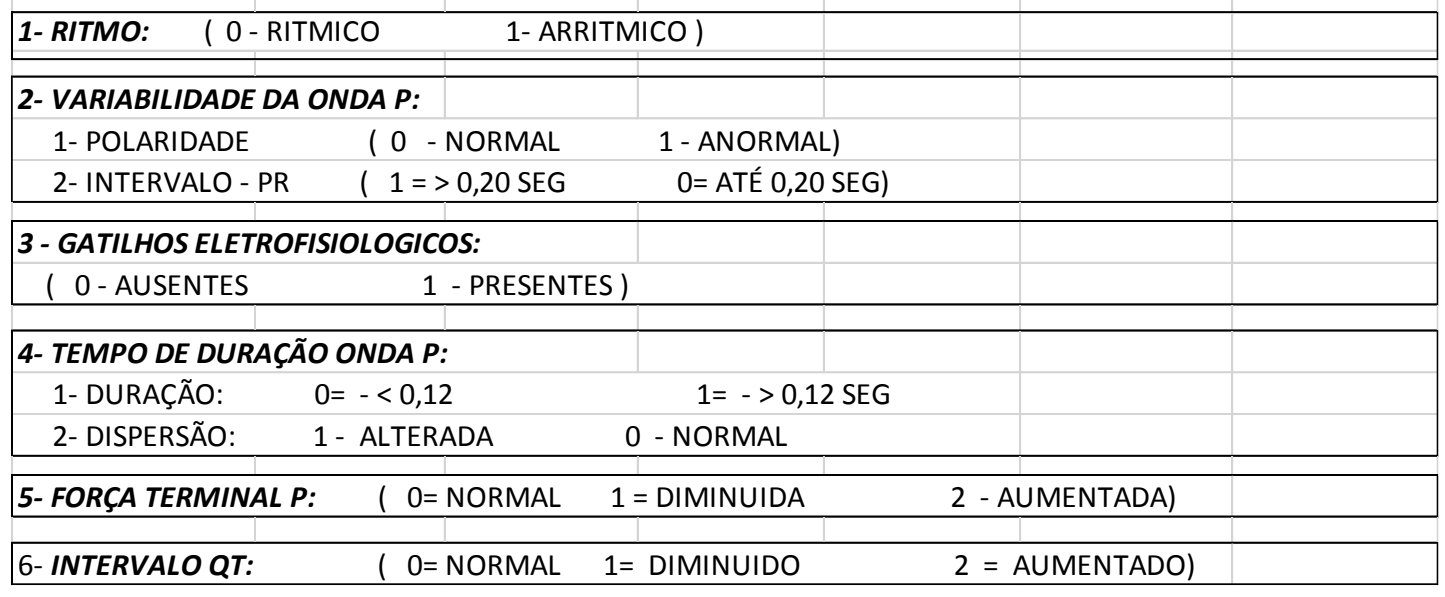


PLANILHA DO ECOCARDIOGRAMA

\begin{tabular}{|c|c|c|c|c|c|c|c|c|c|c|c|}
\hline NOME & 1 & 2 & 3 & 4 & 5 & 6 & 7 & 8 & 9 & 10 & 11 \\
\hline & & & & & & & & & & & \\
\hline & & & & & & & & & & & \\
\hline & & & & & & & & & & & \\
\hline & & & & & & & & & & & \\
\hline & & & & & & & & & & & \\
\hline & & & & & & & & & & & \\
\hline & & & & & & & & & & & \\
\hline & & & & & & & & & & & \\
\hline & & & & & & & & & & & \\
\hline & & & & & & & & & & & \\
\hline & & & & & & & & & & & \\
\hline & & & & & & & & & & & \\
\hline & & & & & & & & & & & \\
\hline & & & & & & & & & & & \\
\hline & & & & & & & & & & & \\
\hline & & & & & & & & & & & \\
\hline & & & & & & & & & & & \\
\hline & & & & & & & & & & & \\
\hline & & & & & & & & & & & \\
\hline & & & & & & & & & & & \\
\hline & & & & & & & & & & & \\
\hline & & & & & & & & & & & \\
\hline & & & & & & & & & & & \\
\hline & & & & & & & & & & & \\
\hline & & & & & & & & & & & \\
\hline & & & & & & & & & & & \\
\hline & & & & & & & & & & & \\
\hline & & & & & & & & & & & \\
\hline & & & & & & & & & & & \\
\hline & & & & & & & & & & & \\
\hline
\end{tabular}

TABELA DE ECO:

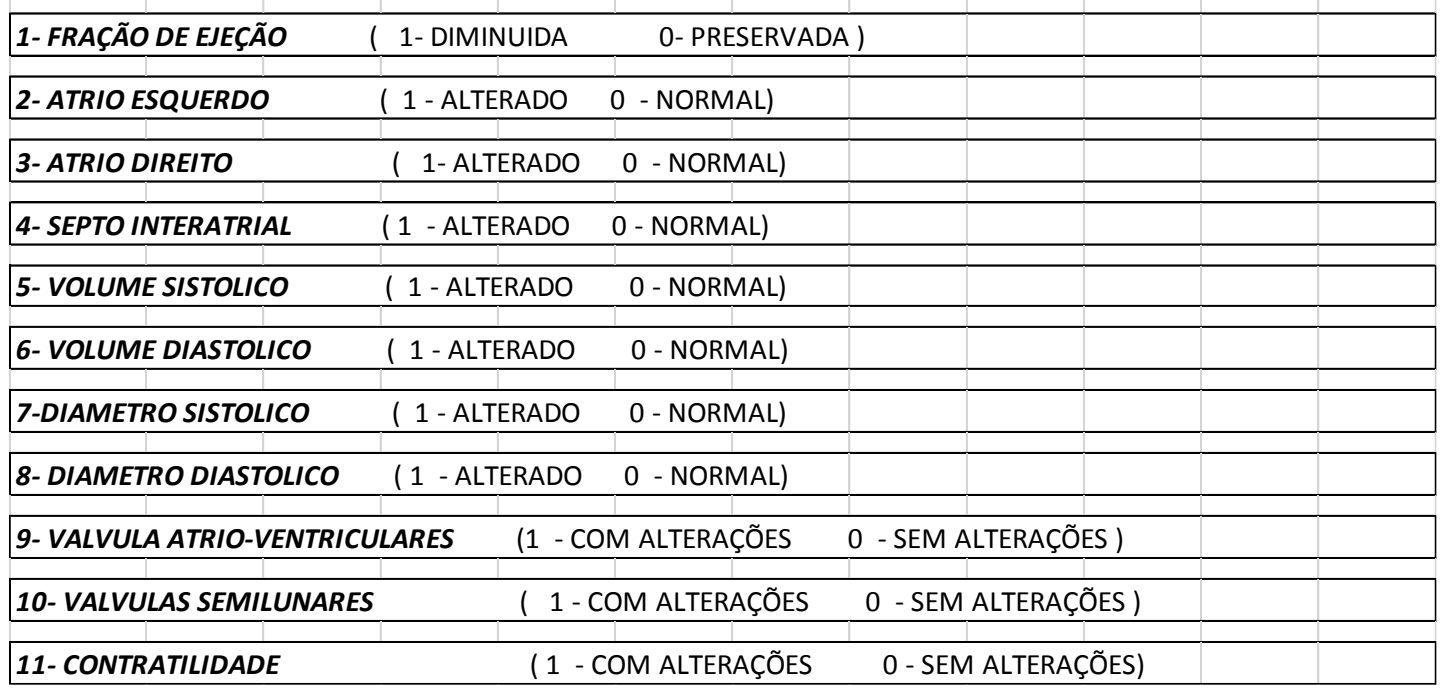

